\title{
Estudo do processo de complexação de calixarenos com íons metálicos e espécies neutras por simulações de Dinâmica Molecular.
}

\section{Alexandre Suman de Araujo}

Tese apresentada ao Instituto de Física de São Carlos, da Universidade de São Paulo, para a obtenção do título de Doutor em Ciências: Física aplicada.

Orientadores: Prof. Dr. Eduardo Ernesto Castellano Prof. Dr. Oscar Enrique Piro 
A minha esposa Kely, pelo companheirismo, paciência e carinho mesmo nos momentos mais críticos, aos meus pais e irmãos, que sempre me incentivaram a seguir o caminho da ciência desde a infância e ao Fuyu, companheiro fiel de todas as horas a frente do computador. 


\section{Agradecimentos}

- Aos meus orientadores Prof. Eduardo Ernesto Castellano e Prof. Oscar Enrique Piro, por sempre se esforçarem ao máximo para trilharem, junto a mim, o caminho nessa área de pesquisa, estando presentes a todo e qualquer momento que necessitei de ajuda.

- Ao amigo Dr. Milton, que sempre me incentivou a seguir essa área e, principalmente, me ensinou grande parte do pouco que hoje sei.

- Ao Dr. Ernesto que, mesmo pouco me conhecendo, me acolheu em seu laboratório como um antigo colaborador, se tornando desde então um grande amigo e professor.

- A meus avós, tios e primos que tanto se preocuparam com meu bem-estar e que sempre acreditaram no meu potencial e na relevância do meu trabalho.

- A todos os amigos que compartilham comigo a paixão pela pesca esportiva, atividade indispensável para manter minha mente sã. O stress de dias de trabalho desaparece em poucas horas no rio com vocês.

- A FAPESP pelo apoio financeiro imprescindível. 


\section{Sumário}

$\begin{array}{ll}\text { Capítulo } 1 \text { - Introdução Geral. } & 1\end{array}$

Capítulo 2 - Simulações de Dinâmica Molecular. $\quad 8$

2.1 - Introdução $\quad 8$

2.2 - Algoritmos de Integração - Métodos de Diferenças Finitas. $\quad 10$

2.2.1 - Algoritmo de Verlet. 11

2.2.2 - Algoritmo Leap-Frog. 13

2.2.3 - Algoritmo de Verlet com velocidades. 14

2.3 - Campos de Forças. $\quad 16$

Capítulo 3 - Desenvolvimento dos parâmetros para os íons $\mathrm{Cd}^{2+} \mathbf{e ~ P b}^{2+} \mathbf{2 0}$

3.1 - Introdução 20

3.2 - Teoria e Metodologia 22

3.3 - Detalhes Computacionais 27

3.4 - Resultados e Discussões 28

3.4.1 - Energia livre de hidratação absoluta 28

3.4 .2 - Propriedades estruturais 31

3.4.3 - Propriedades dinâmicas 35

3.5 - Conclusões $\quad 39$

Capítulo 4 - Simulações dos Calixa[4]arenos em vácuo 41 
4.3 - Simulações do tetraethylester p-tert-butyl calix[4]arene isolado

4.4 - Simulações do tetraethylester p-tert-butyl calix[4]arene com uma molécula de acetonitrila na cavidade hidrofóbica

4.5 - Simulações do tetraethylester p-tert-butyl calix[4]arene com um íon $\mathrm{Pb}^{2+}$ na cavidade hidrofílica

4.6 - Simulações do tetraethylester p-tert-butyl calix[4]arene com um íon $\mathrm{Cd}^{2+}$ na cavidade hidrofílica

4.7 - Simulações do tetramethylketone p-tert-butyl calix[4]arene isolado

4.8 - Simulações do tetramethylketone p-tert-butyl calix[4]arene com uma molécula de acetonitrila na cavidade hidrofóbica

4.9 - Simulações do tetramethylketone p-tert-butyl calix[4]arene com um íon $\mathrm{Pb}^{2+}$ na cavidade hidrofílica

4.10 - Simulações tetramethylketone p-tert-butyl calix[4]arene com um íon $\mathrm{Cd}^{2+}$ na cavidade hidrofílica

$4.11-$ Conclusões

\section{Capítulo 5 - Simulações dos Calixa[4]arenos em Acetonitrila}

5.1 - Introdução

5.2 - Metodologia e Detalhes Computacionais

5.3 - Simulações do tetraethylester p-tert-butyl calix[4]arene nãocomplexado em acetonitrila

5.4 - Simulações do complexo tetraethylester p-tert-butyl calix[4]arene $\mathrm{Pb}^{2+}$ em acetonitrila 
5.5 - Simulações do complexo tetraethylester p-tert-butyl calix[4]arene $\mathrm{Cd}^{2+}$ em acetonitrila

5.6 - Simulações do tetramethylketone p-tert-butyl calix[4]arene nãocomplexado em acetonitrila

5.7 - Simulações do complexo tetramethylketone p-tert-butyl calix[4]arene $\mathrm{Pb}^{2+}$ em acetonitrila 100

5.8 - Simulações do complexo tetramethylketone p-tert-butyl calix[4]arene $\mathrm{Cd}^{2+}$ em acetonitrila

$5.9-$ Conclusões 


\section{Lista de Figuras}

Figura 1 - Monômero básico dos calixarenos estudados. A substituição de R e Y por diferentes grupos químicos gera as diferentes moléculas. O oxigênio ligado ao anel é chamado de oxigênio fenólico.

Figura 2 - Estrutura cristalográfica do calixareno 5,11,17,23-tetra-tertbutil[25,26,27,28-tetrakis(2-piridilmetil) oxy]-calixa(4)areno vista lateral e superiormente.

Figura 3 - Estrutura cristalográfica do calixareno 5,11,17,23-tetra-tertbutil[25,26,27,28-tetrakis(2-piridilmetil) oxy]-calixa(4)areno complexada com uma molécula de acetonitrila e um íon $\mathrm{Na}^{+}$visto lateral e superiormente.

Figura 4 - Ciclo termodinâmico utilizado para os cálculos de energia livre de hidratação dos íons. Átomos dummy apresentam carga e parâmetros de LennardJones iguais a zero.

Figura 5 - Distribuição Radial de Pares $\mathrm{Pb}^{2+}-\mathrm{O}$ e $\mathrm{Pb}^{2+}-\mathrm{H}$ para os quatro modelos de água utilizados.

Figura 6 - Distribuição Radial de Pares $\mathrm{Cd}^{2+}-\mathrm{O}$ e $\mathrm{Cd}^{2+}-\mathrm{H}$ para os quatro modelos de água utilizados.

Figura $7-D_{\text {ion }} / D_{\text {water }}$ para diferentes modelos de água e entre os valores experimentais. 
Figura 8 - Duas possíveis conformações que podem assumir os calixarenos estudados.

Figura 9 - tetraethylester p-tert-butyl calix[4]arene isolado depois de 10 ns de simulação.

Figura 10 - Configuração final após 10 ns de simulação. No círculo destacado é mostrada a molécula de acetonitrila "expulsa" da cavidade hidrofóbica.

Figura 11 - Configuração final depois de 10ns de simulação. O íon se manteve na cavidade hidrofílica durante toda a simulação.

Figura 12 - Resultado da superposição da estrutura média calculada e da estrutura resolvida por raios-X.

Figura 13 - Configuração final depois de 10ns de simulação. O íon se manteve na cavidade hidrofílica durante toda a simulação.

Figura 14 - Superposição da estrutura média calculada com a estrutura experimental obtida por difração de raios-X.

Figura 15 - tetramethylketone p-tert-butyl calix[4]arene isolado depois de $10 \mathrm{~ns}$ de simulação.

Figura 16 - Configuração do sistema depois de 10 ns de simulação. A molécula de acetonitrila permanece complexada durante toda a simulação.

Figura 17 - Conformação do sistema depois de 10 ns de simulação.

Figura 18 - Superposição da estrutura média calculada com a estrutura experimental obtida por difração de raios-X.

Figura 19 - Configuração final da simulação do calixareno CLC com o íon $\mathrm{Cd}^{2+}$ em sua cavidade hidrofílica.

Figura 20 - Superposição da estrutura cristalográfica com a estrutura média calculada no último 1 ns de simulação. 
Figura 21 - Configuração final do sistema depois de 2 ns de simulação. Vista lateral e superior do calixareno onde observamos a ausência de moléculas de solvente nas cavidades hidrofóbica e hidrofílica.

Figura 22 - Configuração final do sistema depois de 2 ns de simulação. Vista lateral e superior do calixareno onde observamos a presença de uma molécula de acetonitrila na cavidade hidrofóbica e o íon $\mathrm{Pb}^{2+}$ na cavidade hidrofílica.

Figura 23 - Configuração final do sistema depois de 2 ns de simulação. Vista lateral e superior do calixareno onde observamos a presença de uma molécula de acetonitrila na cavidade hidrofóbica e o íon $\mathrm{Cd}^{2+}$ na cavidade hidrofílica.

Figura 24 - Configuração final do sistema depois de 2 ns de simulação. Vista lateral e superior do calixareno onde observamos a presença de uma molécula de acetonitrila complexada na cavidade hidrofóbica.

Figura 25 - Configuração final do sistema depois de 2 ns de simulação. Vista lateral e superior do calixareno onde observamos a presença de uma molécula de acetonitrila complexada na cavidade hidrofóbica e o íon $\mathrm{Pb}^{2+}$ na borda da cavidade hidrofílica.

Figura 26 - Configuração final do sistema depois de 2 ns de simulação. Vista lateral e superior do calixareno onde observamos a presença de uma molécula de acetonitrila complexada na cavidade hidrofóbica e o íon $\mathrm{Cd}^{2+}$ na borda da cavidade hidrofílica. 


\section{Lista de Gráficos}

Gráfico 1 - Distância entre carbonos apicais. 45

Gráfico 2 - Distância entre oxigênios fenólicos. 46

Gráfico 3 - Distância entre oxigênios carbonílicos. 46

Gráfico 4 - Distância entre o centro de massa da molécula de acetonitrila e o fundo da cavidade hidrofóbica.

Gráfico 5 - Energia de interação não-ligada (Coulomb e Lennard-Jones) entre a molécula de acetonitrila e a cavidade hidrofóbica.

Gráfico 6 - Energia de interação não-ligada (Coulomb e Lennard-Jones) entre o $\mathrm{Pb}^{2+}$ e a cavidade hidrofílica.

Gráfico 7 - Distância entre carbonos apicais.

Gráfico 8 - Distância entre oxigênios fenólicos.

Gráfico 9 - Distância entre oxigênios carbonílicos.

Gráfico 10 - Energia de interação não-ligada (Coulomb e Lennard-Jones) entre o $\mathrm{Cd}^{2+}$ e a cavidade hidrofílica.

Gráfico 11 - Distância entre carbonos apicais.

Gráfico 12 - Distância entre oxigênios fenólicos. 56

Gráfico 13 - Distância entre oxigênios carbonílicos. 56

Gráfico 14 - Distância entre carbonos apicais. 
Gráfico 15 - Distância entre oxigênios fenólicos.

Gráfico 16 - Distância entre oxigênios carbonílicos.

Gráfico 17 - Distância entre o centro de massa da molécula de acetonitrila e o fundo da cavidade hidrofóbica.

Gráfico 18 - Energia de interação não-ligada (Coulomb e Lennard-Jones) entre a molécula de acetonitrila e a cavidade hidrofóbica.

Gráfico 19 - Distância entre carbonos apicais.

Gráfico 20 - Distância entre oxigênios fenólicos.

Gráfico 21 - Distância entre oxigênios carbonílicos.

Gráfico 22 - Energia de interação não-ligada (Coulomb e Lennard-Jones) entre $\mathrm{o} \mathrm{Pb}^{2+}$ e a cavidade hidrofílica.

Gráfico 23 - Distância entre carbonos apicais.

Gráfico 24 - Distância entre oxigênios fenólicos.

Gráfico 25 - Distância entre oxigênios carbonílicos.

Gráfico 26 - Energia de interação não-ligada (Coulomb e Lennard-Jones) entre o $\mathrm{Cd}^{2+}$ e a cavidade hidrofílica.

Gráfico 27 - Distância entre carbonos apicais.

Gráfico 28 - Distância entre oxigênios fenólicos.

Gráfico 29 - Distância entre oxigênios carbonílicos.

Gráfico 30 - Distância entre carbonos apicais.

Gráfico 31 - Distância entre oxigênios fenólicos.

Gráfico 32 - Distância entre oxigênios carbonílicos.

Gráfico 33 - Energia de interação não-ligada (Coulomb e Lennard-Jones) entre o $\mathrm{Pb}^{2+}$ e a cavidade hidrofílica. 
Gráfico 34 - Distância entre o centro de massa da molécula de acetonitrila complexada e o fundo da cavidade hidrofóbica.

Gráfico 35 - Energia de interação não-ligada (Coulomb e Lennard-Jones) entre a molécula de acetonitrila complexada e toda a cavidade hidrofóbica

Gráfico 36 - Energia de interação não-ligada (Coulomb e Lennard-Jones) entre a molécula de acetonitrila complexada e o íon $\mathrm{Pb}^{2+}$. 86

Gráfico 37 - Distância entre carbonos apicais. 86

Gráfico 38 - Distância entre oxigênios fenólicos.

Gráfico 39 - Distância entre oxigênios carbonílicos.

Gráfico 40 - Distância entre a acetonitrila complexada e o fundo da cavidade hidrofóbica.

Gráfico 41 - Energia de interação não-ligada (Coulomb e Lennard-Jones) entre a molécula de acetonitrila e o íon $\mathrm{Cd}^{2+}$.

Gráfico 42 - Energia de interação não-ligada (Coulomb e Lennard-Jones) entre a molécula de acetonitrila e o a cavidade hidrofóbica.

Gráfico 43 - Energia de interação não-ligada (Coulomb e Lennard-Jones) entre o íon $\mathrm{Cd}^{2+}$ e a cavidade hidrofílica.

Gráfico 44 - Distância entre carbonos apicais.

Gráfico 45 - Distância entre oxigênios fenólicos.

Gráfico 46 - Distância entre oxigênios carbonílicos.

Gráfico 47 - Distância entre o centro de massa da molécula de acetonitrila complexada e o fundo da cavidade hidrofóbica.

Gráfico 48 - Energia de interação não-ligada (Coulomb e Lennard-Jones) entre a molécula de acetonitrila e a cavidade hidrofóbica. 
Gráfico 50 - Distância entre oxigênios fenólicos. 98

Gráfico 51 - Distância entre oxigênios carbonílicos.

Gráfico 52 - Energia de interação não-ligada (Coulomb e Lennard-Jones) entre $\mathrm{o} \mathrm{Pb}^{2+}$ e a cavidade hidrofílica.

Gráfico 53 - Distância entre o centro de massa da acetonitrila complexada e o fundo da cavidade hidrofóbica.

Gráfico 54 - Energia de interação não-ligada (Coulomb e Lennard-Jones) entre a acetonitrila complexada e a cavidade hidrofóbica.

Gráfico 55 - Distância entre carbonos apicais.

Gráfico 56 - Distância entre oxigênios fenólicos.

Gráfico 57 - Distância entre oxigênios carbonílicos.

Gráfico 58 - Distância entre o centro de massa da acetonitrila complexada e o fundo da cavidade hidrofóbica.

Gráfico 59 - Energia de interação não-ligada (Coulomb e Lennard-Jones) entre a acetonitrila complexada e a cavidade hidrofóbica.

Gráfico 60 - Energia de interação não-ligada (Coulomb e Lennard-Jones) entre o $\mathrm{Cd}^{2+}$ e a cavidade hidrofílica.

Gráfico 61 - Distância entre os carbonos apicais.

Gráfico 62 - Distância entre oxigênios fenólicos.

Gráfico 63 - Distância entre oxigênios carbonílicos. 


\section{Lista de Tabelas}

Tabela I - Parâmetros Lennard-Jones finais.

Tabela II - Energias livres de hidratação calculada, experimental e o erro relativo entre os dois valores.

Tabela III - Valores característicos da g(r) e números de coordenação do $\mathrm{Cd}^{2+} \mathrm{e}$ $\mathrm{Pb}^{2+}$. A coluna ref. mostra o modelo de água utilizado em nossos cálculos ou a referência de onde foram obtidos os valores para comparação.

Tabela IV - Coeficiente de Difusão, em $10^{-5} \mathrm{~cm}^{2} / \mathrm{s}$, para os íons $\mathrm{Pb}^{2+}\left(\mathrm{D}_{\mathrm{Pb} 2+}\right)$ e $\mathrm{Cd}^{2+}\left(\mathrm{D}_{\mathrm{Cd} 2+}\right)$, calculados em diferentes modelos de água, e valores experimentais. $\mathrm{D}_{\text {water }}$ é o coeficiente de difusão própria da água (self-diffusion coefficient), calculado para cada modelo utilizado, e o valor experimental.

Tabela V - Tempos médios de residência para a primeira camada de solvatação do $\mathrm{Pb}^{2+}\left(\tau_{\mathrm{Pb} 2+}\right)$ para diferentes modelos de água e tempos de intermitência. 


\section{Resumo}

Apresentamos uma série de estudos, baseados em simulações de Dinâmica Molecular no vácuo e em solução, sobre o processo de complexação das supramoléculas tetraethylester p-tert-butyl calix[4]arene (CLE) e tetramethylketone p-tert-butyl calix[4]arene (CLC) com os íons $\mathrm{Pb}^{2+}$ e $\mathrm{Cd}^{2+}$ e espécies neutras. Os modelos para as moléculas de calixareno e do solvente foram baseados no campo de forças OPLS-AA. Os parâmetros para os íons foram desenvolvidos a partir de uma metodologia de ajuste de valores de modo a reproduzirem simultaneamente propriedades termodinâmicas e estruturais obtidas experimentalmente ou por cálculos de QM/MM. As simulações no estado líquido nos mostraram que o CLE aprisiona os íons de maneira mais eficiente que o CLC, formando complexos mais estáveis. A complexação do íon desencadeia um efeito alostérico em ambos os calixarenos estudados, permitindo a complexação de uma molécula de acetonitrila na cavidade hidrofóbica estabilizando o complexo. Nas simulações com o CLC observamos que a complexação da acetonitrila é necessária para manter o íon ligado à cavidade hidrofílica, evidenciando a dependência desses complexos com esse solvente em específico. Apesar de observarmos que o CLE apresenta maior afinidade com os íons $\mathrm{Pb}^{2+} \mathrm{e} \mathrm{Cd}^{2+}$ que o CLC, somente futuras simulações utilizando a água como solvente poderão confirmar a viabilidade do uso desta molécula em sistemas destinados à despoluição ambiental. 


\begin{abstract}
We report a series of Molecular Dynamics simulations, in vacuum and in acetonitrile solution, on the complexation process of the calixarens tetraethylester $p$ tert-butyl calix[4]arene (CLE) and tetramethylketone p-tert-butyl calix[4]arene (CLC) with $\mathrm{Pb}^{2+}$ and $\mathrm{Cd}^{2+}$ anions and neutral species. The solvent and calixarene molecules were modeled based on the OPLS-AA force field. The parameters for the ions were adjusted to simultaneously reproduce some structural and thermodynamic properties obtained either experimentally or from QM/MM calculations. The simulations in the liquid phase show CLE to be more efficient than CLC in trapping the studied metal ions, leading to more stable complexes. Ion complexation gives rise to an allosteric effect by which a solvent molecule is trapped in the hydrophobic cavity giving rise to further stabilization of the complex. Simulations on CLC show that formation of the calixarene-acetonitrile adduct is essential to the stabilization of the ionic complex, thus exhibiting the influence of this particular solvent in the very existence of the complex. In spite of the conclusion that CLE has higher affinity than CLC for $\mathrm{Pb}^{2+}$ and $\mathrm{Cd}^{2+}$ ions, only further studies in water solution will permit to evaluate the real potential of this molecule as an efficient scavenger of environmental heavy metal pollution.
\end{abstract}




\section{Capítulo 1- Introdução Geral.}

A poluição por metais pesados é um dos mais preocupantes problemas ambientais da humanidade, principalmente no caso do cádmio e chumbo [1-4]. O descarte indevido de baterias, a utilização indiscriminada de herbicidas e fungicidas, a queima de gasolina e vários tipos de processos industriais são os principais responsáveis pela emissão dessas substâncias. A presença de metais em organismos vivos causa severa intoxicação podendo, em alguns casos, apresentar biomagnificação contaminando toda a cadeia alimentar $[5,6]$. Em seres humanos a principal fonte de intoxicação por cádmio e chumbo provém da ingestão de alimentos animais e vegetais ou pelo fumo [7-10]. Apesar dos esforços para a diminuição da emissão desses poluentes, os níveis de contaminação em diversos ambientes ainda se mantém muito altos, o que torna necessário uma intervenção por meio de processos químicos que removam ou coloquem numa forma química inerte esses metais [11].

Os calixarenos são moléculas macrocíclicas capazes de interagir com cátions, ânions e espécies neutras, com potencial aplicação no desenvolvimento de compostos capazes de realizar despoluição de ambientes por metais pesados. Nos últimos anos diversas patentes internacionais vem sendo publicadas. Estas patentes em geral estão centradas no uso potencial de calixarenos como retentores de íons metálicos e 
espécies neutras. Existem muitas razões para o atual interesse nos calixarenos, sendo a maneira notavelmente simples para se sintetizar os compostos precursores uma das mais importantes. Além disso, a funcionalização das bordas superior e inferior destas moléculas resulta em uma grande variedade de derivados possíveis. O crescimento da química de calixarenos vem sendo motivado pelo interesse em encontrar derivados capazes de realizar complexação seletiva com espécies neutras ou iônicas. Na Figura 1 vemos um monômero a partir do qual são formados alguns calixarenos. O número de vezes que esta unidade se repete (n) define a qual classe pertence a molécula formada, denominada então de Calix[n]areno sendo os mais comuns $\mathrm{n}=$ 4,6 e 8. Os grupos R e Y completam a caracterização de cada calix[n]areno.

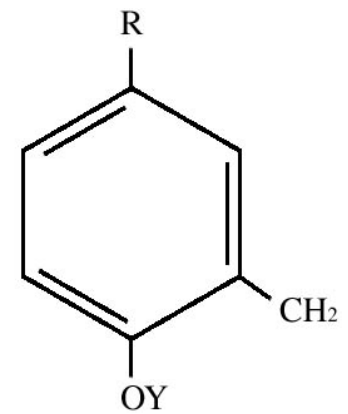

Figura 1 - Monômero básico dos calixarenos estudados. A substituição de R e Y por diferentes grupos químicos gera as diferentes moléculas. O oxigênio ligado ao anel é chamado de oxigênio fenólico.

Os anéis aromáticos formam uma cavidade hidrofóbica capaz de interagir com espécies neutras, dando origem a complexos moleculares. Uma cavidade hidrofílica pode ser criada ligando-se resíduos apropriados ao oxigênio fenólico. A cavidade hidrofóbica apresenta propriedades seletivas sobre moléculas de solvente dependendo da interação de íons metálicos dentro da cavidade hidrofílica [12]. Este tipo de reação acoplada, na qual a ligação de um íon metálico com um sítio hidrofílico na supramolécula produz mudanças conformacionais que alteram as 
propriedades seletivas da cavidade hidrofóbica com moléculas orgânicas é conhecida como efeito alostérico.

$\mathrm{Na}$ Figura 2 vemos um exemplo do calix[4]areno 5,11,17,23-tetra-tertbutil[25,26,27,28-tetrakis(2-piridilmetil)oxy]-calixa(4)areno visto em duas perspectivas diferentes. Nesse calixareno o grupo R é um tert-butil e o Y um piridilmetil. Esses dois grupos desempenham um papel importante no processo de complexação, pois determinam o estado conformacional da molécula nãocomplexada e a forma como o calixareno interage com moléculas de solvente e íons.

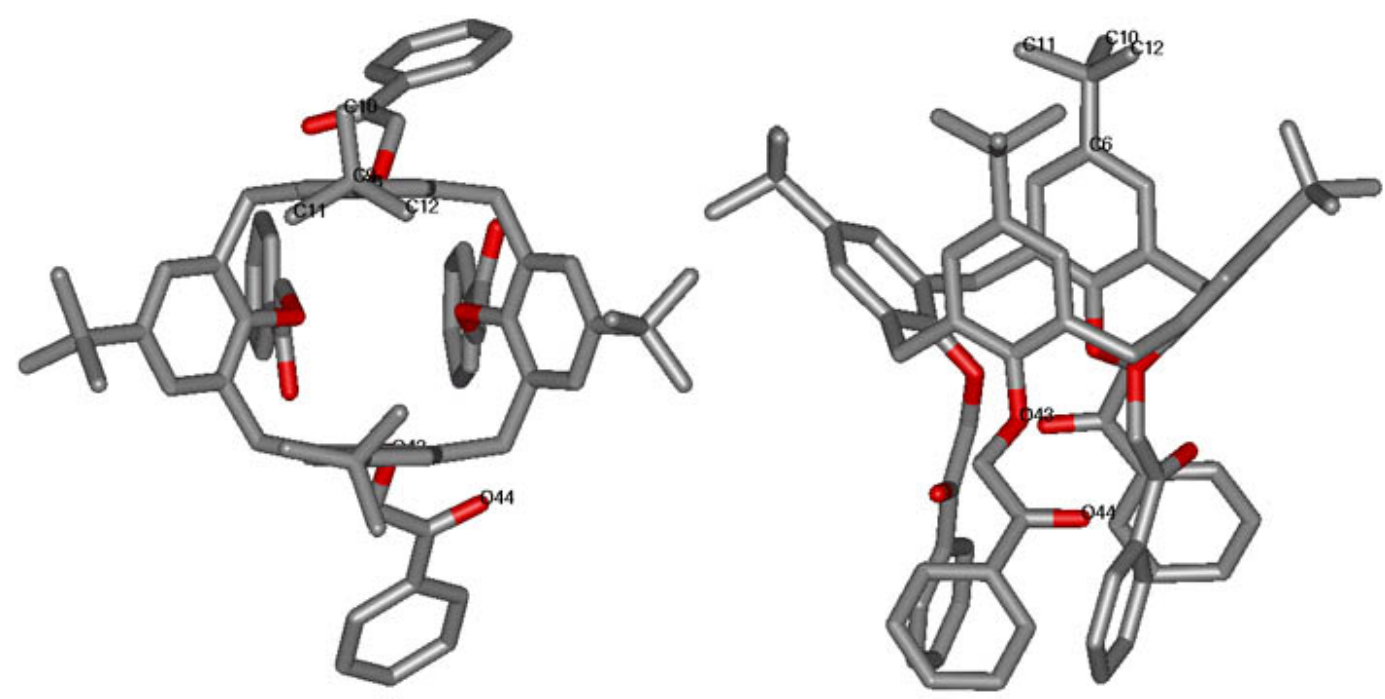

Figura 2 - Estrutura cristalográfica do calixareno 5,11,17,23-tetra-tert-butil[25,26,27,28-tetrakis(2piridilmetil) oxy]-calixa(4)areno vista lateral e superiormente.

Na Figura 3 vemos um exemplo do mesmo calixareno da Figura 2, mas agora complexado a um íon $\mathrm{Na}^{+}$na cavidade hidrofílica e a uma molécula do solvente acetonitrila $\left(\mathrm{CH}_{3} \mathrm{CN}\right)$ na cavidade hidrofóbica. $\mathrm{Na}$ perspectiva da esquerda observamos que esta molécula apresenta um eixo de simetria de ordem 4 sendo que na molécula não-complexada existe um eixo aproximado de ordem 2 [13]. Observamos que o processo de complexação do íon metálico na cavidade hidrofílica 
alterou a simetria interna da molécula favorecendo a entrada da acetonitrila na cavidade hidrofóbica, evidenciando o efeito alostérico.
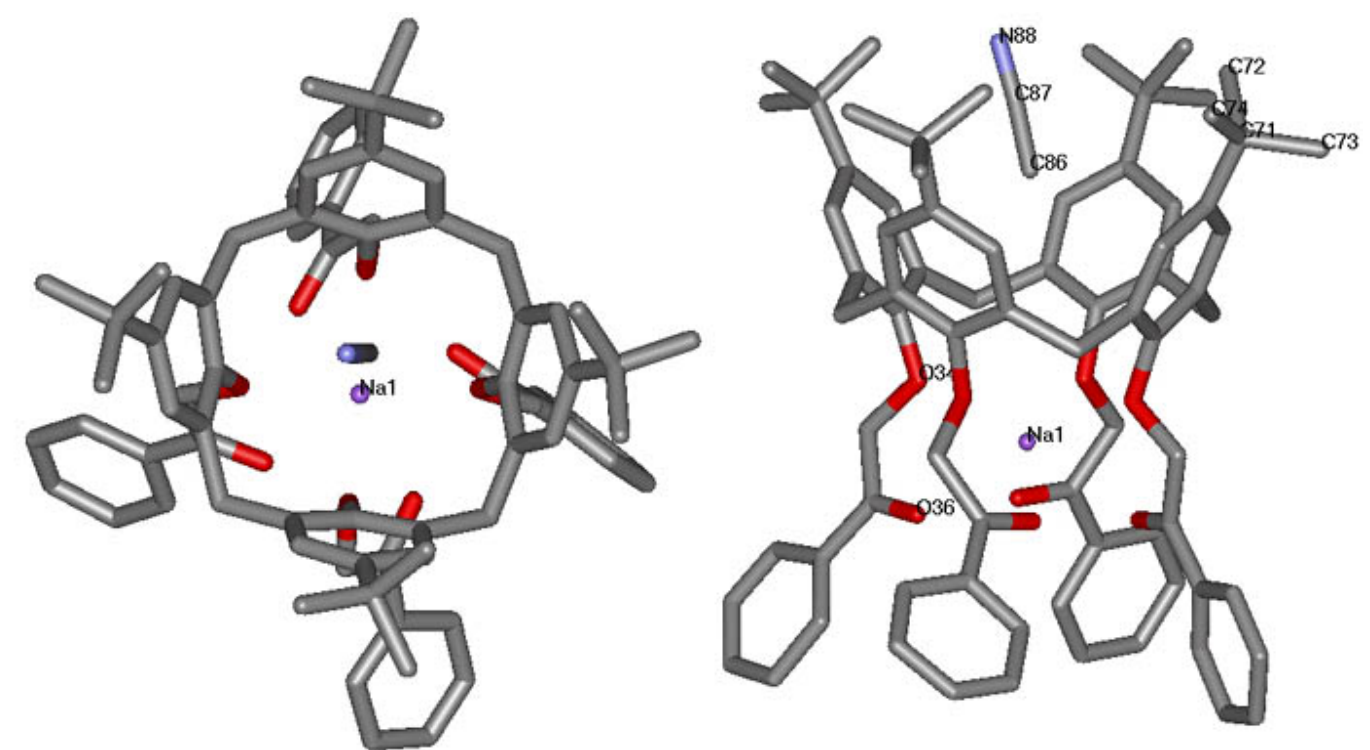

Figura 3 - Estrutura cristalográfica do calixareno 5,11,17,23-tetra-tert-butil[25,26,27,28-tetrakis(2piridilmetil) oxy]-calixa(4)areno complexada com uma molécula de acetonitrila e um ion $\mathrm{Na}^{+}$visto lateral e superiormente.

A utilização de simulações de Dinâmica Molecular (DM) no estudo de sistemas aquosos é muito difundida atualmente, pois fornece resultados extremamente satisfatórios e confiáveis. A possibilidade de se observar o comportamento e organização do soluto e solvente microscopicamente e obter propriedades importantes, utilizando técnicas específicas, fazem desses cálculos ferramentas úteis para estudos em físico-química. Para que essas simulações descrevam bem os sistemas líquidos estudados, é necessária uma modelagem acurada das moléculas envolvidas, de modo que as interações entre elas reproduzam o mais fielmente possível as que acontecem nos sistemas reais.

Simulações de Dinâmica Molecular da complexação de calixarenos com moléculas neutras e íons metálicos são de grande utilidade e vem sendo objeto de 
estudos publicados em diversos trabalhos nos últimos anos [14-17]. Um melhor entendimento a nível atômico/molecular desse mecanismo contribui significativamente para o desenho otimizado de moléculas com propriedades específicas, tais como a complexação seletiva de íons de interesse. Nesse trabalho estudaremos o processo de complexação dos calixarenos tetraethylester p-tert-butyl calix [4] arene (CLE) e tetramethylketone p-tert-butyl calix[4]arene (CLC) com íons de cádmio, chumbo e acetonitrila (solvente), cuja síntese, resolução de estrutura cristalográfica, espectroscopia RMN e medidas de calorimetria foram reportados na referência [12]. A proposta é contribuir no entendimento do processo de aprisionamento dos íons como um todo a partir da observação e análise das interações em escala atômica provida pelas simulações de Dinâmica Molecular em solução. Além disso, pretendemos apresentar uma metodologia que possa ser utilizada sistematicamente em simulações de calixarenos hipotéticos, construídos segundo critérios de interesse, com a finalidade de fornecer opções para a síntese racional de calixarenos baseadas em resultados de simulações computacionais.

Sendo a área de trabalho proposta nesse projeto inédita em nosso laboratório, foi necessário escolher um dos diversos programas destinados à realização de simulações de DM disponíveis no mercado. Escolhemos o pacote de programas GROMACS [18], desenvolvido originalmente pelo grupo do Prof. Herman Berendsen da Universidade de Groningen na Holanda e que hoje é mantido por desenvolvedores de diversas partes do mundo. O GROMACS é notório pela velocidade nos cálculos, vasto pacote de ferramentas de análises e construção de modelos e pelo fato de ser gratuito e de código aberto, o que torna a eliminação de bugs muito mais eficiente. 
Além da escolha do pacote de programas para realizarmos nossas simulações, foi necessário também definir o campo de forças a ser utilizado, pois o número de opções é grande e a escolha correta deve levar em consideração diversos fatores. $\mathrm{O}$ fato dos calixarenos serem moléculas orgânicas e pequenas, nossas simulações serem realizadas no estado líquido e nossos estudos exigirem uma análise de interações detalhada, nos levou a escolher o OPLS-AA (Optimized Parameters for Liquid Simulations - All Atoms) [19]. As principais vantagens desse campo de forças é o fato dele ser otimizado para simulações de sistemas líquidos, seus parâmetros serem desenvolvidos sob uma metodologia que lhes trazem extrema confiabilidade e o fato de seguir o paradigma All Atoms, onde são modelados todos os átomos do sistema, inclusive os hidrogênios não-polares.

A construção dos modelos para os calixarenos e moléculas de solvente foi realizada utilizando-se os parâmetros do OPLS-AA, sendo que algumas cargas parciais da cavidade hidrofóbica dos calixarenos foram obtidas da referência [14]. A modelagem dos íons representou uma das maiores dificuldades desse projeto, pois o fato do chumbo e cádmio não serem comuns em simulações de sistemas biológicos, não encontramos na literatura parâmetros que os descrevessem no campo de forças OPLS-AA. Dessa forma, foi necessário que desenvolvêssemos nossos próprios parâmetros para os íons $\mathrm{Pb}^{2+}$ e $\mathrm{Cd}^{2+}$ seguindo uma metodologia baseado no ajuste dos parâmetros de van der Waals dos íons de modo a reproduzirem propriedades termodinâmicas, estruturais e dinâmicas dos íons reais. A descrição completa do trabalho de modelagem dos íons é apresentada no capítulo 3.

A partir dos modelos desenvolvidos para os íons e dos modelos construídos para os calixarenos e solvente, iniciamos as simulações propostas para o estudo do processo de complexação. Realizamos simulações com os calixarenos tetraethylester 
p-tert-butyl calix[4]arene e tetramethylketone p-tert-butyl calix[4]arene isolados e complexados no vácuo com a finalidade de validar os modelos construídos, pois sem a influência externa do solvente, obtivemos resultados que puderam ser comparados com os experimentais provenientes de difração de raios-X por monocristais [12].

Cálculos com os calixarenos tetraethylester p-tert-butyl calix[4]arene e tetramethylketone p-tert-butyl calix[4]arene solvatados por acetonitrila com ou sem a presença de íons, utilizando os modelos validados, permitiu-nos observar o comportamento dinâmico das moléculas de calixarenos e dos complexos calixarenoíon no solvente utilizado para a obtenção dos cristais e das amostras utilizadas nas medidas de NMR, possibilitando a análise a nível microscópico das moléculas em solução. Essas simulações esclareceram diversas dúvidas que envolviam o processo de complexação dos calixarenos estudados e que não podiam ser respondidas a partir dos dados experimentais disponíveis. Esse trabalho contribuiu positivamente para o entendimento do processo de complexação dos calixarenos, o que é fundamental para o potencial uso dessas moléculas em compostos destinados à despoluição ambiental. 


\section{Capítulo 2 - Simulações de Dinâmica Molecular.}

\section{1 - Introdução}

Os estudos propostos no projeto de doutorado consistiram em cálculos de diferentes propriedades como energia livre de hidratação, distribuição radial de pares, coeficiente de difusão, energia de interação a nível molecular, etc., para os sistemas estudados. Cada uma dessas propriedades exigiu a aplicação de técnicas e análises específicas às simulações, que foram todas realizadas utilizando o método de Dinâmica Molecular clássica. Nesse capítulo daremos um enfoque teórico simplificado a esse método com a finalidade de fornecer as idéias básicas ao leitor não especialista. Diversos textos abordam o método por completo [20-22], oferecendo excelente material para os interessados em aprofundar seus conhecimentos sobre DM.

Em simulações de Dinâmica Molecular acompanha-se a evolução temporal dos sistemas estudados em escala atômica e molecular obtida a partir da integração das equações de Newton para cada átomo (sítio) do sistema. A força que atua sobre cada sítio é obtida a partir de um potencial clássico que define todas as interações modeladas, sendo que a forma desse potencial depende do nível de detalhamento com que se pretende descrever o sistema. Ao final da simulação é obtida uma 
trajetória contendo a posição e momento de cada partícula do sistema em cada instante de tempo de onde se pode, a partir de médias sobre propriedades microscópicas, obter características do líquido macroscópico, permitindo a comparação entre resultados teóricos e experimentais de modo que se possa associar acontecimentos observados a nível atômico a fenômenos macroscópicos.

As primeiras simulações de DM foram realizadas por Alden e Wainwright no final da década de 1950 [23] usando o modelo de esferas rígidas idênticas, com o potencial sendo zero para distâncias entre as esferas maiores que o seu raio e infinito para distâncias menores, se movimentando com velocidade constante em linha reta e com colisões perfeitamente elásticas. Nessas simulações simplificadas os sítios somente interagem no momento das colisões, o que limita o problema à resolução de interações entre dois corpos, que possui solução analítica. Com o desenvolvimento do método de DM, foram criados potenciais de interação contínuos em que a força aplicada sobre cada sítio depende da interação com todos os átomos do sistema simulado. A primeira simulação utilizando esse tipo de potencial foi realizada por Rahman em 1964 [24] para um sistema constituido por átomos de argônio, sendo o mesmo cientista, juntamente com Stillinger, o responsável pela primeira simulação de um líquido molecular, no caso a água, em 1974 [25]. A utilização de potenciais contínuos acopla o movimento de todas as partículas, de modo que obtem-se um problema de muitos-corpos, não resolúvel analiticamente, exigindo o uso de um método numérico para a integração das equações de movimento que, no caso de simulações de DM, é o Método de Diferenças Finitas. A evolução dos modelos e potenciais utilizados, juntamente com os avanços na área computacional permitem hoje em dia realizar simulações de Dinâmica Molecular, com enorme nível de 
detalhamento, desde sólidos cristalinos até sistemas líquidos contendo proteínas, lipídios e ácidos nucléicos com excelentes resultados.

Uma simulação que reproduza com fidelidade os sistemas reais estudados exige a aplicação de algoritmos específicos para o tratamento de interações eletrostáticas, condições de contorno, controle de temperatura e pressão, etc. Como nossa proposta é abordar o método de Dinâmica Molecular de modo introdutório para leitores não especialistas, nos ateremos somente à descrição dos assuntos que consideramos mais básicos e fundamentais. Dessa forma, nos tópicos seguintes apresentaremos os algoritmos de integração e campos de força mais utilizados em simulações de DM, com enfoque especial para os utilizados nas simulações apresentadas nesse trabalho.

\section{2 - Algoritmos de Integração - Métodos de Diferenças}

\section{Finitas.}

No método de diferenças finitas a integral é calculada dividindo-se a variável integrada, nesse caso o tempo, em diversos intervalos iguais $\delta t$ de modo que, a partir do valor das posições, velocidades e acelerações em um tempo $t$ arbitrário, podemos calcular a nova configuração do sistema no tempo $t+\delta t$. Considerando a expansão de Taylor da posição e suas derivadas temporais em torno de $t$ obtemos:

$$
\begin{gathered}
\mathbf{r}(t+\delta t)=\mathbf{r}(t)+\delta t \dot{\mathbf{r}}(t)+\frac{1}{2} \delta t^{2} \ddot{\mathbf{r}}(t)+\frac{1}{6} \delta t^{3} \dddot{\mathbf{r}}(t)+\cdots, \\
\dot{\mathbf{r}}(t+\delta t)=\dot{\mathbf{r}}(t)+\delta t \ddot{\mathbf{r}}(t)+\frac{1}{2} \delta t^{2} \dddot{\mathbf{r}}(t)+\cdots,
\end{gathered}
$$




$$
\ddot{\mathbf{r}}(t+\delta t)=\ddot{\mathbf{r}}(t)+\delta t \ddot{\mathbf{r}}(t)+\cdots
$$

Assumindo que durante o intervalo de tempo $\delta t$ a força que atua sobre cada sítio devido à interação com todos os outros sítios do sistema se mantenha constante, calcula-se a aceleração sofrida por cada sítio no tempo $t$. A partir das equações 1 e 2 e da aplicação do método de diferenças finitas obtemos a posição e velocidade dos sítios no tempo $t+\delta t$.

Sendo as equações 1, 2 e 3 somatórias infinitas de termos não é possível calcular a integral exatamente, pois é necessário que a série seja truncada em um determinado ponto. A partir da maneira como essa truncagem é realizada e dos erros que essa operação acarreta é que surgem os diversos algoritmos de integração. $O$ algoritmo de integração mais utilizado em cálculos de Dinâmica Molecular é o desenvolvido por Verlet em 1967 [26] e suas variantes. Nos tópicos seguintes descreveremos três desses algoritmos: de Verlet, Leap-Frog e de Verlet com velocidades.

\subsection{1 - Algoritmo de Verlet.}

A partir da equação 1 para os tempos $t+\delta t$ e $t-\delta t$ temos:

$$
\begin{aligned}
& \mathbf{r}(t+\delta t)=\mathbf{r}(t)+\delta t \dot{\mathbf{r}}(t)+\frac{1}{2} \delta t^{2} \ddot{\mathbf{r}}(t)+\frac{1}{6} \delta t^{3} \dddot{\mathbf{r}}(t)+\cdots, \\
& \mathbf{r}(t-\delta t)=\mathbf{r}(t)-\delta t \dot{\mathbf{r}}(t)+\frac{1}{2} \delta t^{2} \ddot{\mathbf{r}}(t)-\frac{1}{6} \delta t^{3} \dddot{\mathbf{r}}(t)+\cdots
\end{aligned}
$$


Somando as equações 4 e 5 , substituindo as derivadas temporais da posição pela velocidade e aceleração e truncando a série nos termos de quarta ordem obtemos:

$$
\mathbf{r}(t+\delta t)=2 \mathbf{r}(t)-\mathbf{r}(t-\delta t)+\delta t^{2} \mathbf{a}(t)
$$

A equação 6 é a expressão utilizada para se calcular as novas posições dos sítios de uma simulação de DM utilizando o algoritmo de Verlet. A utilização de $\mathbf{r}(t-$ $\delta t)$ no cálculo das posições no tempo $t+\delta t$ torna o método reversível temporalmente. Além disso, o método mostra excelente conservação de energia mesmo com $\delta t$ longos [20].

Observamos que a velocidade não aparece explicitamente na fórmula de modo que não se pode calcular a energia cinética e temperatura do sistema diretamente, o que representa um ponto fraco do algoritmo. Diversas maneiras são utilizadas para se calcular a velocidade no algoritmo de Verlet. A mais simples delas é calcular a "velocidade média" entre as posições $\mathbf{r}(t+\delta t)$ e $\mathbf{r}(t-\delta t)$ :

$$
\mathbf{v}(t)=\frac{\mathbf{r}(t+\delta t)-\mathbf{r}(t-\delta t)}{2 \delta t}
$$

Apesar da equação 6 desprezar termos a partir da quarta ordem, o que torna o método preciso, a equação para a velocidade (eq. 7) é truncada em termos de segunda ordem o que não é muito satisfatório. Outro inconveniente é o fato de podermos calcular $\mathbf{v}(t)$ somente depois de se conhece $\mathbf{r}(t+\delta t)$, dificultando o cálculo da energia cinética e temperatura do sistema. 
Um dos principais problemas do algoritmo é que as posições (eq. 6) são obtidas a partir da adição de termos pequenos $\left(\delta t^{2} \mathbf{a}(t)\right)$ à diferença $2 \mathbf{r}(t)-\mathbf{r}(t-\delta t)$ entre termos grandes, o que acarreta em severa perda de precisão. Além disso, a utilização das posições em $t$ - $\delta t$ na equação 6 dificulta o cálculo quando $t=0$, sendo necessário utilizar o artifício de se truncar a equação 5 a partir do termo de primeira ordem, obtendo $\mathbf{r}(0-\delta t)=\mathbf{r}(0)-\delta t \dot{\mathbf{r}}(0)$.

\subsection{2 - Algoritmo Leap-Frog.}

A partir do algoritmo de Verlet foram desenvolvidas algumas variantes com o objetivo de sanar os problemas apresentados no original. O algoritmo leap-frog [27] (pula-cela em português) é uma das variantes mais populares, sendo a utilizada pelo pacote de programas GROMACS [18] com o qual realizamos as simulações desenvolvidas no doutorado.

A origem do nome fica evidente pelas expressões utilizadas para os cálculos das posições de velocidades:

$$
\begin{gathered}
\mathbf{r}(t+\delta t)=\mathbf{r}(t)+\delta t \mathbf{v}\left(t+\frac{1}{2} \delta t\right) \\
\mathbf{v}\left(t+\frac{1}{2} \delta t\right)=\mathbf{v}\left(t-\frac{1}{2} \delta t\right)+\delta t \mathbf{a}(t)
\end{gathered}
$$

As velocidades são primeiramente calculadas a partir da aceleração no tempo $t$ e das velocidades do "meio-passo" anterior. A posição "salta" sobre a velocidade e é calculada para o tempo $t+\delta t$ a partir da posição no tempo $t$ e da própria velocidade 
em $t+1 / 2 \delta t$. O cálculo da velocidade no tempo $t$ é feito pela média das velocidades no meio-passo anterior e posterior:

$$
\mathbf{v}(t)=\frac{\mathbf{v}\left(t+\frac{1}{2} \delta t\right)-\mathbf{v}\left(t-\frac{1}{2} \delta t\right)}{2} .
$$

As vantagens desse algoritmo é o fato de que a velocidade é calculada explicitamente, evitando perda de precisão como acontece com o Verlet original. Outra vantagem é que nenhuma das equações é obtida a partir da adição de termos pequenos a termos grandes (ausência de $\delta \mathrm{t}^{2}$ ). Uma característica que pode ser considerada uma desvantagem é o fato das posições e velocidades estarem sempre defasadas no tempo, o que implica no fato de que a energia cinética não pode ser calculada no mesmo tempo que a energia potencial (obtida a partir das posições atômicas). A utilização da equação 10 resolve esse problema sem perda de precisão.

\subsection{3 - Algoritmo de Verlet com velocidades.}

Apesar de todas as vantagens apresentadas pelo algoritmo de leap-frog sobre o de Verlet original, manteve-se ainda o problema de não se obter um tratamento adequado para as velocidades. Isso levou Swope et al. [28] a propor o algoritmo de Verlet com velocidades, onde as posições e velocidades são armazenadas sempre no mesmo passo e os erros de arredondamento são minimizados. As equações 11 e 12 mostram as expressões definidas pelo algoritmo: 


$$
\begin{gathered}
\mathbf{r}(t+\delta t)=\mathbf{r}(t)+\delta t \mathbf{v}(t)+\frac{1}{2} \delta t^{2} \mathbf{a}(t) \\
\mathbf{v}(t+\delta t)=\mathbf{v}(t)+\frac{1}{2} \delta t[\mathbf{a}(t)+\mathbf{a}(t+\delta t)]
\end{gathered}
$$

$\mathrm{O}$ algoritmo inicia-se com o cálculo da posição no tempo $t+\delta t$ utilizando a posição, velocidade e aceleração no tempo $t$. Em seguida, é calculada a velocidade no "meio-passo":

$$
\mathbf{v}\left(t+\frac{1}{2} \delta t\right)=\mathbf{v}(t)+\frac{1}{2} \delta t \mathbf{a}(t)
$$

computa-se a aceleração no tempo $t+\delta$ t e finalmente a velocidade:

$$
\mathbf{v}(t+\delta t)=\mathbf{v}\left(t+\frac{1}{2} \delta t\right)+\frac{1}{2} \delta t \mathbf{a}(t+\delta t)
$$

O algoritmo apresenta todos os pré-requisitos para um bom integrador com a vantagem de calcular as energias cinética e potencial no mesmo passo de simulação. Um ponto que pode ser considerado negativo é a necessidade do cálculo de duas velocidades para cada passo $\delta t$, entretanto, esse cálculo adicional representa um aumento percentual muito baixo no tempo total de simulação, pois o custo computacional do integrador propriamente dito é muito baixo. A maior parte do tempo de computação de uma simulação de DM é gasto no cálculo das energias de interação de cada sítio, o que depende fortemente do campo de forças escolhido, assunto a ser discutido no tópico a seguir. 


\section{3 - Campos de Forças.}

Em toda simulação de DM a evolução temporal do sistema, obtida a partir da utilização de um dos algoritmos de integração descritos no tópico anterior, é determinada pela aceleração aplicada em cada um dos sítios. Essa aceleração é obtida a partir da força resultante da interação do sítio em questão com todos os outros sítios do sistema. A maneira como essas interações entre átomos e moléculas acontecem é determinada por um conjunto de potenciais empíricos chamado de campo de forças. Existe um grande número de campos de forças desenvolvidos por diversos grupos de pesquisas. Existem campos de forças destinados a simulações de gases, líquidos e sólidos, campos de forças polarizáveis e não-polarizáveis, que modelam átomos individualmente ou grupos de átomo, etc, fornecendo opções às mais diversas "modalidades" de DM. A escolha de um desses campos de forças para modelar um determinado sistema pode levar em consideração desde o nível de detalhamento que se pretende aplicar ao modelo até preferências pessoais do pesquisador.

As simulações desenvolvidas durante o doutorado visaram sistemas líquidos contendo supramoléculas, sem a intenção de modelar a polarização dos átomos. Alguns dos campos de forças mais populares que satisfazem esses pré-requisitos são o CHARMM [29], OPLS-UA [30], OPLS-AA [19], GROMOS96 [31] e AMBER [32]. De maneira geral esses campos de forças apresentam potenciais de interação muito parecidos, sendo o diferencial de cada um os parâmetros desenvolvidos para descrever os sítios (tabela de parâmetros) e a utilização dos paradigmas de Átomos Unidos (UA, do inglês United Atoms) ou Todos os Átomos (AA, do inglês All Atoms) para modelar os grupos não polares $\left(\mathrm{CH}_{2}, \mathrm{CH}_{3}\right.$, etc.). $\mathrm{O}$ fato de nossos sistemas apresentarem moléculas pequenas de no máximo 170 átomos e a necessidade de 
observarmos interações envolvendo átomos individualmente exigiu a escolha de um campo de forças que utilizasse o paradigma AA. Dentro das possibilidades apresentadas foi escolhido o campo de forças OPLS-AA, pois ele é otimizado para simulações de líquidos, seus parâmetros são desenvolvidos sob uma metodologia extremamente confiável e é implementado no pacote de programas GROMACS.

Com a finalidade didática de apresentar os potenciais de interação comumente utilizados em simulações de sistemas líquidos biomoleculares, descreveremos os potenciais utilizados pelo campo de forças OPLS-AA. O campo de forças é composto por diversos termos funcionais que representam as diferentes interações abrangidas pelo modelo. De maneira geral podemos dividir os potenciais em duas categorias: ligados e não-ligados.

Os potenciais não-ligados representam as interações coulombianas entre as cargas parciais atribuídas a cada sítio e as interações de van der Waals descritas pela função de Lennard-Jones como é mostrado na equação 15:

$$
V_{i j}=\frac{q_{i} q_{j}}{4 \pi \varepsilon_{o} r_{i j}}+4 \varepsilon_{i j}\left[\left(\frac{\sigma_{i j}}{r_{i j}}\right)^{12}-\left(\frac{\sigma_{i j}}{r_{i j}}\right)^{6}\right],
$$

onde os índices $i$ e $j$ se referem aos dois átomos interagentes, $\varepsilon_{i j}$ e $\sigma_{i j}$ são os parâmetros da função de Lennard-Jones e $q_{i}$ e $q_{j}$ são as cargas parciais atribuídas aos átomos $i$ e $j$.

Os potenciais ligados descrevem interações entre átomos ligados covalentemente e descrevem o estiramento da ligação entre dois átomos (eq. 16), a distorção do ângulo formado por três átomos (eq. 17) e a torção do ângulo diedro formado por quatro átomos (eq. 18). As funções que descrevem o estiramento das 
ligações covalentes e distorção dos ângulos de ligação são harmônicas enquanto a descrição da torção de ângulos diedros é feita por uma expansão em funções periódicas da seguinte forma:

$$
\begin{gathered}
V_{\text {lig. }}=K_{B}\left(r-r_{e q}\right)^{2}, \\
V_{\text {ang. }}=K_{\theta}\left(\theta-\theta_{\text {eq }}\right)^{2}, \\
V_{\text {die. }}=\sum_{n} \frac{V_{n}}{2}[1+\cos (n \phi-\gamma)],
\end{gathered}
$$

onde $K_{B}$ e $K_{\theta}$ são constantes harmônicas, $r_{e q}$ e $\theta_{e q}$ são as posições de equilíbrio das ligações e ângulos, $n$ a ordem das funções periódicas utilizadas na expansão, $\mathrm{V}_{\mathrm{n}} \mathrm{a}$ amplitude de cada função, $\phi$ o ângulo diedro e $\gamma$ a sua fase.

O desenvolvimento dos parâmetros para cada campo de força segue uma metodologia própria definida pelos seus criadores. Em geral os parâmetros que modelam interações ligadas são obtidos a partir de dados espectroscópicos e/ou cálculos quânticos. As cargas parciais dos átomos, responsáveis pelas interações de Coulomb, são determinadas em geral por meio de cálculos quânticos. Os parâmetros para a função de Lennard-Jones podem ser obtidos por meio de técnicas experimentais de espectroscopia. Entretanto, atualmente vem sendo muito utilizado, principalmente para o caso de íons metálicos, um método onde se ajusta os valores de $\sigma_{i j}$ e $\varepsilon_{i j}$ de modo a reproduzirem propriedades experimentais diversas como calor de vaporização, energia livre de hidratação, distribuição radial de pares, números de coordenação, etc. A presença de íons de cádmio e chumbo nas simulações com os calixarenos e a ausência de parâmetros já publicados para esses íons exigiu que 
desenvolvêssemos tais parâmetros. A metodologia desenvolvida e os resultados obtidos são apresentados no próximo capítulo. 


\section{Capítulo 3 - Desenvolvimento dos parâmetros para os íons $\mathrm{Cd}^{2+} \mathbf{e} \mathbf{P b}^{2+}$}

\section{1 - Introdução}

O projeto de doutorado teve como objetivo principal o estudo do processo de complexação de calixarenos com íons metálicos e espécies neutras por meio de simulações computacionais de Dinâmica Molecular. Uma das principais dificuldades na realização de simulações de DM é a escolha de modelos que descrevam com fidelidade o comportamento das moléculas do sistema real. Em nosso caso, construir um modelo para descrever os calixarenos estudados e o solvente utilizado, no caso a acetonitrila, não foi uma dificuldade muito grande devido ao fato dessas moléculas serem compostas por grupos químicos cujos parâmetros já haviam sido desenvolvidos no campo de forças OPLS-AA. Por outro lado, a modelagem dos íons complexados pelos calixarenos foi uma das tarefas mais difíceis de todo o trabalho, pois como o cádmio e o chumbo não são átomos comuns em simulações de sistemas biológicos, não encontramos na literatura parâmetros que modelassem os íons $\mathrm{Cd}^{2+} \mathrm{e}$ $\mathrm{Pb}^{2+}$ com a qualidade exigida. Dessa forma, foi necessário que desenvolvêssemos 
nossos próprios parâmetros para esses íons a fim de utilizá-los nas simulações com os calixarenos.

Em geral os íons presentes em simulações de DM não realizam ligações covalentes, de modo que os parâmetros, nesse caso, se limitam àqueles utilizados nos potenciais não-ligados, descritos no capítulo anterior, como a carga parcial e os parâmetros de Lennard-Jones. Como íons sempre apresentam cargas inteiras, a determinação desse parâmetro se torna trivial e o trabalho mais intenso é para a determinação de $\sigma$ e $\quad \varepsilon$. Atualmente, um método muito utilizado para o desenvolvimento desses parâmetros é o ajuste de seus valores de modo que a simulação com os íons reproduza propriedades características dos íons reais como energia livre de hidratação, número de coordenação, coeficiente de difusão, etc. Diversos trabalhos utilizando essa metodologia já foram publicados [33-37], obtendo parâmetros para íons de metais alcalinos, alcalino-terroso, halogênios e alguns metais de transição e lantanídeos que reproduzem muito bem o comportamento dos íons reais. Em geral utiliza-se apenas uma das propriedades como parâmetro para o ajuste e a partir dos valores finais obtidos calcula-se outras propriedades para a validação dos resultados.

Em nossa metodologia ajustamos os parâmetros para os íons de cádmio (II) e chumbo (II) de modo a reproduzirem simultaneamente valores experimentais de energia livre de hidratação [38] e distâncias médias íon-água e número de coordenação da primeira camada de solvatação obtidos experimentalmente e a partir de cálculos QM/MM [39-41]. Nas simulações para a obtenção dos parâmetros foi utilizado o modelo TIP3P [42] para a água. A transferabilidade dos parâmetros obtidos foi analisada a partir de cálculos em outros modelos de água: SPC [43], SPC/E [44] e TIP4P [42]. Para validarmos os modelos desenvolvidos realizamos 
cálculos de propriedades dinâmicas como coeficiente de difusão e tempo médio de residência de moléculas de água na primeira camada de solvatação do íon para os quatro modelos de água utilizados. Mais detalhes sobre a metodologia utilizada e a teoria envolvida são apresentados no tópico seguinte.

\section{2 - Teoria e Metodologia}

A parametrização da função de Lennar-Jones (eq. 19) para os íons $\mathrm{Pb}^{2+}{\mathrm{e} \mathrm{Cd}^{2+}}^{2+}$ foi baseada no trabalho desenvolvido por Åqvist [33] no estudo de íons de metais alcalinos e alcalino-terrosos em solução. Implementamos alterações na metodologia proposta no trabalho original visando maior confiabilidade nos modelos obtidos e menor custo computacional. No desenvolvimento dos parâmetros utilizamos o modelo TIP3P para a água. Nos cálculos de energia livre utilizamos o método Linear Interaction Energy (LIE) [45] ao invés de métodos clássicos como o método de Perturbação Termodinâmica (FEP, para Free Energy Perturbation) [46] e Integração Termodinâmica (TI, para Thermodynamic Integration) [47] por motivos discutidos posteriormente. Os parâmetros foram refinados de modo a reproduzirem simultaneamente valores experimentais de energia livre de hidratação absoluta $\left(\Delta \mathrm{G}_{\mathrm{Hidr}}\right)$ [38] e propriedades estruturais obtidas a partir de espalhamento de raios-X [39] e cálculos QM/MM [40, 41]. Em nossas simulações a estrutura de hidratação do ín foi obtida a partir da análise da função distribuição radial de pares $g(r)$. A transferabilidade dos modelos obtidos foi estudada pelo cálculo da função $g(r)$ e $\Delta \mathrm{G}_{\text {Hidr }}$ para os modelos de água SPC, SPC/E e TIP4P. A validação dos novos parâmetros foi obtida pela comparação de propriedades dinâmicas calculadas com resultados experimentais. Calculamos o coeficiente de difusão dos íons em solução, 
através da relação de Einstein [20], e a persistência da primeira camada de solvatação utilizando o método proposto por Impey et al [48].

$$
U_{i j}=4 \varepsilon_{i j}\left[\left(\frac{\sigma_{i j}}{r_{i j}}\right)^{12}-\left(\frac{\sigma_{i j}}{r_{i j}}\right)^{6}\right] .
$$

Para calcular a energia livre de hidratação absoluta utilizamos o ciclo termodinâmico mostrado na Figura 4, onde um átomo Dummy significa um sítio com carga e parâmetros de Lennard-Jones iguais a zero.

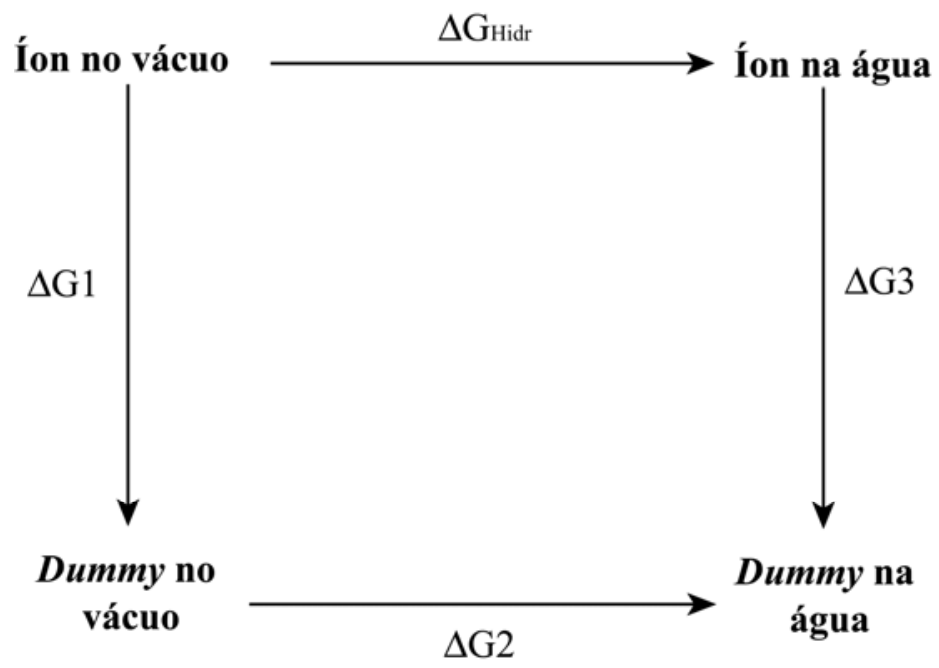

Figura 4 - Ciclo termodinâmico utilizado para os cálculos de energia livre de hidratação dos ions. Átomos dummy apresentam carga e parâmetros de Lennard-Jones iguais a zero.

Como $\Delta G 1=\Delta G 2=0$, o ciclo termodinâmico se reduz a $\Delta G_{H i d r}=-\Delta G 3$ e o estado inicial (A) consiste no átomo dummy em água e o estado final (B) se refere ao íon em água.

A energia livre de hidratação absoluta de íons é obtida a partir da relação: 


$$
\Delta G_{H i d r}\left(I^{n+}\right)=\Delta G_{S R}\left(I^{0} \rightarrow I^{n+}\right)+\Delta G_{B o r n}+\Delta G_{C a v}
$$

A contribuição das interações de curto alcance para a energia livre de hidratação absoluta, $\Delta \mathrm{G}_{\mathrm{SR}}$, normalmente apresenta valores da ordem de milhares de $\mathrm{kJ} /$ mol. Essa escala de energia torna os métodos perturbativos, como FEP e TI, inviáveis devido ao grande número de simulações necessárias para se obter uma boa sobreposição do espaço de fase entre estados intermediários consecutivos [22]. Nesses casos o método LIE é mais conveniente devido ao fato de exigir somente simulações dos estados inicial e final para o cálculo da diferença de energia livre, não demandando recursos computacionais para cálculos de estados intermediários [45, 49]. A utilização do método LIE com o ciclo termodinâmico da Figura 4, considerando que o átomo dummy não interage com a água, reduz nossos cálculos a uma única simulação do íon em água.

O método semi-empírico LIE foi originalmente desenvolvido para o cálculo de energia livre de ligação envolvendo macromoléculas e seus ligantes e de energia livre de hidratação, baseando-se na aproximação de resposta linear da energia livre para alterações na interação eletrostática [45]. A diferença de energia livre entre dois estados A e B é calculada pela expressão:

$$
\Delta G=\frac{1}{2}\left(\left\langle V_{i-s}^{e l}\right\rangle_{B}-\left\langle V_{i-s}^{e l}\right\rangle_{A}\right)+\alpha\left(\left\langle V_{i-s}^{v d w}\right\rangle_{B}-\left\langle V_{i-s}^{v d w}\right\rangle_{A}\right),
$$

onde $\left\langle V_{i-s}^{e l}\right\rangle_{Y}$ e $\left\langle V_{i-s}^{v d w}\right\rangle_{Y}$ são, respectivamente, as médias da interação eletrostática e de van der Waals entre o íon (i) e o solvente (s) no estado Y. O fator $1 / 2$ é obtido a partir da aproximação de resposta linear e o parâmetro $\alpha$, o qual é obtido 
empiricamente a partir de cálculos de DM em solventes não-polares, toma o valor 0,181 nesse trabalho [50]. Os valores médios da equação 21 são calculados a partir de simulações de DM nos estados A e B. Como já mencionado, no caso de cálculos de energia livre de solvatação absoluta de íons, o estado A corresponde ao átomo dummy em água, resultando em $\left\langle V_{i-s}^{e l}\right\rangle_{A}=\left\langle V_{i-s}^{v d w}\right\rangle_{A}=0$. Nas simulações do íon em água (estado B), somente foram consideradas para o cálculo das médias de energia as interações entre íon e moléculas de água separadas por uma distância menor que um determinado raio de corte.

A contribuição para a energia livre da interação do íon com o solvente fora do raio de corte foi calculada utilizando a conhecida fórmula de Born[33], que em $\mathrm{kJ} / \mathrm{mol}$ é dada por:

$$
\Delta G_{\text {Born }}=\frac{-1347\left(1-\varepsilon^{-1}\right) q^{2}}{2 r_{\text {Born }}}
$$

onde $\varepsilon$ é a constante dielétrica do solvente, q a carga do íon em número de elétrons e $\mathrm{r}_{\text {Born }} \mathrm{O}$ raio de corte em Å. A correção de Born somente é necessária em cálculos de energia livre absoluta, pois em cálculos de energia livre relativa esse termo se cancela. $\mathrm{O}$ termo $\Delta \mathrm{G}_{\mathrm{cav}}$ da equação 20 corresponde à energia livre necessária para se criar uma cavidade no solvente para acomodar o íon, podendo ser desprezado pois assume valores da ordem de alguns $\mathrm{kJ} / \mathrm{mol}$, e portanto dentro do erro estimado[51].

As propriedades estruturais foram analisadas a partir da distribuição radial de pares, representada pela função $g_{i j}(r)$ dada por: 


$$
g_{i j}(r)=\frac{\left\langle N_{j}(r, r+\Delta r)\right\rangle}{\rho_{j} 4 \pi r^{2} \Delta r},
$$

onde $N_{j}(r, r+\Delta r)$ é o número médio de átomos $j$ na casca esférica definida pelos raios $r$ e $r+\Delta r$ centrada no átomo i e $\rho_{\mathrm{j}}$ é a densidade numérica dos átomos $j$. O cálculo dessa função em nossas simulações, assumindo $i$ como o íon e $j$ como os átomos da molécula de água, nos forneceu as distâncias médias íon- $\mathrm{O}_{\mathrm{w}}\left(\mathrm{O}_{\mathrm{w}}\right.$ é o oxigênio da molécula de água $)$ e íon- $\mathrm{H}_{\mathrm{w}}\left(\mathrm{H}_{\mathrm{w}}\right.$ é cada um dos hidrogênios da molécula de água). A partir da integração da função $g(r)$ obtemos o número de coordenação do íon.

Os cálculos de propriedades dinâmicas, como já dito, foram baseados no trabalho desenvolvido por Impey et al. [48] no estudo da mobilidade de íons em solução. Calculamos o coeficiente de difusão do íon $\left(\mathrm{D}_{\mathrm{ion}}\right)$ e o tempo de residência médio das moléculas de solvente na primeira camada de coordenação do íon $\left(\tau_{\text {ion }}\right)$. $\mathrm{O}$ coeficiente de difusão foi calculado a partir do deslocamento médio quadrático (MSD, para Mean Square Displacement) do íon, $\left\langle|\vec{R}(t)-\vec{R}(0)|^{2}\right\rangle$, utilizando a relação de Einstein:

$$
6 \mathrm{D}_{\text {ion }}=\lim _{t \rightarrow \infty} \frac{\mathrm{d}}{\mathrm{dt}}\left\langle|\vec{R}(t)-\vec{R}(0)|^{2}\right\rangle .
$$

A estrutura de hidratação do íon fornecida pela função $g(r)$ é obtida a partir de uma média temporal, resultando em uma descrição estática do processo. Entretanto, a solvatação apresenta uma natureza dinâmica com moléculas de solvente entrando e saindo das diversas camadas de solvatação do íon. Esse processo temporal pode ser quantificado pela função $S(t)$ (Survival Probability Function), definida como: 


$$
S(t)=\frac{1}{\bar{N}}\left\langle\sum_{j=1}^{M} P_{j}\left(t_{0}, t+t_{0} ; t^{*}\right)\right\rangle_{t_{0}},
$$

onde $\mathrm{M}$ é o número total de moléculas de solvente, $\langle\mathbf{O}\rangle_{t_{0}}$ representa a média

temporal de $\mathbf{O}, \bar{N}$ é o número de coordenação médio e $P_{j}\left(t_{0}, t+t_{0} ; t^{*}\right)$ é a probabilidade de uma molécula de solvente $j$ estar na camada de solvatação no tempo $t+t_{0}$, sendo que ela participava desse camada de solvatação no tempo $t_{0}$ e nesse meiotempo não deixou a camada de solvatação por um tempo maior que $t^{*}$. Exceto para tempos curtos, o decaimento da função $S(t)$ pode ser ajustado pela função exponencial $\exp \left(-\mathrm{t} / \tau_{\text {ion }}\right)$, de onde obtemos o tempo médio de residência $\tau_{\text {ion }}$ [48].

\section{3 - Detalhes Computacionais}

As simulações foram realizadas utilizando o pacote de programas GROMACS e o campo de forças OPLS-AA. Inicialmente realizamos cálculos de energia livre de

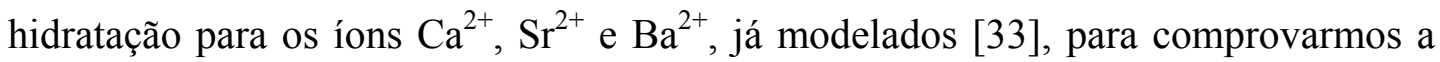

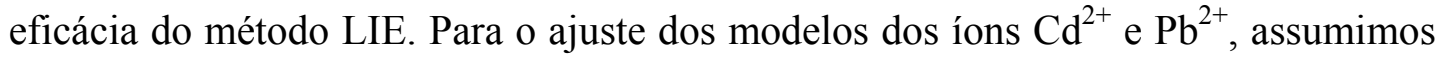
como parâmetros iniciais os obtidos no campo de forças UFF [52]. Os íons foram posicionados no centro de uma caixa de aproximadamente $35 \AA$ contendo 1409 moléculas de água TIP3P com densidade igual à experimental. Para cada íon realizamos uma simulação de 500 ps para equilibração e outra de 5 ns para aquisição de dados, ambas com passos de 1 fs. A pressão e temperatura foram mantidos constantes a 1 bar e $300 \mathrm{~K}$ (ensemble NPT), respectivamente, utilizando algoritmos de 
Berendsen [53] com constantes de tempo de 1,0 ps e 0,1 ps. Aplicamos condições periódicas de contorno e raio de corte de $15 \AA$ para as interações de Coulomb e Van der Waals de baixo alcance. Diferentes raios de corte foram utilizados para testar sua influência nos resultados obtidos, mas não foram observadas alterações substanciais. As interações coulombianas de longo alcance não foram computadas e a contribuição para o valor da energia livre dessas interações foi calculada pela fórmula de Born (equação 22) utilizando $\varepsilon=78$ e $\mathrm{r}_{\text {Born }}$ igual ao raio de corte.

Após um grande número de simulações de ajustes obtivemos parâmetros para o

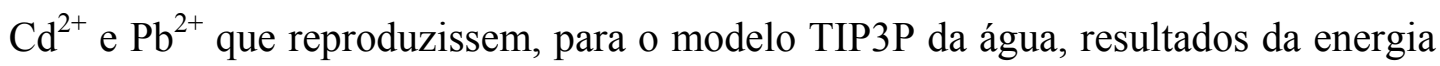
livre de hidratação e propriedades estruturais $(g(r)$ e números de coordenação) obtidos experimentalmente e a partir de cálculos QM/MM. Foram realizadas simulações para outros modelos de água (TIP4P, SPC e SPCE), utilizando os mesmos procedimentos das simulações anteriores, para verificarmos a transferabilidade dos parâmetros desenvolvidos. Os cálculos das propriedades dinâmicas, utilizadas na validação dos parâmetros, foram realizados para os quatro modelos de água utilizados a partir das trajetórias de 5 ns.

\section{4 - Resultados e Discussões}

\subsection{1 - Energia livre de hidratação absoluta}

A variação de energia livre é uma das mais importantes propriedades para se caracterizar a espontaneidade de um processo químico. Devido às características entrópicas da energia livre, os cálculos dessa grandeza por simulações 
computacionais exigem a utilização de técnicas específicas e uma alta demanda computacional. O valor da energia livre de hidratação é uma das características experimentais mais utilizadas no desenvolvimento de parâmetros, além disso, ela nos fornece informação sobre o estado de solvatação do soluto estudado. Utilizamos valores calculados da energia livre de hidratação absoluta como valores de referência

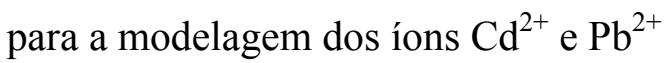

Para avaliarmos a viabilidade do uso do método LIE na modelagem dos íons, inicialmente realizamos cálculos da energia livre de hidratação absoluta em água TIP3P para íons divalentes já modelados para o campo de forças OPLS. Os resultados da energia livre de hidratação absoluta obtidos para os íon $\mathrm{Ca}^{2+}, \mathrm{Sr}^{2+} \mathrm{e}$ $\mathrm{Ba}^{2+}$ são mostrados na Tabela II. Os valores calculados estão em ótimo acordo com os experimentais, mostrando a tendência de íons menores (menor raio atômico) apresentarem um valor de energia livre de hidratação mais negativo pois interagem mais fortemente com as moléculas de água na primeira camada de solvatação. Esses resultados mostram que a utilização do método LIE é adequada para cálculos em sistemas iônicos aquosos.

Os parâmetros Lennard-Jones finais obtidos para os íons $\mathrm{Cd}^{2+}$ e $\mathrm{Pb}^{2+}$ são mostrados na Tabela I. A Tabela II mostra os valores calculados da energia livre de hidratação absoluta, obtidos a partir dos parâmetros finais para os íons cádmio(II) e chumbo(II), para diversos modelos de água. Para o íon $\mathrm{Pb}^{2+}$ obtivemos um excelente acordo entre nossos resultados e o valor experimental [38], sendo que para os modelos TIP3P, SPC e SPC/E o erro fica em torno de 3,5\% e para o TIP4P 7,2\%. Para o íon $\mathrm{Cd}^{2+}$ os resultados calculados não são tão próximos dos experimentais como no caso do $\mathrm{Pb}^{2+}$, mas ainda podem ser considerados bons. As diferenças percentuais com relação ao valor experimental foram de 9,8\% para o modelo TIP3P, 
$8,4 \%$ para o SPC/E, $10,2 \%$ para o SPC e $14,1 \%$ para o TIP4P. Observamos que, em ambos os casos, os melhores resultados para a energia livre de hidratação foram obtidos utilizando-se os modelos TIP3P e SPC/E. As simulações com o modelo TIP4P para a água apresentaram as maiores diferenças quando comparadas com os valores experimentais, chegando a $14,1 \%$ no caso da energia livre de hidratação do $\mathrm{Cd}^{2+}$. O fato do TIP4P modelar a água com 4 sítios pode ser a causa dessa discrepância, já que os parâmetros foram ajustados em simulações com o modelo TIP3P, que usa 3 sítios para modelar a água, da mesma forma que o SPC e o SPC/E.

$\mathrm{O}$ valor para a energia livre de hidratação do íon $\mathrm{Cd}^{2+}$ aproximadamente 250 $\mathrm{kJ} /$ mol mais negativo comparado com o obtido para o íon $\mathrm{Pb}^{2+}$ nos mostra que a solvatação do íon de cádmio pela água é mais intensa, indicando que a solvatação dos dois íons é bem distinta como confirmado pelos cálculos de propriedades estruturais e dinâmicas.

Os resultados mostram que os parâmetros desenvolvidos reproduzem satisfatoriamente bem valores de energia livre de hidratação absoluta para os diversos modelos de água, mostrando a confiabilidade do modelo desenvolvido e sua transferabilidade.

Tabela I - Parâmetros Lennard-Jones finais.

\begin{tabular}{ccc}
\hline Íon & $\sigma(\AA)$ & $\varepsilon(\mathbf{k J} / \mathbf{m o l})$ \\
\hline $\mathbf{P b}^{2+}$ & 3,0 & 0,800 \\
$\mathbf{C d}^{2+}$ & 2,7 & 0,025 \\
\hline
\end{tabular}


Tabela II - Energias livres de hidratação calculada, experimental e o erro relativo entre os dois valores.

\begin{tabular}{ccccc}
\hline Íon & $\Delta \mathbf{G}_{\text {calc. }} \pm \mathbf{1 0}(\mathbf{k J} / \mathbf{m o l})$ & $\left.\Delta \mathbf{G}_{\text {exp. }} \mathbf{( k J / m o l}\right)^{\mathbf{a}}$ & Modelo de água & Erro (\%) \\
\hline $\mathbf{C a}^{2+}$ & -1534 & $-1593,27$ & TIP3P & 3,7 \\
$\mathbf{S r}^{2+}$ & -1439 & $-1447,25$ & TIP3P & 0,5 \\
$\mathbf{B a}^{2+}$ & -1339 & $-1318,38$ & TIP3P & 1,5 \\
$\mathbf{P b}^{2+}$ & -1440 & $-1497,04$ & TIP3P & 3,8 \\
$\mathbf{P b}^{2+}$ & -1433 & $-1497,04$ & SPC & 4,3 \\
$\mathbf{P b}^{2+}$ & -1451 & $-1497,04$ & SPC/E & 3,0 \\
$\mathbf{P b}^{2+}$ & -1389 & $-1497,04$ & TIP4P & 7,2 \\
$\mathbf{C d}^{2+}$ & -1624 & $-1801,21$ & TIP3P & 9,8 \\
$\mathbf{C d}^{2+}$ & -1618 & $-1801,21$ & SPC & 10,2 \\
$\mathbf{C d}^{2+}$ & -1650 & $-1801,21$ & SPC/E & 8,4 \\
$\mathbf{C d}^{2+}$ & -1548 & $-1801,21$ & TIP4P & 14,1 \\
\hline${ }^{2+} \mathrm{Refer}^{2+}$ & & & &
\end{tabular}

\subsection{2 - Propriedades estruturais}

O cálculo da distribuição radial de pares fornece informações importantes sobre as camadas de solvatação dos íons, indicando as distâncias médias íon-solvente e o número de coordenação. Utilizamos a $g(r)$ íon- $\mathrm{O}_{\mathrm{w}}$ e íon- $\mathrm{H}_{\mathrm{w}}$ com o modelo TIP3P para a água na modelagem dos íons $\mathrm{Pb}^{2+}$ e $\mathrm{Cd}^{2+}$, ajustando os parâmetros de modo que reproduzissem os resultados obtidos experimentalmente [39] ou por cálculos QM/MM [40, 41]. Calculamos também a $g(r)$ dos íons modelados para outros três modelos de água (SPC, SPC/E e TIP4P) e comparamos com os valores de referência para verificarmos a transferabilidade dos modelos. 
As Figuras 5 e 6 nos mostram funções $g(r)$ calculadas para os dois íons com os quatro modelos de água utilizados. Os resultados obtidos para os diferentes modelos de água são praticamente idênticos, mostrando que com relação às propriedades estruturais, nossos parâmetros apresentam uma ótima transferabilidade. As $g(r)$ calculadas para o íon $\mathrm{Cd}^{2+}$ apresentam primeiros picos e mínimos acentuados tanto para os átomos de oxigênio como para os de hidrogênio da água, o que caracteriza uma primeira camada de solvatação muito bem definida e com pouca ou nenhuma troca de moléculas com o bulk. Os gráficos de $g(r)$ para o íon $\mathrm{Pb}^{2+}$ também apresentam essa característica mas de maneira menos intensa que no caso do $\mathrm{Cd}^{2+}, \mathrm{o}$ que significa uma camada de solvatação menos persistente.

A Tabela III mostra detalhadamente os valores característicos das funções $g(r)$, os números de coordenação calculados e a comparação com resultados experimentais e de cálculos ab initio. Com relação ao íon de cádmio, a primeira camada de solvatação está aproximadamente $0,2 \AA$ mais próxima quando comparada com os resultados experimentais da referência [39], entretanto, o número de coordenação calculado é praticamente idêntico. Em nossos cálculos, a distância da primeira camada de solvatação do íon $\mathrm{Pb}^{2+}$ e o número de coordenação apresentam valores muito próximos dos obtidos em cálculos QM/MM [40]. Para ambos os íons a caracterização da segunda camada de solvatação apresenta bom acordo, de maneira geral, com os resultados das referências utilizadas. Entretanto, observamos algumas divergências entre nossos resultados e os obtidos por cálculos QM/MM devido ao fato de ser mais difícil caracterizar essa camada e por diferenças inerentes entre os dois métodos comparados (DM e QM/MM). 


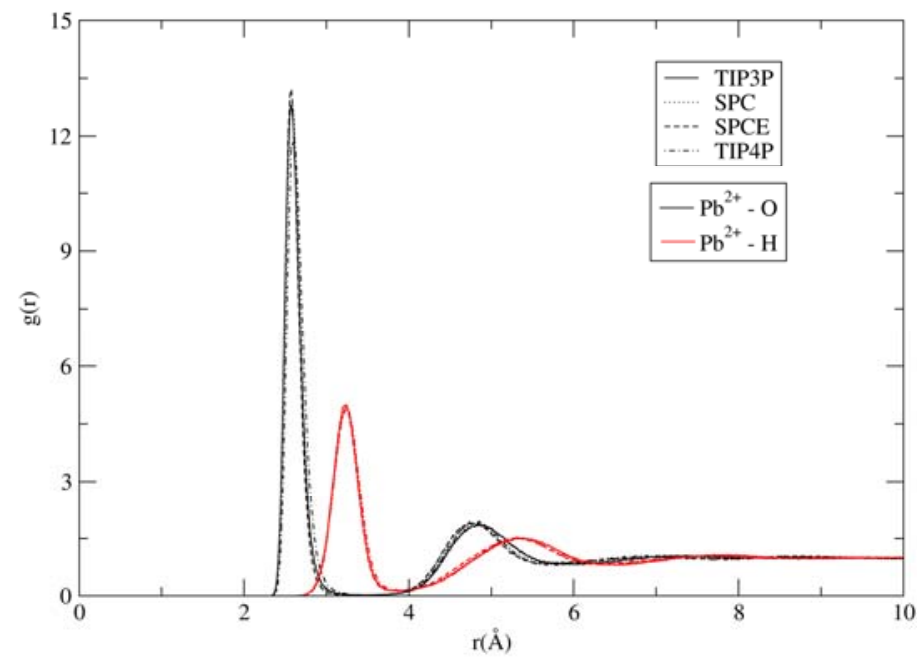

Figura 5 - Distribuição Radial de Pares $\mathrm{Pb}^{2+}-\mathrm{O}$ e $\mathrm{Pb}^{2+}$-H para os quatro modelos de água utilizados.

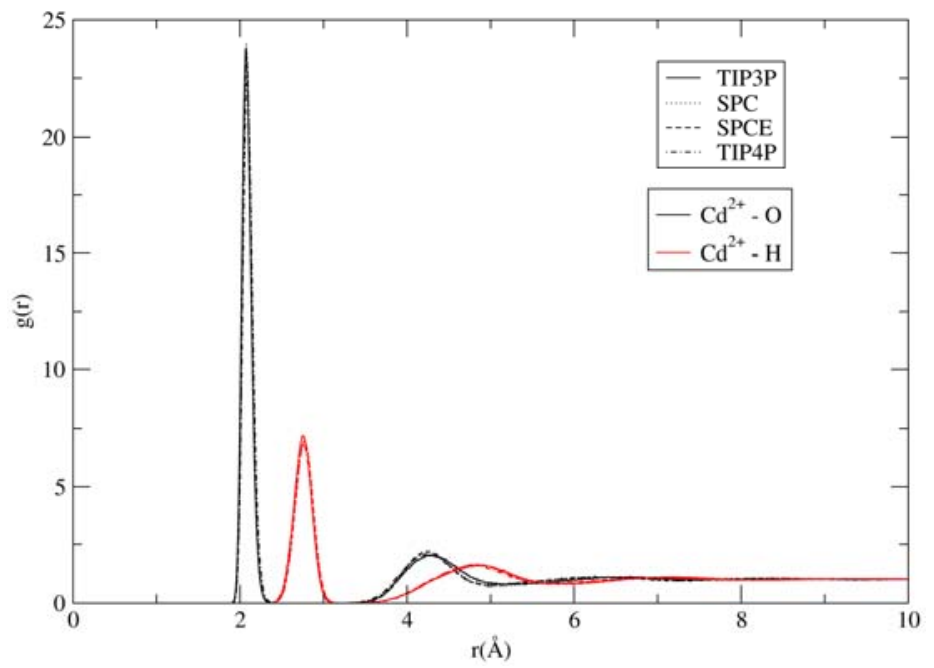

Figura 6 - Distribuição Radial de Pares $\mathrm{Cd}^{2+}-\mathrm{O}$ e $\mathrm{Cd}^{2+}$-H para os quatro modelos de água utilizados. 
Tabela III - Valores característicos da $g(r)$ e números de coordenação do $\mathrm{Cd}^{2+}$ e $\mathrm{Pb}^{2+}$. A coluna ref. mostra o modelo de água utilizado em nossos cálculos ou a referência de onde foram obtidos os valores para comparação.

\begin{tabular}{|c|c|c|c|c|c|c|c|}
\hline Íon & $\mathbf{r}_{M 1}{ }^{a}$ & $\mathbf{r}_{\mathbf{m} 1}$ & $\mathbf{N}_{1}$ & $\mathbf{r}_{\mathbf{M} 2}$ & $\mathbf{r}_{\mathrm{m} 2}$ & $\mathbf{N}_{2}$ & Ref. \\
\hline Cd-O & 2,08 & 2,80 & 6,01 & 4,26 & 5,20 & 22,20 & TIP3P \\
\hline Cd-O & 2,09 & 2,83 & 6,13 & 4,25 & 5,03 & 20,63 & SPC \\
\hline Cd-O & 2,08 & 2,84 & 5,99 & 4,24 & 5,00 & 20,10 & $\mathrm{SPC} / \mathrm{E}$ \\
\hline Cd-O & 2,08 & 2,80 & 5,99 & 4,24 & 5,00 & 20,12 & TIP4P \\
\hline Cd-O & 2,29 & 2,78 & 6,0 & 4,22 & 5,27 & 12,00 & {$[39,41]$} \\
\hline Cd - H & 2,75 & 3,30 & 12,03 & 4,86 & 5,80 & 55,00 & TIP3P \\
\hline Cd - H & 2,78 & 3,36 & 12,27 & 4,83 & 5,69 & 52,60 & SPC \\
\hline Cd - H & 2,77 & 3,30 & 11,97 & 4,81 & 5,72 & 53,00 & $\mathrm{SPC} / \mathrm{E}$ \\
\hline Cd - H & 2,76 & 3,26 & 12,00 & 4,80 & 5,66 & 50,39 & TIP4P \\
\hline Cd - H & 3,03 & - & - & 4,85 & - & - & [41] \\
\hline $\mathbf{P b}-\mathbf{O}$ & 2,58 & 3,50 & 8,45 & 4,83 & 5,95 & 32,00 & TIP3P \\
\hline $\mathbf{P b}-\mathbf{O}$ & 2,60 & 3,51 & 8,53 & 4,80 & 5,89 & 31,21 & SPC \\
\hline Pb -O & 2,56 & 3,50 & 8,13 & 4,79 & 5,72 & 28,72 & $\mathrm{SPC} / \mathrm{E}$ \\
\hline Pb-O & 2,61 & 3,48 & 8,78 & 4,81 & 5,72 & 29,00 & TIP4P \\
\hline Pb -O & 2,60 & 3,65 & 9,0 & 5,00 & 6,40 & 24,30 & {$[40]$} \\
\hline $\mathbf{P b}-\mathbf{H}$ & 3,22 & 3,85 & 17,13 & 5,35 & 6,52 & 77,30 & TIP3P \\
\hline $\mathbf{P b}-\mathbf{H}$ & 3,24 & 3,90 & 17,37 & 5,34 & 6,43 & 74,43 & SPC \\
\hline $\mathbf{P b}-\mathbf{H}$ & 3,26 & 3,90 & 16,73 & 5,32 & 6,38 & 72,50 & SPC/E \\
\hline $\mathbf{P b}-\mathbf{H}$ & 3,25 & 3,91 & 17,87 & 5,30 & 6,35 & 71,96 & TIP4P \\
\hline $\mathbf{P b}-\mathbf{H}$ & 3,25 & 4,00 & 18,00 & 5,35 & 6,40 & 57,60 & [40] \\
\hline
\end{tabular}

${ }^{a}$ rM1, rM2, rm1 e rm2 são o primeiro e segundo máximos e primeiro e segundo mínimos da $g(r)$, respectivamente. N1 e N2 são os números de coordenação da primeira e segunda camada de solvatação. 
Os bons resultados obtidos nas simulações dos sistemas iônicos aquosos apresentados garantem confiabilidade aos modelos desenvolvidos. Um detalhe importante é o fato de termos utilizado dois tipos de propriedades (termodinâmicas e estruturais) para ajustar o modelo dos íons, o que não nos permitiu reproduzir com maior precisão os valores experimentais. Para ambos os íons obtivemos parâmetros $\sigma$ e $\varepsilon$ que reproduziam os valores de energia livre de hidratação experimentais com uma grande precisão, entretanto, os resultados da função $g(r)$ e os números de coordenação eram muito distantes dos valores de referência. Devido a esse problema, ajustamos nossos parâmetros de modo a minimizar os erros simultaneamente para os dois tipos de propriedades calculadas.

\subsection{3 - Propriedades dinâmicas}

Em soluções iônicas aquosas o fato de o soluto ser carregado implica em interações íon-água muito fortes, o que se reflete em camadas de solvatação muito bem definidas como pode ser observado nas $g(r)$ calculadas. Entretanto, uma descrição completa das camadas de solvatação dos íons inclui um estudo de seu comportamento dinâmico a partir do cálculo de propriedades como coeficiente de difusão e tempo de residência. $O$ coeficiente de difusão $\left(D_{\text {ion }}\right)$ nos fornece informações quantitativas de como o íon se desloca dentro da solução, o que depende fortemente da maneira como ele interage com sua primeira camada de solvatação. Os

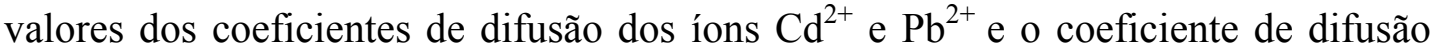
própria calculado para cada modelo de água [54] (self-diffusion coefficient, $D_{\text {water }}$ ) são mostrados na Tabela IV. Os diferentes valores de $\mathrm{D}_{\text {water }}$ calculados para cada modelo de água influenciam o valor do coeficiente de difusão dos íons, de modo que 
não é possível uma comparação direta com o valor experimental. Isso acontece porque um modelo de água mais "rápido" consequentemente vai permitir um deslocamento mais veloz do íon, aumentando seu coeficiente de difusão. Para elucidar esse comportamento construímos o gráfico (Figura 7 ) de $\mathrm{D}_{\text {ion }} / \mathrm{D}_{\text {water }}$ em função do modelo de água utilizado para os dois íons modelados, também é mostrada a mesma razão obtida a partir dos valores experimentais. O gráfico mostra que as razões entre os valores obtidos em nossas simulações são menores que a razão entre os valores experimentais, entretanto, o comportamento do coeficiente de difusão para os diferentes modelos de água é o mesmo para ambos os íons. Para o modelo de água com 4 sítios (TIP4P) a razão $\mathrm{D}_{\text {ion }} / \mathrm{D}_{\text {water }}$ é menor que as obtidas para os modelos de 3 sítios (SPC, SPC/E e TIP3P), mostrando que o MSD dos íons é influenciado pela modelagem diferenciada da água empregada no modelo TIP4P. Os valores do coeficiente de difusão obtidos utilizando-se modelos de 3 sítios para a água apresentam praticamente a mesma proporcionalidade com relação ao $D_{\text {water, }}$, evidenciando que os resultados obtidos são coerentes. Pelo fato do cádmio apresentar raio atômico menor que o chumbo, a princípio o íon $\mathrm{Cd}^{2+}$ teria mais facilidade de se deslocar pelo solvente e portanto esperávamos que o valor do $\mathrm{D}_{\mathrm{Cd} 2+}$ fosse maior que o do $\mathrm{D}_{\mathrm{Pb} 2+}$, entretanto, nossos resultados mostram o contrário. Isso acontece porque o íon $\mathrm{Cd}^{2+}$ apresenta a primeira camada de solvatação fortemente ligada e persistente, fato evidenciado pelos cálculos de tempo de residência apresentados posteriormente, o que acarreta numa menor mobilidade e explica o valor obtido para o coeficiente de difusão. 
Tabela IV - Coeficiente de Difusão, em $10^{-5} \mathrm{~cm}^{2} / \mathrm{s}$, para os ions $\mathrm{Pb}^{2+}\left(D_{P_{b 2}+}\right)$ e $\mathrm{Cd}^{2+}\left(D_{\mathrm{Cd2}_{2}}\right)$,

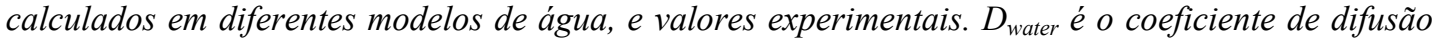
própria da água (self-diffusion coefficient), calculado para cada modelo utilizado, e o valor experimental.

\begin{tabular}{cccccc}
\hline Modelo de água & $\mathbf{D}_{\mathbf{P b} 2+}$ & $\mathbf{D}_{\mathrm{Cd} 2+}$ & $\mathbf{D}_{\text {water }}{ }^{a}$ & $\mathbf{D}_{\mathbf{P b} 2+} / \mathbf{D}_{\text {water }}$ & $\mathbf{D}_{\mathbf{C d} 2+/ \mathbf{D}_{\text {water }}}$ \\
\hline SCP & 2,49 & 1,65 & 3,85 & 0,65 & 0,43 \\
SCP/E & 1,52 & 1,33 & 2,49 & 0,61 & 0,53 \\
TIP3P & 3,21 & 2,54 & 5,19 & 0,62 & 0,49 \\
TIP4P & 1,13 & 0,83 & 3,29 & 0,34 & 0,25 \\
Exp. $^{b}$ & 1,890 & 1,438 & 2,30 & 0,82 & 0,625 \\
\hline
\end{tabular}

${ }^{a}$ Referência [54]. ${ }^{b}$ Referências [55, 56].

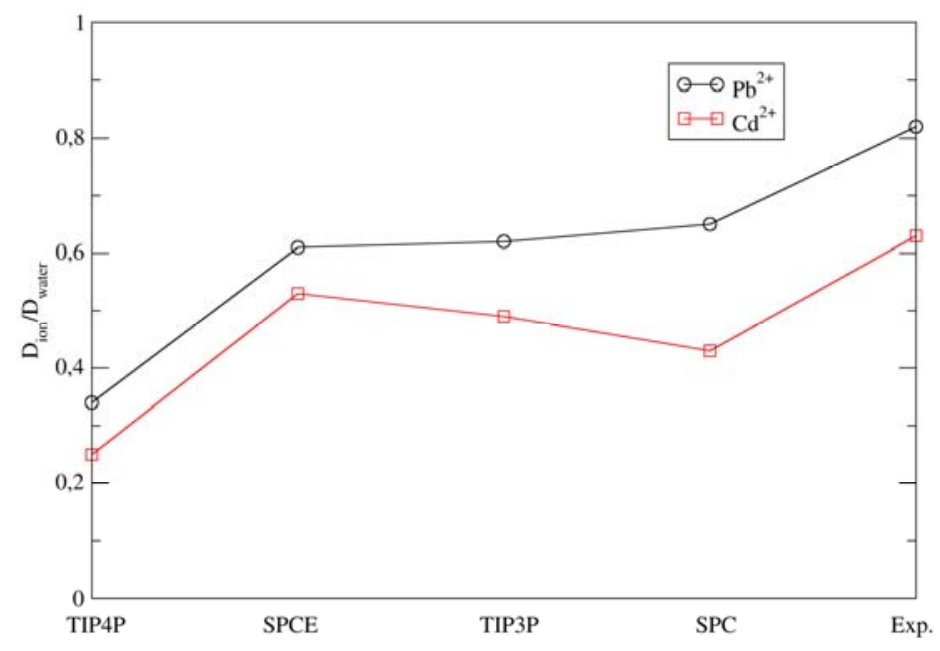

Figura 7 - $D_{\text {ion }} / D_{\text {water }}$ para diferentes modelos de água e entre os valores experimentais.

O tempo de residência ( $\tau_{\text {ínn }}$ ) é obtido a partir da função $S(t)$ e representa o tempo médio que as moléculas de solvente participam das camadas de solvatação, fornecendo dados sobre a persistência do solvente em torno do íon. No cálculo das $S(t)$ definimos a primeira camada de solvatação como as moléculas de água que apresentaram distâncias íon- $\mathrm{O}_{\mathrm{w}}$ menores que o primeiro mínimo da $g(r)$ correspondente (coluna $\mathrm{r}_{\mathrm{m} 1}$ na Tabela III). Nossos cálculos mostraram que no caso do íon $\mathrm{Cd}^{2+}$, a primeira camada de solvatação se manteve estática para todos os modelos 
de água utilizados durante os $5 \mathrm{~ns}$ de simulação. Isso ocorre porque as interações $\mathrm{Cd}^{2+}$ - água são tão fortes, devido a seu raio atômico menor, que não acontecem trocas de moléculas entre a primeira camada de solvatação e o bulk durante o tempo de simulação. Podemos interpretar então que na realidade o que se desloca pelo solvente, pelo menos na escala de tempo de nossas simulações, é o "íon" formado pelo $\mathrm{Cd}^{2+}$ coordenado pelas águas pertencentes à sua primeira camada de solvatação. Esse comportamento já foi observado em estudos com o íon $\mathrm{Ca}^{2+}$ [57] e explica os valores para o coeficiente de difusão do $\mathrm{Cd}^{2+}$ menores que os obtidos para o íon $\mathrm{Pb}^{2+}$.

Os cálculos com o íon $\mathrm{Pb}^{2+}$ resultaram em valores para o tempo de residência da primeira camada de solvatação da ordem de centenas de ps, o que é consistente quando comparado com valores obtidos para outros íons divalentes [57]. $\mathrm{Na}$ definição da $S(t)$ consideramos o tempo de intermitência $\left(\mathrm{t}^{*}\right)$ como sendo o tempo máximo permitido para flutuações da camada de solvatação, pois é comum que moléculas de solvente pertencentes a essa camada se distanciem do íon temporariamente devido a interações com moléculas do bulk. Realizamos cálculos utilizando diversos valores para $\mathrm{t}^{*}$ entre 0 e 10 ps e observamos que a $S(t)$ se torna progressivamente menos acentuada quando $\mathrm{t}^{*}$ varia de 0 ps a 2 ps. A partir de 2 ps a $S(t)$ obtida é a mesma independente do valor de $\mathrm{t}^{*}$, o que nos levou a assumir como tempo médio de residência da primeira camada de solvatação dos íons o valor de $\tau_{\text {ion }}$ obtido quando $\mathrm{t}^{*}=2$ ps. A escolha desse valor para o tempo de intermitência também é justificada pelo fato dele ser aproximadamente o tempo de residência calculado para a água pura $\left(\widetilde{\tau}_{\text {bulk }}^{S}=1.8 \mathrm{ps}\right)$ segundo Impey et al. [48]. Nesse mesmo trabalho, argumenta-se que para íons que apresentam tempo de residência consideravelmente maiores que 2 ps, como é o caso de íons divalentes, os valores de $\tau_{\text {ín }}$ calculados com $\mathrm{t}^{*}$ igual a 0 ps ou 2 ps deveriam ser próximos, entretanto, não foi o que observamos 
em nossas simulações. $\mathrm{Na}$ Tabela $\mathrm{V}$ mostramos os tempos de residência para a primeira camada de solvatação do íon $\mathrm{Pb}^{2+}$ calculados considerando-se $\mathrm{t}^{*}$ igual a 0,2 e 10 ps. Os resultados mostram que os valores para $\tau_{\text {ion }}$ calculados com $\mathrm{t}^{*}=0$ e $\mathrm{t}^{*}=2$ ps variam substancialmente, indicando que mesmo para íons divalentes é importante considerar as flutuações das camadas de solvatação. Entre os valores calculados com $\mathrm{t}^{*}=2$ ps e $\mathrm{t}^{*}=10$ ps não são observadas grandes variações no tempo de residência como já mencionado.

Tabela $V$ - Tempos médios de residência para a primeira camada de solvatação do $\mathrm{Pb}^{2+}\left(\tau_{P b 2+}\right)$ para diferentes modelos de água e tempos de intermitência.

\begin{tabular}{cccc}
\hline \multirow{2}{*}{ Modelo de água } & \multicolumn{3}{c}{$\tau_{\mathbf{P b 2}+} \mathbf{( p s )}$} \\
\cline { 2 - 4 } & $\mathbf{t}^{*}=\mathbf{0} \mathbf{p s}$ & $\mathbf{t}^{*}=\mathbf{2} \mathbf{~ p s}$ & $\mathbf{t}^{*}=\mathbf{1 0} \mathbf{~ p s}$ \\
\hline SPC & 104 & 133 & 134 \\
SPC/E & 192 & 227 & 228 \\
TIP3P & 93 & 133 & 134 \\
TIP4P & 82 & 142 & 149 \\
\hline
\end{tabular}

\section{5 - Conclusões}

A metodologia apresentada para o desenvolvimento de parâmetros de LennardJones baseada no ajuste simultâneo de propriedades termodinâmicas e estruturais se

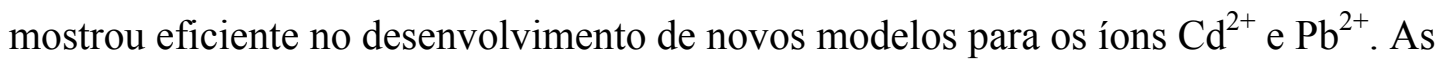
propriedades calculadas para ambos os íons se mostraram coerentes entre si e apresentaram bom acordo com as obtidas na literatura. Os parâmetros obtidos apresentaram boa transferabilidade entre diversos modelos de água e os cálculos de 
propriedades dinâmicas com os parâmetros ajustados validaram nossos modelos. A utilização do método LIE para os cálculos de energia livre de hidratação absoluta se mostrou adequada, pois obtivemos excelentes resultados quando comparados com valores experimentais, com um custo computacional ordens de grandeza menor que o exigido caso utilizássemos os tradicionais métodos perturbativos. Apesar da reprodução simultânea de dois tipos propriedades pelos parâmetros ajustados trazer maior confiabilidade aos nossos modelos, em alguns casos onde o melhor ajuste de uma propriedade acarreta na piora da outra, somos obrigados a encontrar um conjunto de parâmetros que minimizem os erros de ambas as propriedades. 


\title{
Capítulo 4 - Simulações dos Calixa[4]arenos em
}

\author{
vácuo
}

\section{1 - Introdução}

Com a finalidade de validar os modelos construídos para os calixarenos, realizamos simulações dessas moléculas no vácuo em diversas situações tentando reproduzir resultados observados experimentalmente por difração de raios-X em monocristais. Nessas simulações também avaliamos o comportamento dos modelos desenvolvidos para os íons como um teste de validação adicional aos já apresentados no capítulo 3.

Foram feitas simulações dos calixarenos tetraethylester p-tert-butyl calix[4]arene e tetramethylketone p-tert-butyl calix[4]arene isolados para observarmos o comportamento dos modelos não-complexados. Simulamos também os calixarenos com uma molécula de acetonitrila na cavidade hidrofóbica com a finalidade de observar como a presença dessa molécula influencia na organização das duas cavidades do calixareno e se nossos modelos reproduzem resultados experimentais. Por fim, realizamos simulações dos calixarenos com os íons $\mathrm{Pb}^{2+} \mathrm{e}$ $\mathrm{Cd}^{2+}$ na cavidade hidrofílica para analisar como a presença do íon altera a 
conformação do calixareno como um todo, além de avaliarmos o comportamento dos modelos para os íons a partir de comparações com resultados experimentais de difração de raios-X [12].

Utilizaremos uma nomenclatura especial para nos referirmos à conformação dos calixarenos, sendo a conformação quadrada aquela onde a cavidade hidrofóbica apresenta um eixo de simetria aproximado de ordem 4 e a retangular quando a mesma cavidade apresenta um eixo de simetria aproximado de ordem 2. Na Figura 8 são mostrados exemplos dessas conformações para melhor entendimento.

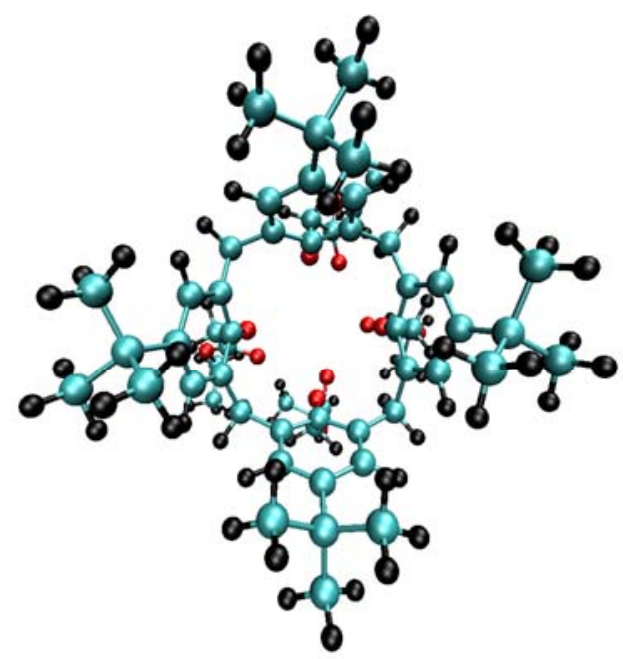

Quadrada

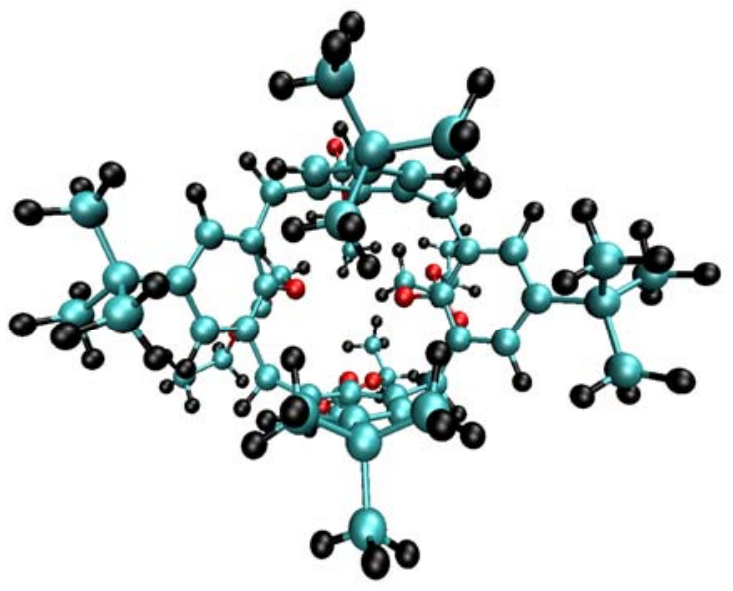

Retangular

Figura 8 - Duas possíveis conformações que podem assumir os calixarenos estudados.

\section{2 - Metodologia e Detalhes Computacionais}

Simulações de DM no vácuo ou estado gasoso se caracterizam por sistemas compostos somente por uma molécula ou complexo em estudo sem uma caixa definida, sem solvente ou outras moléculas provenientes da aplicação de condições de contorno. Além disso, os conceitos de pressão e volume não se aplicam, de modo 
que somente o controle de temperatura é requerido. A observação das interações intramoleculares ou intermoleculares ligante-calixareno, sem a interferência das interações com o solvente, é útil para avaliarmos os modelos desenvolvido com mais detalhes, podendo ser utilizado na validação do mesmo, como é o nosso caso.

Todas as simulações apresentadas nesse capítulo seguem praticamente o mesmo protocolo. Não aplicamos condições periódicas de contorno ou raios de corte. A temperatura foi mantida constante em $300 \mathrm{~K}$ utilizando o algoritmo de Berendsen [53] e aplicamos restrições (constraints) às ligações envolvendo átomos de hidrogênio devido ao fato de estarmos utilizando passos no tempo de 1 fs.

As configurações iniciais foram construídas a partir de resultados de difração de raios-X por monocristais obtidos em nosso laboratório (referência [12] e resultados ainda não publicados). Experimentalmente é observado que os calixarenos em estudo apresentam conformação retangular quando não-complexados. Em nossas simulações dos calixarenos isolados utilizamos na configuração inicial moléculas de calixarenos na conformação quadrada com a finalidade de observarmos se os modelos assumiriam, no decorrer dos cálculos, a conformação observada experimentalmente. Nas simulações dos calixarenos complexados com uma molécula de acetonitrila na cavidade hidrofóbica, utilizamos as coordenadas cristalográficas dos calixarenos na conformação quadrada e inserimos manualmente uma molécula de acetonitrila com o grupo $\mathrm{CH}_{3}$ apontando para o fundo da cavidade, como observado experimentalmente na estrutura cristalográfica do calixareno CLC na ausência de íons na cavidade hidrofílica (resultados não publicados). Para que a molécula de calixareno se adaptasse à presença da molécula de acetonitrila em sua cavidade, utilizamos um recurso disponível no GROMACS chamado freezing (congelamento) onde a atualização das posições e velocidades de um grupo de 
átomos é ignorada mantendo, entretanto, suas interações atuantes. Dessa forma, após simulações de 1 ns obtivemos um sistema com energia total constante (sistema relaxado). As configurações iniciais das simulações dos calixarenos complexados com um íon na cavidade hidrofílica foram tomadas de estruturas cristalográficas experimentais [12], com a retirada de todas as outras moléculas presentes na unidade assimétrica.

As análises realizadas se basearam em propriedades estruturais e energéticas do sistema como a distância entre átomos e energias de interação não-ligada. Algumas de nossas análises consistem em cálculos da distância entre átomos "diametralmente" opostos com a finalidade de caracterizar a conformação assumida pelas cavidades hidrofóbica e hidrofílica do calixareno. Referir-nos-emos a esses átomos como átomos opostos no decorrer do texto.

\section{3 - Simulações do tetraethylester p-tert-butyl calix[4]arene isolado}

Realizamos a simulação de uma molécula de calixareno por $10 \mathrm{~ns}$ com passos de 1 fs. Iniciamos a simulação com o calixareno na conformação quadrada e na Figura 9 observamos a molécula, na conformação retangular, depois de $10 \mathrm{~ns}$ de simulação. Apresentamos também a nomenclatura que será usada para nos referirmos aos carbonos apicais, oxigênios fenólicos e oxigênios carbonílicos. 


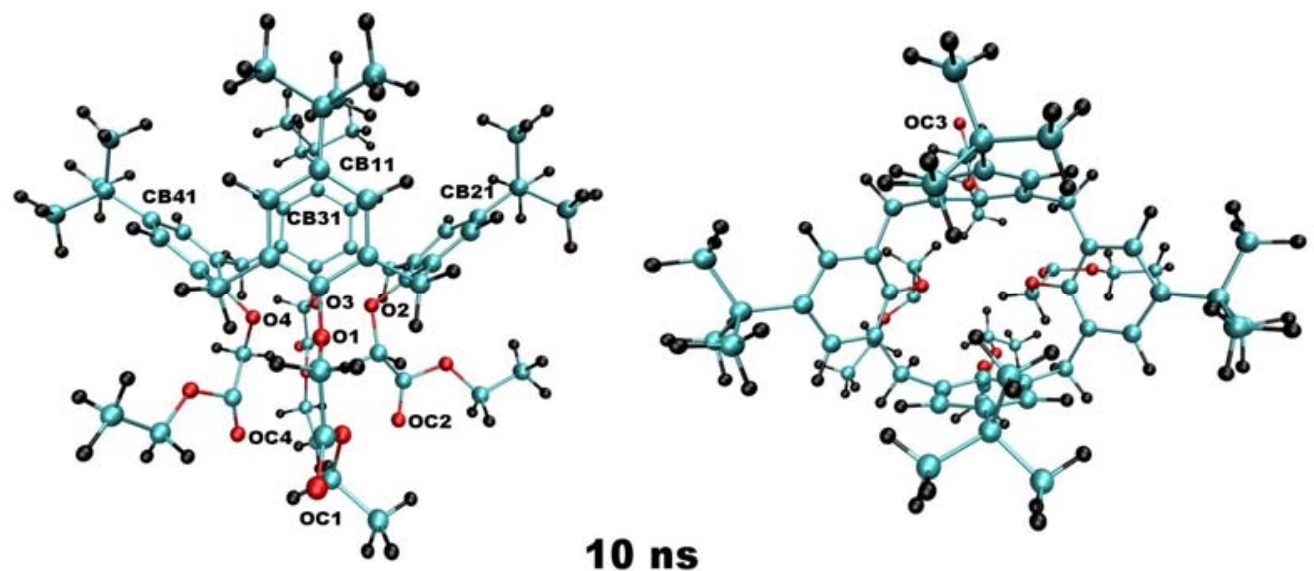

Figura 9 - tetraethylester p-tert-butyl calix[4]arene isolado depois de 10 ns de simulação.

Como mencionado na seção 4.2, iniciamos a simulação na conformação quadrada, apresentada tipicamente no calixareno complexado. Ao assumir rapidamente a conformação retangular o modelo mostra um comportamento fiel à molécula real.

Nos Gráficos 1, 2 e 3 observamos as distâncias entre átomos opostos, de onde podemos tirar informações sobre como acontecem as mudanças de conformação do calixareno durante a simulação.

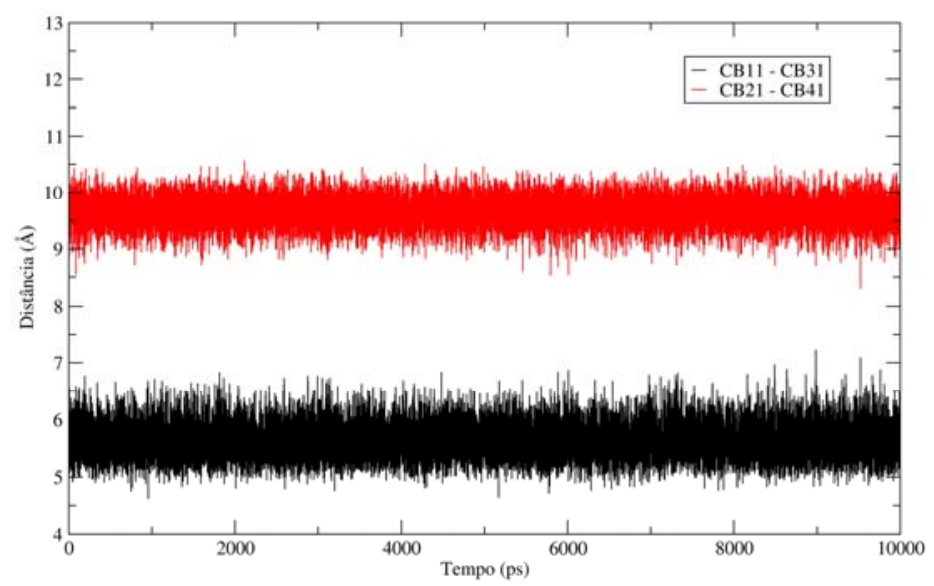

Gráfico 1 - Distância entre carbonos apicais. 


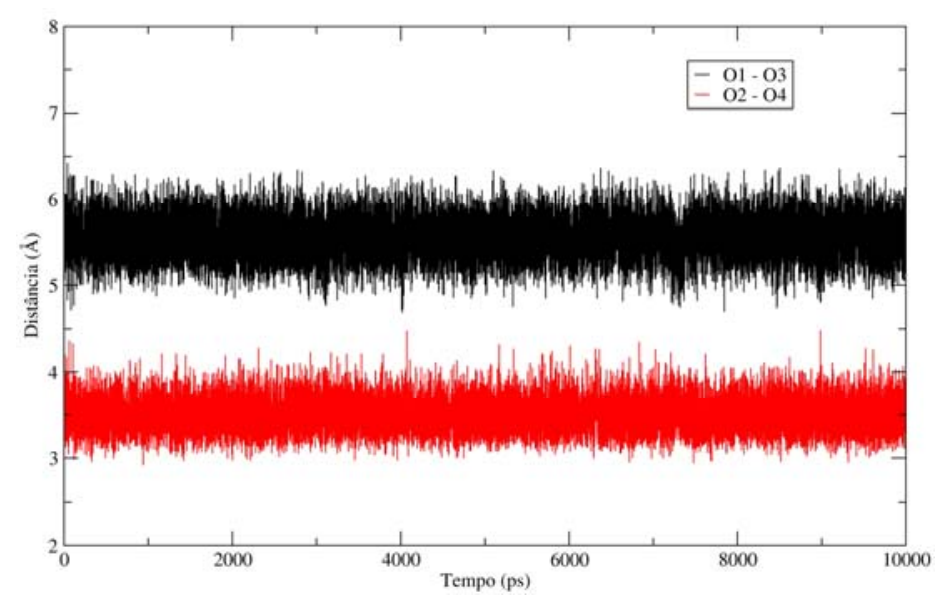

Gráfico 2 - Distância entre oxigênios fenólicos.

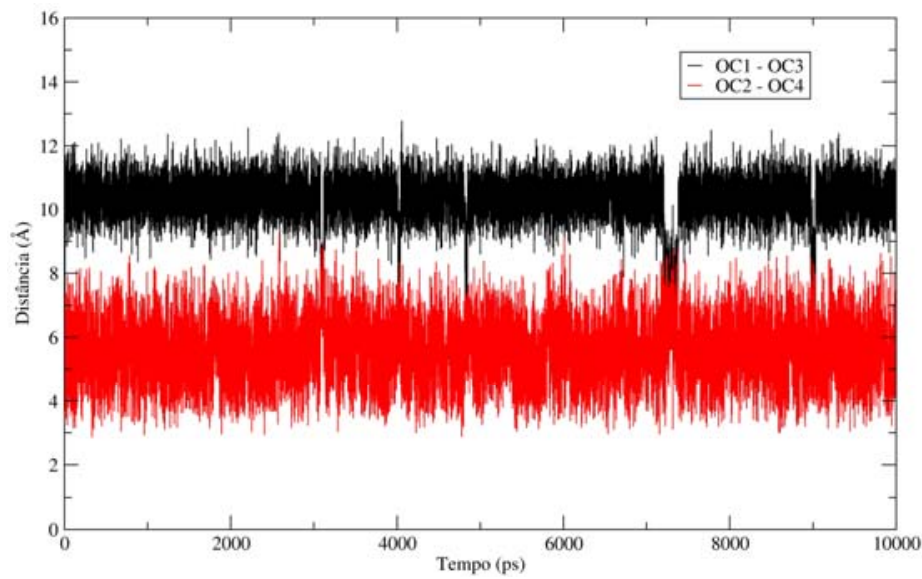

Gráfico 3 - Distância entre oxigênios carbonílicos.

Vemos nos gráficos que durante toda a simulação o calixareno se mantém na conformação retangular. A cavidade hidrofóbica, caracterizada pelos Gráficos 1 e 2, se mantém inalterada durante toda a simulação. A cavidade hidrofílica, representada pelas distâncias mostradas no Gráfico 3, apresenta maior liberdade de movimentos. Podemos observar alguns pontos onde acontecem mudanças nas distâncias entre os oxigênios carbonílicos, o que mostra que apesar da estrutura desse calixareno ser extremamente rígida, a cavidade hidrofílica tem uma certa mobilidade que associamos às ligações sigma entre os átomos que a compõem, o que permite 
rotações praticamente livres. Outra observação importante é o fato de que as flutuações nas distâncias entre os átomos que compõem a cavidade hidrofóbica são da ordem de $1 \AA$, enquanto as flutuações na cavidade hidrofílica ficam em torno de 4 Å, evidenciando também sua a maior liberdade de movimentos.

\section{4 - Simulações do tetraethylester p-tert-butyl calix[4]arene com uma molécula de acetonitrila na cavidade hidrofóbica}

Simulamos uma molécula de calixareno contendo em sua cavidade hidrofóbica uma molécula de acetonitrila. Inicialmente executamos uma simulação de $1 \mathrm{~ns}$, aplicando freezing à molécula de acetonitrila e deixando que o calixareno se adequasse à presença da molécula de solvente. Em seguida realizamos uma simulação de $10 \mathrm{~ns}$ com passos de 1 fs sem aplicar freezing à molécula de acetonitrila. A molécula de acetonitrila se manteve na cavidade durante os primeiros 500 ps quando saiu, se mantendo fora até o fim da simulação. Na Figura 10 podemos ver a conformação do sistema após 10 ns de simulação. 

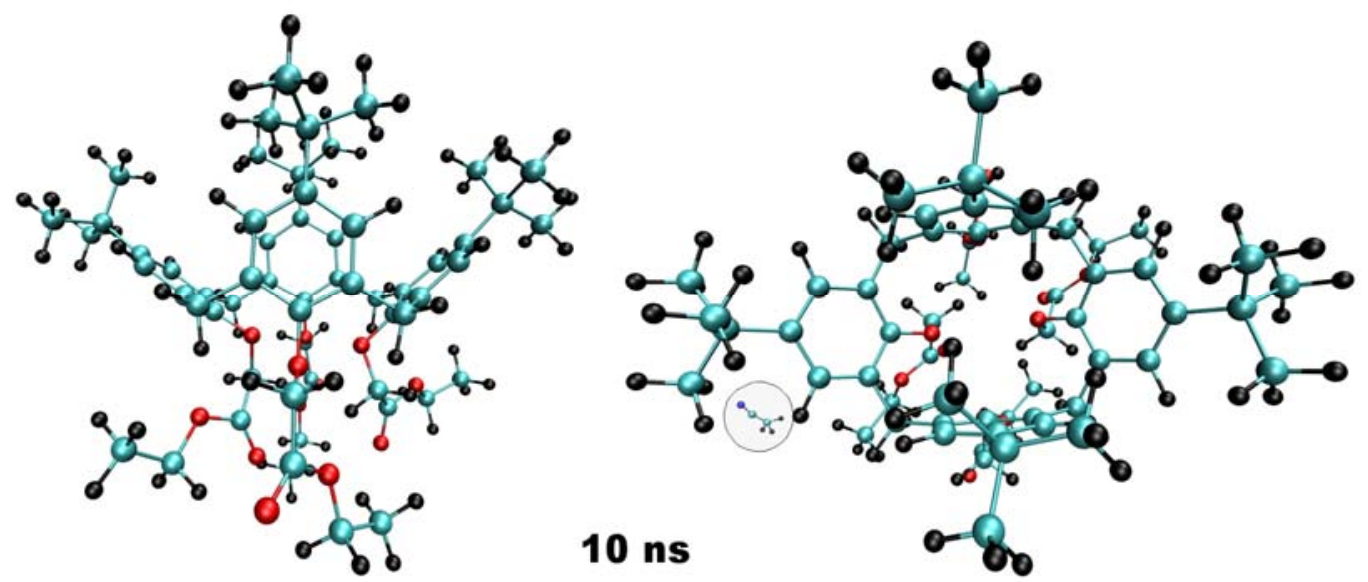

Figura 10 - Configuração final após 10 ns de simulação. No círculo destacado é mostrada a molécula de acetonitrila "expulsa" da cavidade hidrofóbica.

Os Gráficos 4 e 5 nos mostram, respectivamente, a distância entre a molécula de acetonitrila e o fundo da cavidade hidrofóbica ${ }^{1}$ e a energia de interação entre toda a cavidade hidrofóbica e a acetonitrila. Observamos que a interação entre a acetonitrila e a cavidade apresenta, inicialmente, um valor negativo significando um estado ligado. Entretanto, após 500 ps de simulação, a molécula sai da cavidade. Isso acontece porque, apesar da energia de interação ser negativa, a saída da acetonitrila implica numa diminuição da energia potencial total do sistema. Isso acontece devido ao fato de que, como observado na seção 4.3, esse calixareno tende a se manter na conformação retangular e a presença da acetonitrila altera essa sua conformação estável, elevando a energia potencial do sistema.

Experimentalmente observamos um comportamento semelhante. Na estrutura do calixareno sem a presença de íons metálicos, resolvida em nosso laboratório e ainda não publicada, não observamos a presença de moléculas de solvente na

\footnotetext{
${ }^{1}$ Centro de massa dos quatro carbonos dos anéis ligados aos oxigênios fenólicos.
} 
cavidade hidrofóbica. Essa concordância entre o comportamento de nosso modelo e os resultados experimentais evidencia a boa parametrização do calixareno.

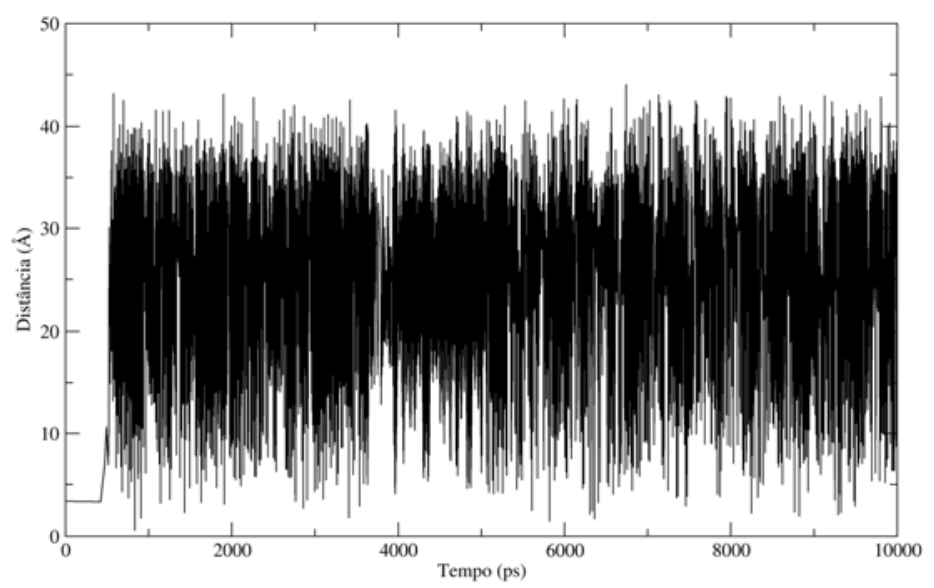

Gráfico 4 - Distância entre o centro de massa da molécula de acetonitrila e o fundo da cavidade hidrofóbica.

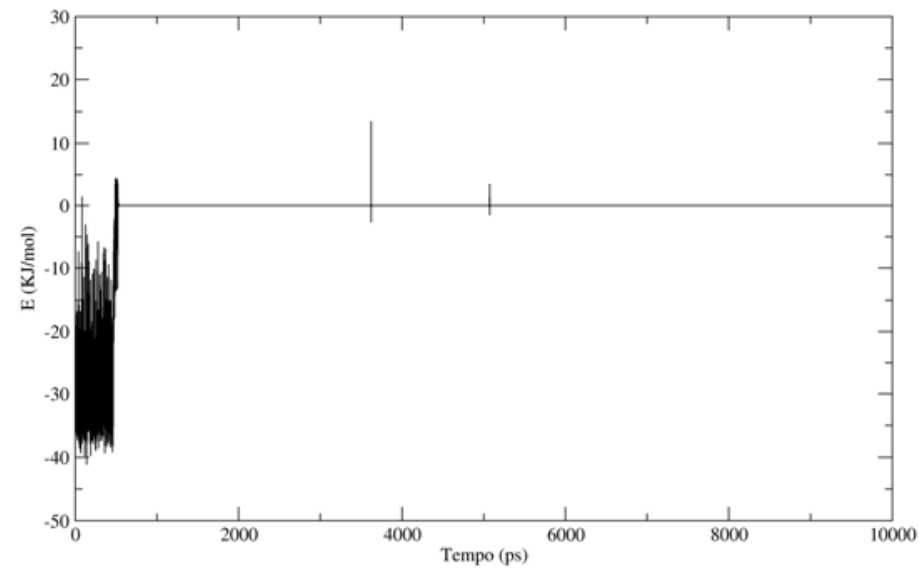

Gráfico 5 - Energia de interação não-ligada (Coulomb e Lennard-Jones) entre a molécula de acetonitrila e a cavidade hidrofóbica.

Monitoramos as distâncias entre átomos opostos, mas, como a molécula de acetonitrila é instável no interior da cavidade hidrofóbica e se mantém por pouco tempo ligada, obtemos basicamente os mesmos resultados que na seção 4.3. 


\section{5 - Simulações do tetraethylester p-tert-butyl calix[4]arene com um íon $\mathrm{Pb}^{2+}$ na cavidade hidrofílica}

Foi simulada uma molécula de calixareno com um íon $\mathrm{Pb}^{2+}$, modelado com os parâmetros apresentados no capítulo 3, no interior de sua cavidade hidrofílica. Inicialmente executamos uma minimização de energia para que o íon se acomodasse adequadamente na cavidade. Em seguida realizamos uma simulação de 10 ns com passos de 1 fs. O íon manteve-se no interior da cavidade durante toda a simulação, coordenando todos os oxigênios fenólicos e carbonílicos. A Figura 11 nos mostra a conformação do sistema depois de 10 ns de simulação. Vemos que a presença do íon na cavidade hidrofílica mantém o calixareno numa conformação quadrada e estável.
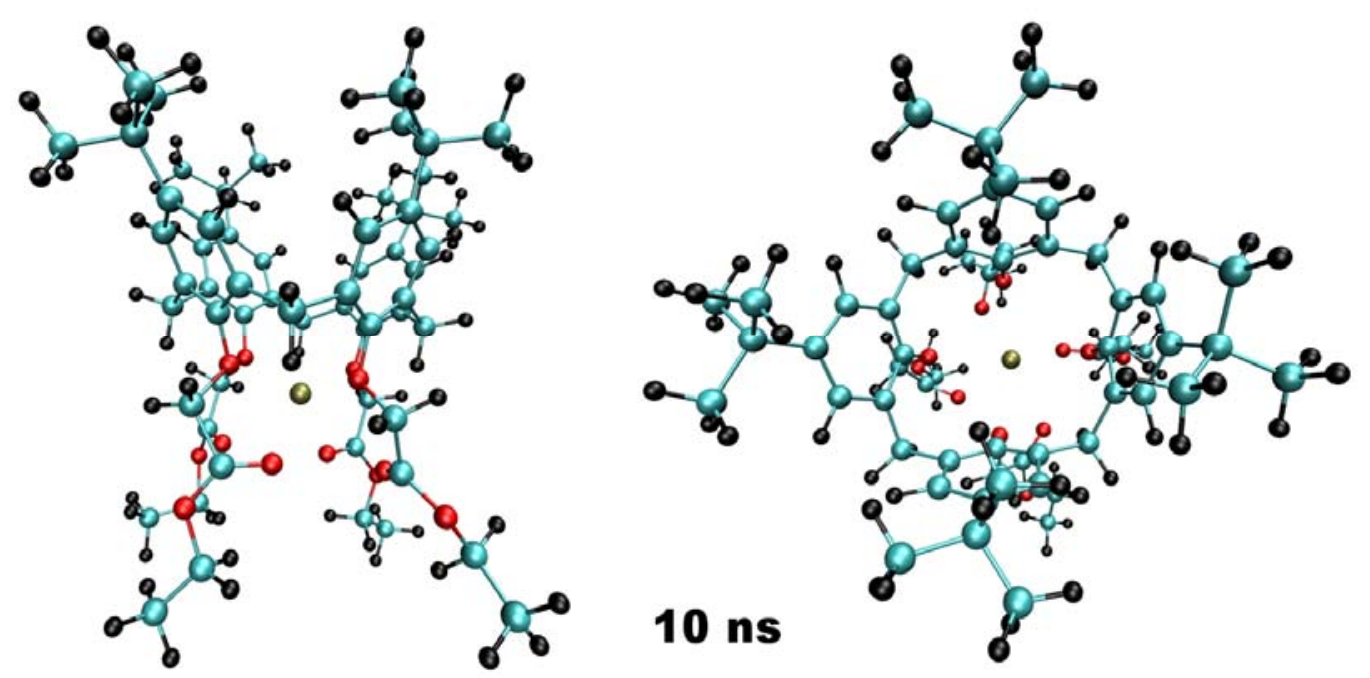

Figura 11 - Configuração final depois de 10ns de simulação. $O$ ion se manteve na cavidade hidrofilica durante toda a simulação.

Calculamos a energia de interação não-ligada entre o íon e a cavidade hidrofílica. O resultado obtido pode ser visto no Gráfico 6 . Vemos que durante toda a 
simulação a energia se mantém em torno de $-1380 \mathrm{~kJ} / \mathrm{mol}$, valor que significa que o íon é estável no interior da cavidade.

Monitoramos também as distâncias entre os átomos opostos com a finalidade de observar a influência da presença do íon na cavidade hidrofílica sobre a estrutura do calixareno como um todo. Os resultados obtidos estão nos Gráficos 7, 8 e 9. Durante toda a simulação o calixareno se mantém na conformação quadrada, caracterizada pelos valores de distância entre átomos opostos iguais.

O valor da energia de interação íon-cavidade e a comprovação de que o calixareno se mantém na conformação quadrada durante toda a simulação nos leva a concluir que a entrada do íon na cavidade hidrofílica altera a conformação de todo o calixareno formando um complexo estável.

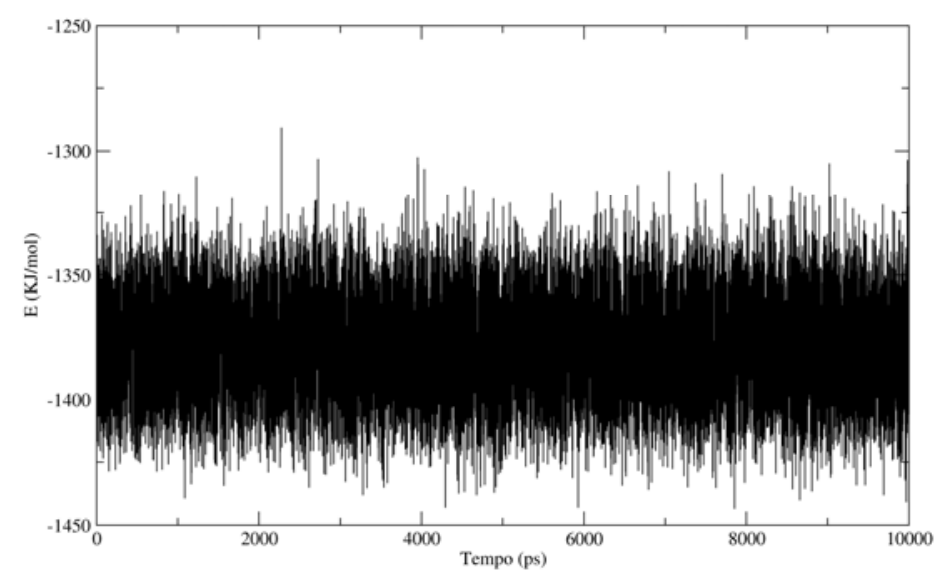

Gráfico 6 - Energia de interação não-ligada (Coulomb e Lennard-Jones) entre o $\mathrm{Pb}^{2+}$ e a cavidade hidrofilica. 


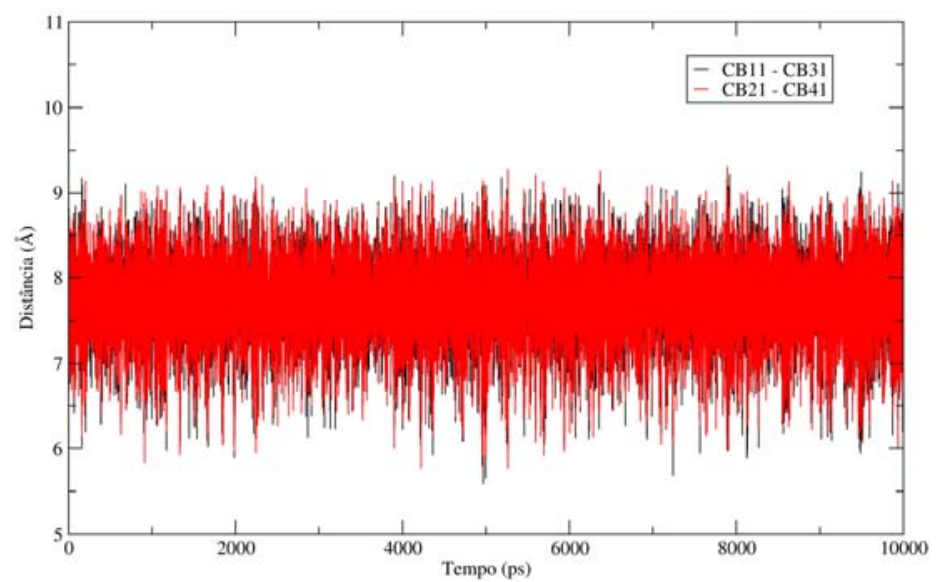

Gráfico 7 - Distância entre carbonos apicais.

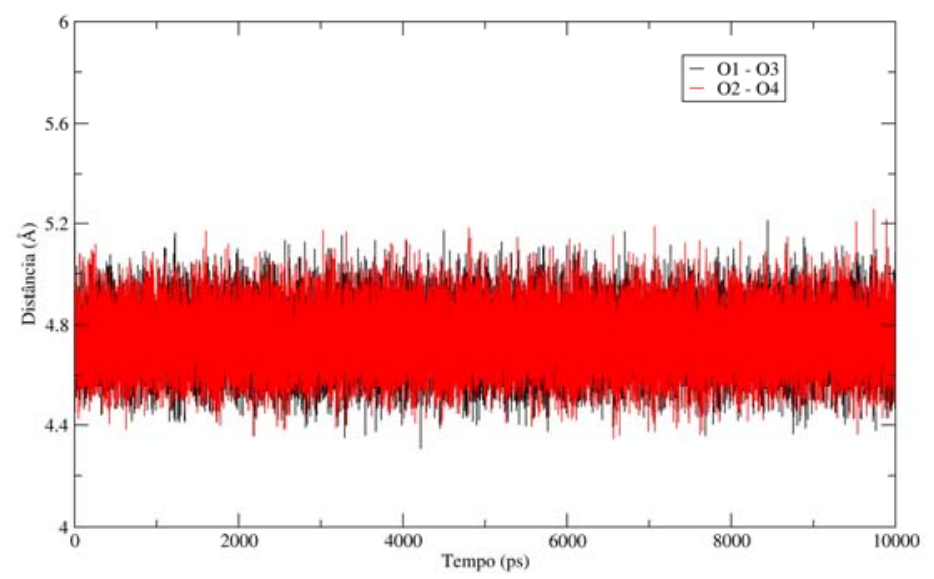

Gráfico 8 - Distância entre oxigênios fenólicos.

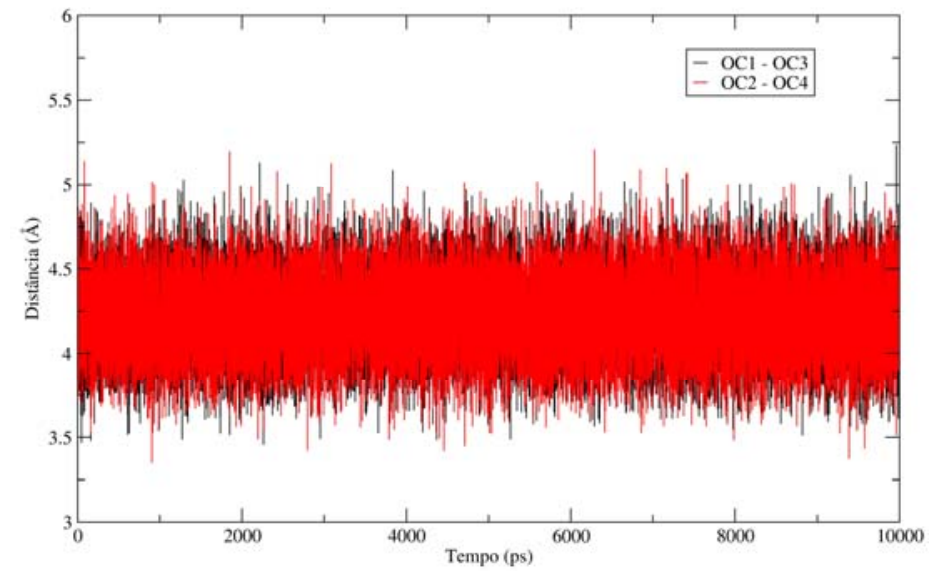

Gráfico 9 - Distância entre oxigênios carbonílicos.

Calculamos também a distância média entre o íon e os oxigênios coordenados para comparar com os valores experimentais obtidos por difração de raios-X da 
referência [12]. As distâncias $\mathrm{Pb}^{2+}-\mathrm{O}$ e $\mathrm{Pb}^{2+}-\mathrm{OC}$ apresentaram um valor médio de $(2,52 \pm 0,08) \AA$ e $(2,6 \pm 0,1) \AA$ respectivamente, enquanto os valores experimentais ficam em torno de 2,67 $\AA$. e 2,5 $\AA$. Em ambos os casos os valores calculados estão em excelente acordo com os experimentais.

Para uma melhor análise comparativa entre nossas simulações e a estrutura resolvida por raios-X, realizamos uma superposição, utilizando o programa WinKabsch [58], da estrutura média calculada no último 1 ns de nossa simulação com a estrutura resolvida por raios-X. O resultado pode ser visto na Figura 12.

A superposição mostra uma grande similaridade entre as duas moléculas com a cavidade hidrofóbica perfeitamente superposta, exceto pelos grupos tert-butil que na estrutura média estão deslocalizados devido ao fato de girarem durante toda a simulação em torno da ligação sigma que une o grupo ao anel. A conformação quadrada coincide perfeitamente entre as duas estruturas. A maior diferença está na posição do íon que difere em torno de $0,3 \AA$ entre as duas estruturas. Esse deslocamento influi no posicionamento dos oxigênios carbonílicos empurrando-os para baixo em torno de $0,2 \AA$. Esses deslocamentos são muito pequenos comparados com as distâncias médias $\mathrm{Pb}^{2+}-\mathrm{OC}$ de 2,6 $\AA$. Na vista superior observamos que os oito oxigênios da cavidade hidrofílica coordenam o íon formando dois quadrados perfeitamente superpostos, de maneira idêntica à conformação observada experimentalmente. 

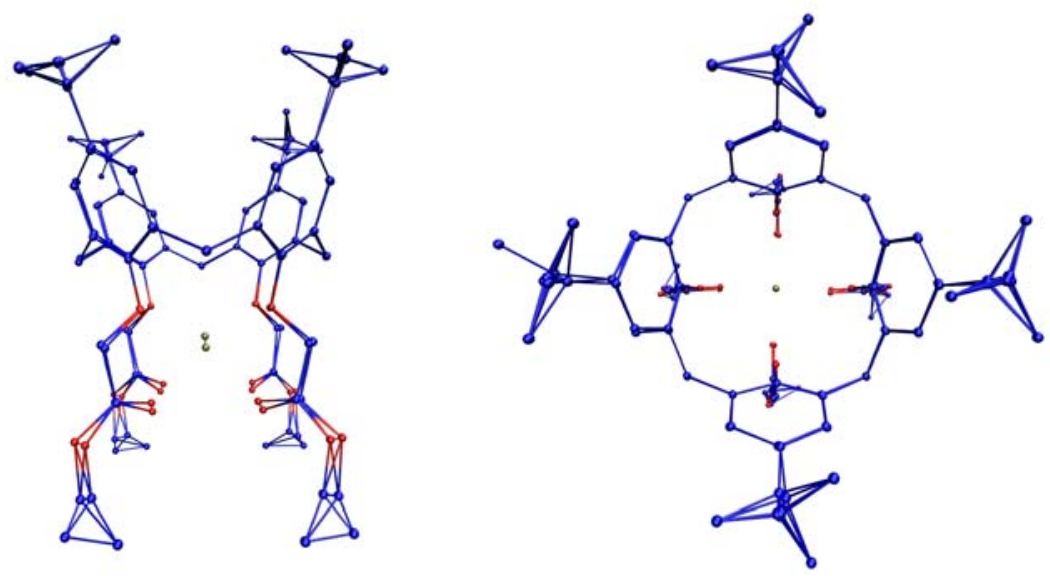

Figura 12 - Resultado da superposição da estrutura média calculada e da estrutura resolvida por raios- $X$

\section{6 - Simulações do tetraethylester p-tert-butyl calix[4]arene com um íon $\mathrm{Cd}^{2+}$ na cavidade hidrofílica}

Foi realizada uma simulação de uma molécula de calixareno com um íon $\mathrm{Cd}^{2+}$, modelado com os parâmetros apresentados no capítulo 3, no interior de sua cavidade hidrofílica. Realizamos uma minimização de energia e em seguida uma simulação de dinâmica molecular com duração de 10 ns e passos de 1 fs. A configuração final da simulação é mostrada na Figura 13. 

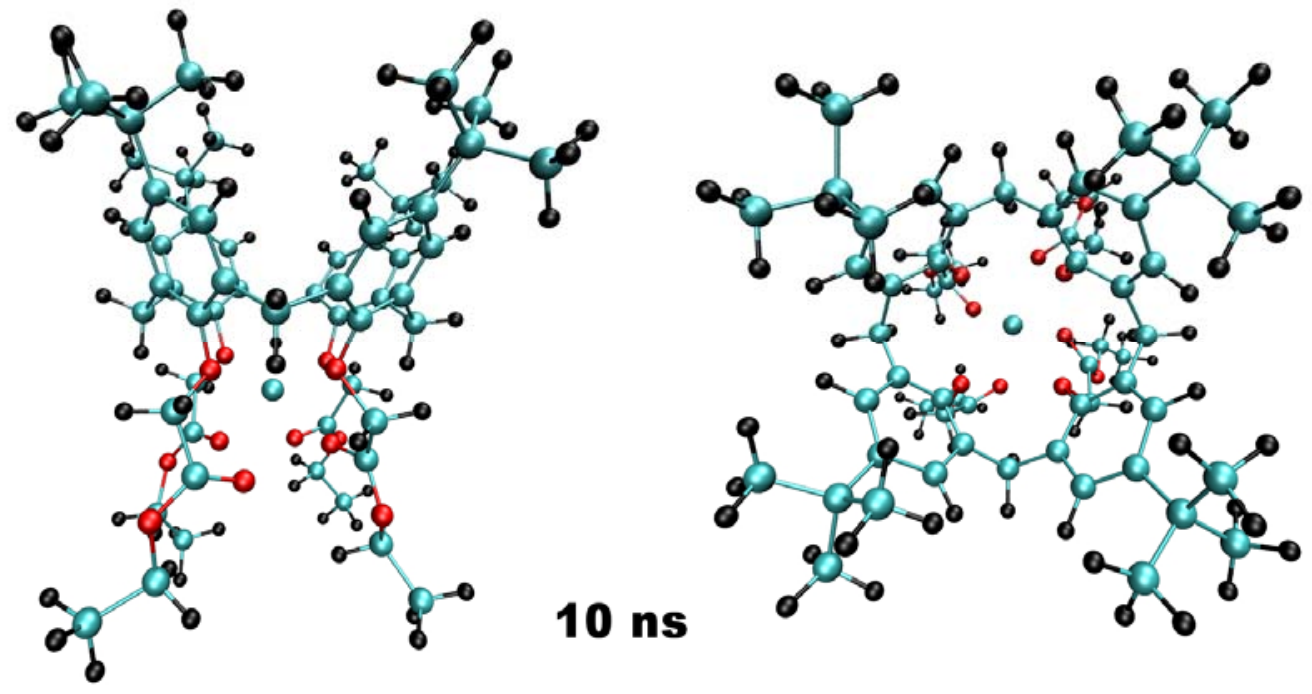

Figura 13 - Configuração final depois de 10ns de simulação. $O$ ion se manteve na cavidade hidrofilica durante toda a simulação.

Durante a simulação monitoramos a energia de interação entre a cavidade hidrofílica e o íon e as distâncias entre os átomos opostos. Os resultados podem ser vistos nos Gráficos 10, 11, 12 e 13.

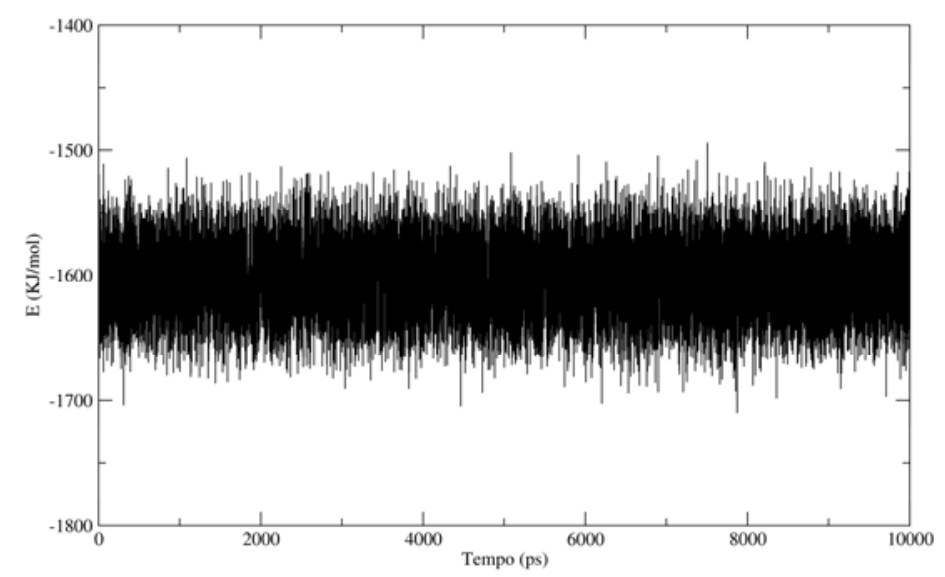

Gráfico 10 - Energia de interação não-ligada (Coulomb e Lennard-Jones) entre o $\mathrm{Cd}^{2+}$ e a cavidade hidrofilica. 


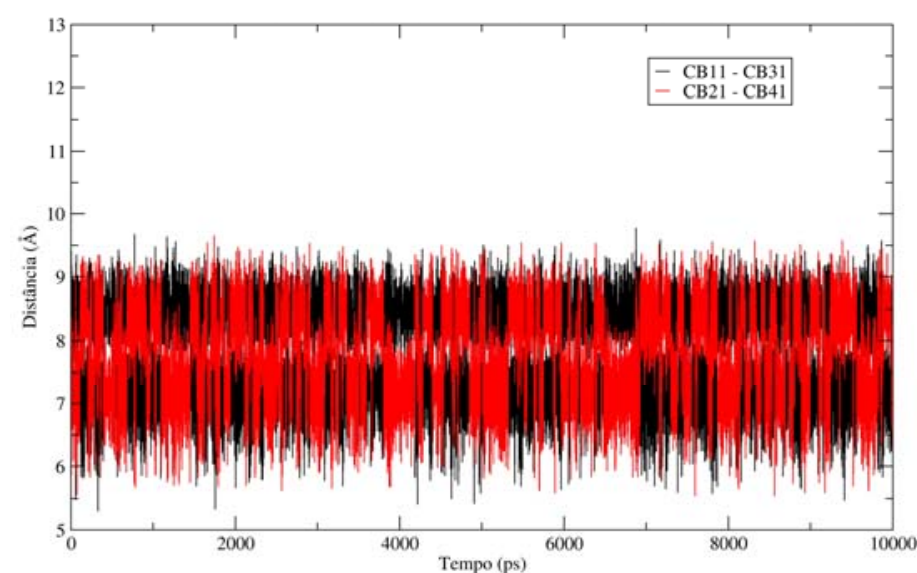

Gráfico 11 - Distância entre carbonos apicais.

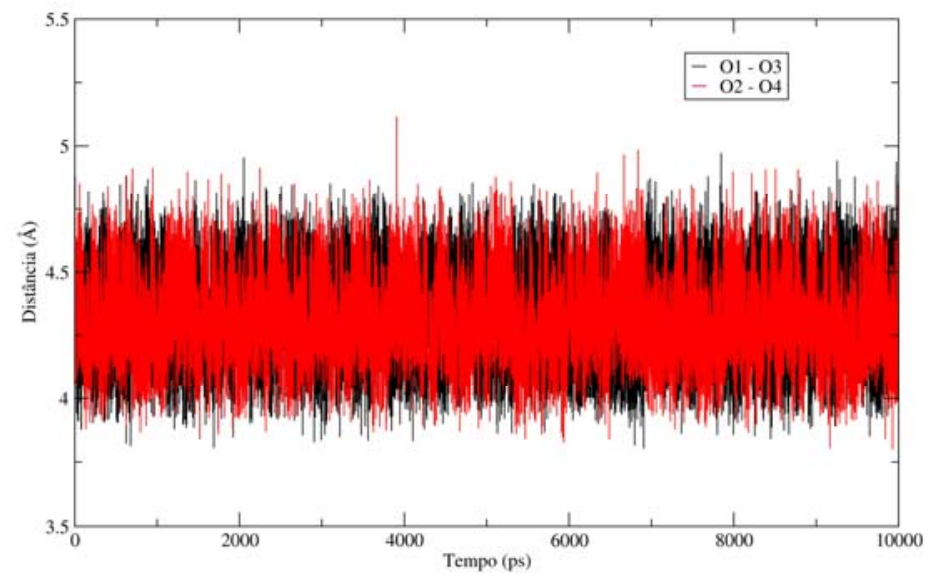

Gráfico 12 - Distância entre oxigênios fenólicos.

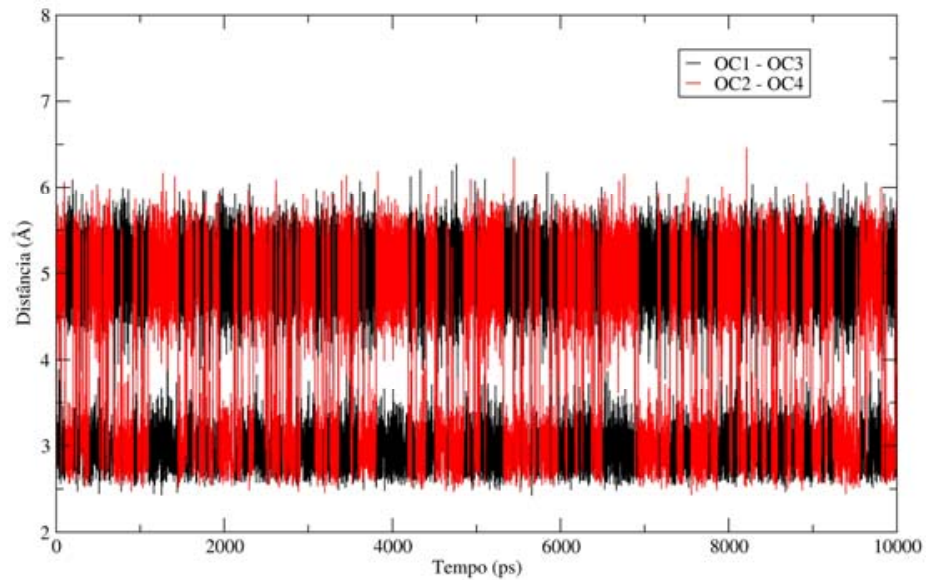

Gráfico 13 - Distância entre oxigênios carbonílicos. 
O Gráfico 10 mostra que a energia de interação entre o íon e a cavidade hidrofílica se mantém em torno de $-1600 \mathrm{~kJ} / \mathrm{mol}$ durante toda a simulação, valor que comprova que o íon é estável dentro da cavidade. Sua interação com os oxigênios deforma o calixareno, mas, diferentemente do que acontece com o íon $\mathrm{Pb}^{2+}$, ele não leva a molécula para uma conformação quadrada mas sim para uma conformação levemente retangular executando transições ${ }^{2}$ durante toda a simulação, como podemos observar no Gráfico 11, o que mostra que os dois estados são energeticamente equivalentes. Analisando os Gráficos 12 e 13 vemos que esse comportamento é decorrente da maneira como o $\mathrm{Cd}^{2+}$ interage com os oxigênios carbonílicos, alternando as duplas de átomos que permanecem mais próximos do íon, agindo na estrutura do calixareno como uma "alavanca" com o ponto de apoio sobre os oxigênios fenólicos que não executam transições. A distância em que ocorre o mínimo de energia na interação $\mathrm{Cd}^{2+}$-oxigênio associada a impedimentos estéricos entre os oxigênios carbonílicos são os fatores que determinam esse comportamento do complexo.

Calculamos as distâncias médias entre o íon e os oxigênios da cavidade hidrofílica e obtivemos para a distância $\mathrm{Cd}^{2+}$ - $\mathrm{O}$ a média de $(2,2 \pm 0,1) \AA$, que é próxima aos valores experimentais $\left(\mathrm{Cd}^{2+}\right.$ - $\mathrm{O}$ variando de $2,37 \AA$ a $2,41 \AA$ ). Para a distância $\mathrm{Cd}^{2+}$ - OC encontramos um valor médio de $(2,6 \pm 0,5) \AA$, que apresenta um erro relativamente alto devido às frequentes mudanças na conformação já descritas. Experimentalmente também é observado esse comportamento através das distâncias

\footnotetext{
${ }^{2}$ Transições conformacionais que pode executar um calixareno na conformação retangular,
} alternando os anéis paralelos e perpendiculares da cavidade hidrofóbica. 
$\mathrm{Cd}^{2+}$ - OC que vão de 2,38 $\AA$ a 2,61 $\AA$, onde um par de oxigênios carbonílicos opostos está próximo do íon a 2,4 Å e o outro distante a 2,6 Å, aproximadamente.

Para esclarecer melhor esse comportamento realizamos a superposição entre a estrutura média (sem hidrogênios) do último 1 ns de simulação com a estrutura cristalográfica, mostrada na Figura 14. A cavidade hidrofóbica se superpõe quase perfeitamente, exceto pelos grupos tert-butil devido aos mesmos motivos apresentados na simulação com o $\mathrm{Pb}^{2+}$. A posição do íon é praticamente idêntica nas duas estruturas. A cavidade hidrofílica apresenta os oxigênios fenólicos com ótima superposição e os oxigênios carbonílicos dispostos de maneira equivalente em ambas as estruturas, formando um quadrado girado com relação ao quadrado formado pelos oxigênios fenólicos. Na vista superior da superposição os oxigênios carbonílicos da direita e da esquerda se superpõem muito bem, enquanto os de cima e de baixo estão deslocados em torno de $0,3 \AA$. Isso acontece porque as diferentes distâncias entre o íon de cádmio e os pares de oxigênios carbonílicos desaparecem quando calculamos a estrutura média, de modo que todos os oxigênios carbonílicos ficam à mesma distância do íon, ao contrário do que se observa dinamicamente durante a simulação e na estrutura cristalográfica. 

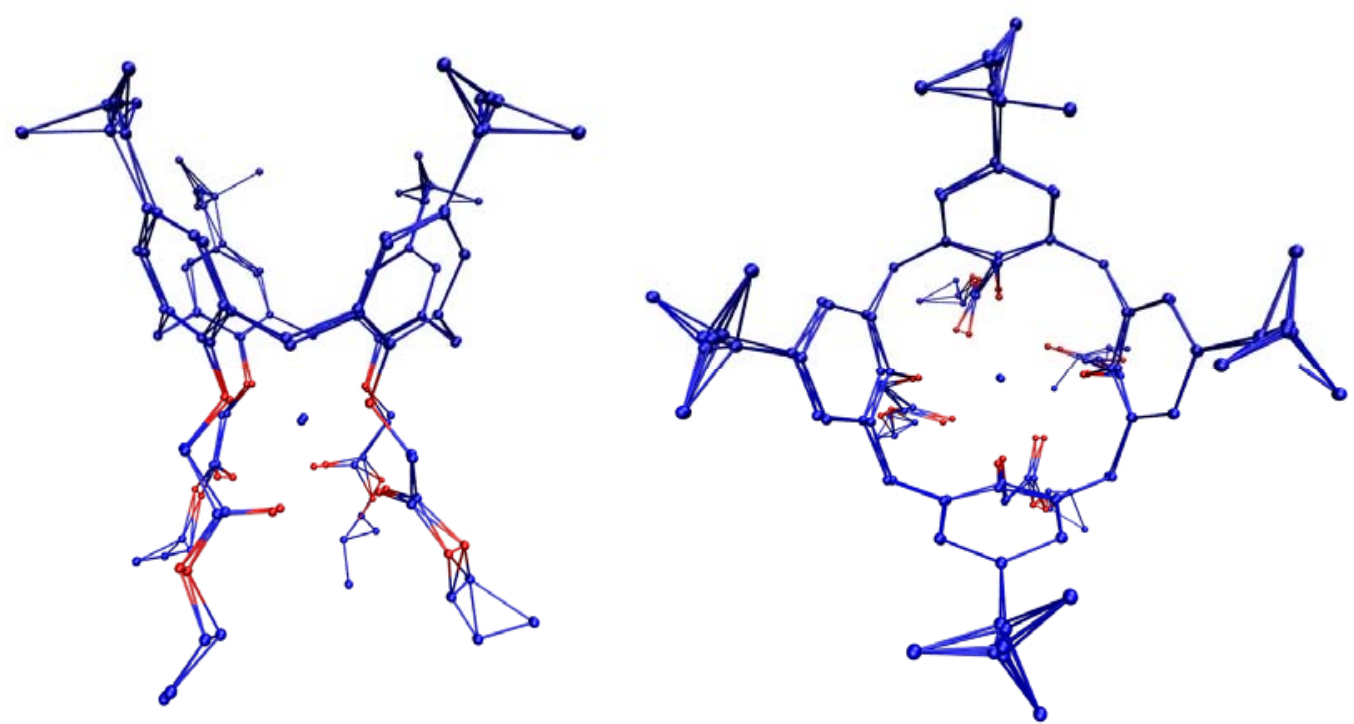

Figura 14 - Superposição da estrutura média calculada com a estrutura experimental obtida por difração de raios- $X$.

\section{7 - Simulações do tetramethylketone p-tert-butyl calix[4]arene isolado}

Realizamos a simulação de uma molécula de tetramethylketone p-tert-butyl calix[4]arene isolada durante $10 \mathrm{~ns}$ com passos de 1 fs. Iniciamos a simulação com as coordenadas obtidas da estrutura cristalográfica na conformação quadrada. O calixareno assume a conformação retangular no inicio da simulação permanecendo assim até o final, como vemos na Figura 15. A nomenclatura utilizada para nos referirmos aos átomos desse calixareno será a mesma utilizada nas seções anteriores. 

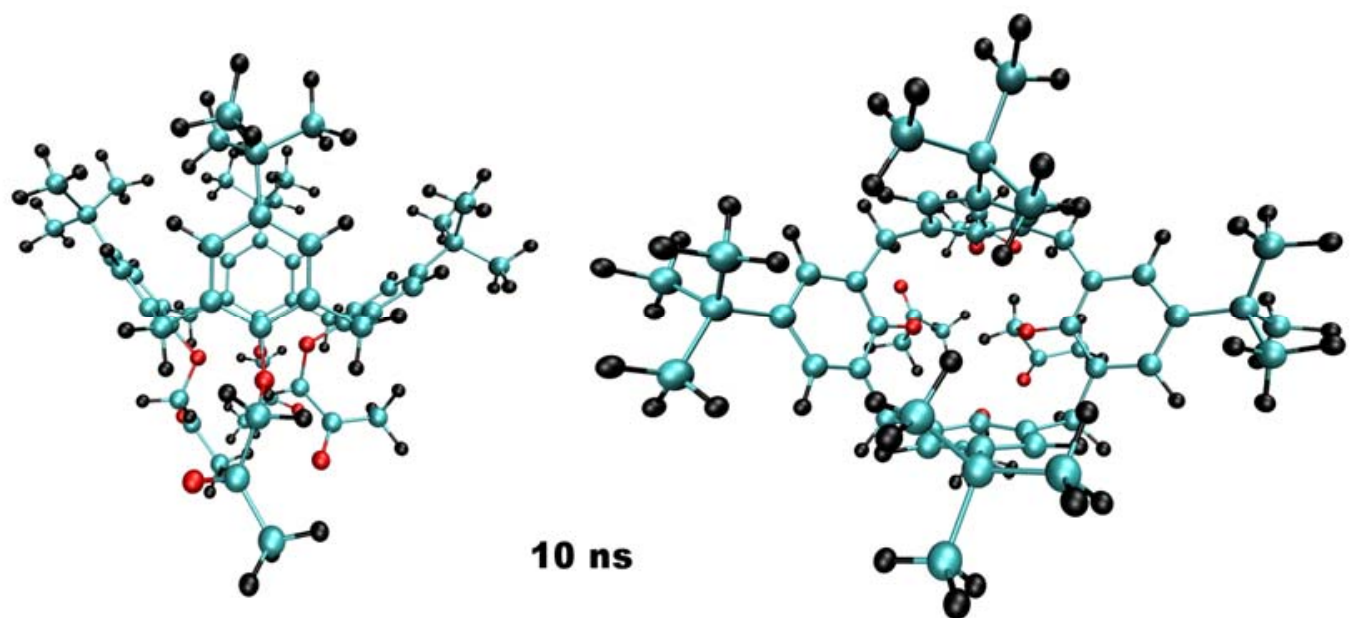

Figura 15 - tetramethylketone p-tert-butyl calix[4]arene isolado depois de $10 \mathrm{~ns}$ de simulação.

Monitoramos as distâncias entre os carbonos apicais, oxigênios fenólicos e oxigênios carbonílicos opostos na estrutura, para observarmos as mudanças conformacionais que acontecem durante a simulação. Os resultados são mostrados nos Gráficos 14, 15 e 16.

Os gráficos nos mostram que durante a simulação o calixareno manteve-se na conformação retangular, alternando várias vezes entre as duas conformações de mesma energia, aproximando e afastando os pares de átomos opostos.

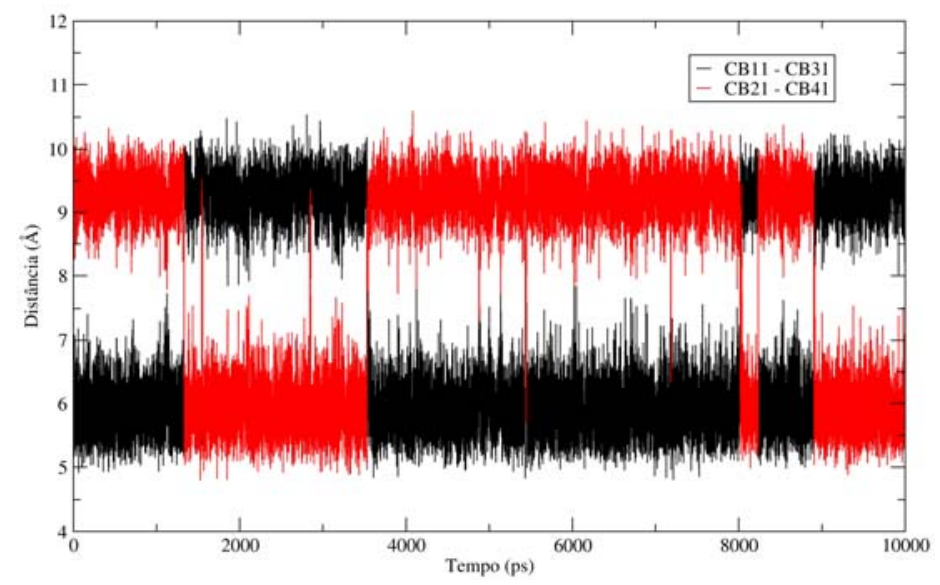

Gráfico 14 - Distância entre carbonos apicais. 


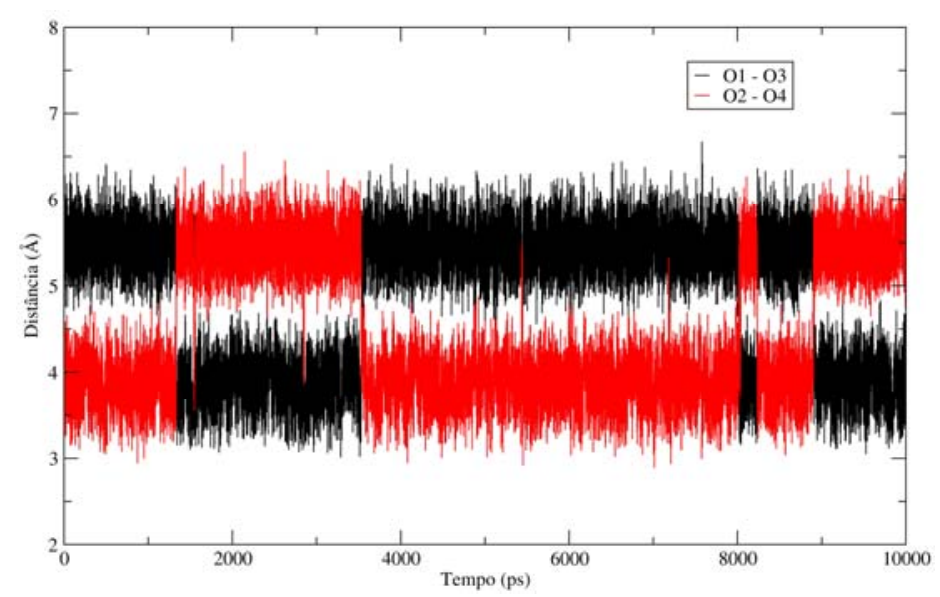

Gráfico 15 - Distância entre oxigênios fenólicos.

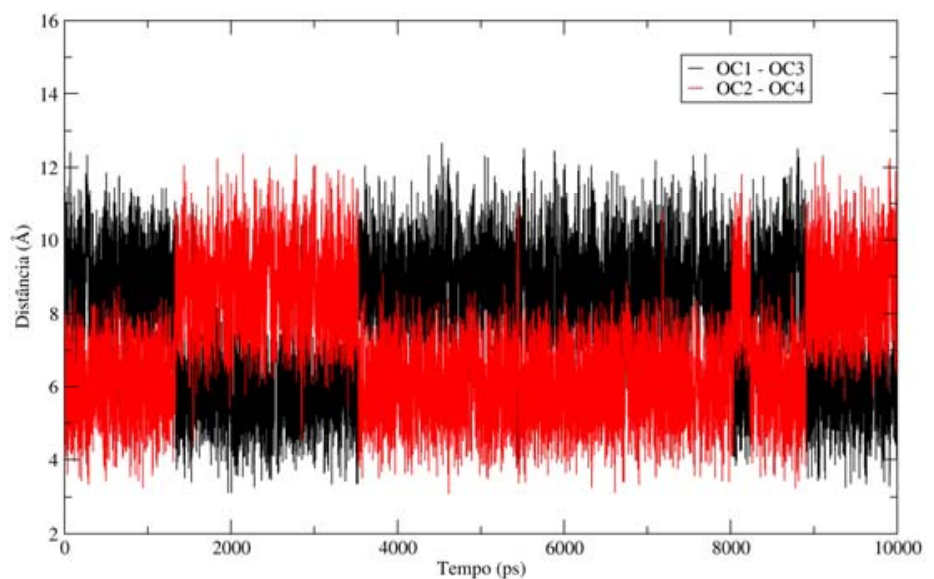

Gráfico 16 - Distância entre oxigênios carbonílicos.

As distâncias entre os carbonos apicais e oxigênios fenólicos estão bem definidas, sendo a flutuação em torno de $0,5 \AA$ da distância média. Os oxigênios carbonílicos seguem as mudanças de conformação da cavidade hidrofóbica mas não apresentam distâncias entre si bem definidas, as quais flutuam aproximadamente $2 \AA$ da posição de equilíbrio. Essas características mostram que a cavidade hidrofóbica é uma parte da molécula sem muitos graus de liberdade, o que já era esperado pela sua constituição, ao contrário da cavidade hidrofílica onde as ligações sigma facilitam a movimentação dos grupos que a constituem. 
Todas essas características nos mostram que o calixareno CLC, ao contrário do CLE, apresenta uma estrutura mais flexível. Isso reflete na maneira como as cavidades interagem com outras moléculas, como veremos nas seções seguintes.

\section{8 - Simulações do tetramethylketone p-tert-butyl calix[4]arene com uma molécula de acetonitrila na cavidade hidrofóbica}

Simulamos uma molécula de calixareno CLC com uma molécula de acetonitrila posicionada no interior de sua cavidade hidrofóbica conforme observado experimentalmente. Realizamos 1 ns de simulação aplicando freezing à molécula de acetonitrila para que o calixareno se adaptasse à presença do ligante. Em seguida realizamos uma simulação de 10 ns com passos de 1 fs sem aplicar freezing a molécula alguma. A Figura 16 nos mostra a conformação do sistema após 10 ns de simulação.

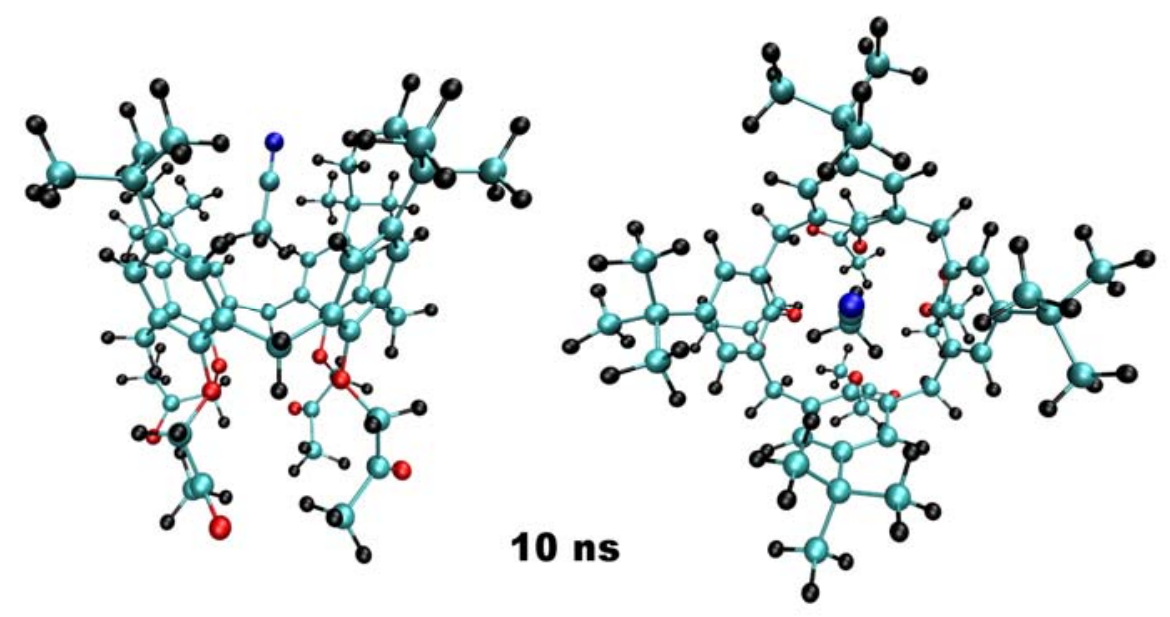

Figura 16 - Configuração do sistema depois de $10 \mathrm{~ns}$ de simulação. A molécula de acetonitrila permanece complexada durante toda a simulação. 
No Gráfico 17 podemos ver a distância entre a molécula de acetonitrila e o fundo da cavidade hidrofóbica. A acetonitrila permanece no interior da cavidade durante toda a simulação. O Gráfico 18 mostra a energia de interação entre a acetonitrila e toda a cavidade hidrofóbica. Vemos que o valor da energia de interação é praticamente o mesmo obtido na simulação da seção 4.4, mas nesse caso a molécula de acetonitrila permanece no interior da cavidade.

Isso pode ser explicado pelos resultados obtidos nas simulações apresentadas na seção 4.7, onde observamos que o calixareno CLC isolado executa transições conformacionais durante toda a simulação. Isso mostra que a tendência do CLC se manter na conformação retangular é muito menor que no caso do CLE, tornando possível uma molécula de acetonitrila se manter estável dentro da cavidade hidrofóbica forçando-a a se manter na conformação quadrada.

O mesmo comportamento é observado na estrutura resolvida experimentalmente e ainda não publicada, na qual o calixareno CLC, sem a presença de íons, cristaliza com uma molécula de acetonitrila na cavidade hidrofóbica. Isso mostra que nossos modelos para o calixareno e acetonitrila são bons pois apresentam comportamento semelhante às moléculas reais. 


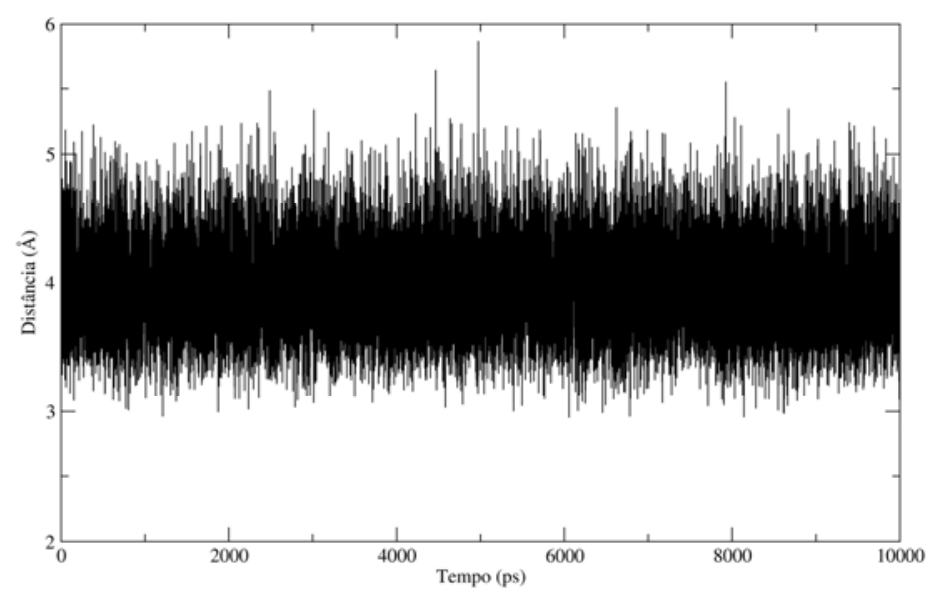

Gráfico 17 - Distância entre o centro de massa da molécula de acetonitrila e o fundo da cavidade hidrofóbica.

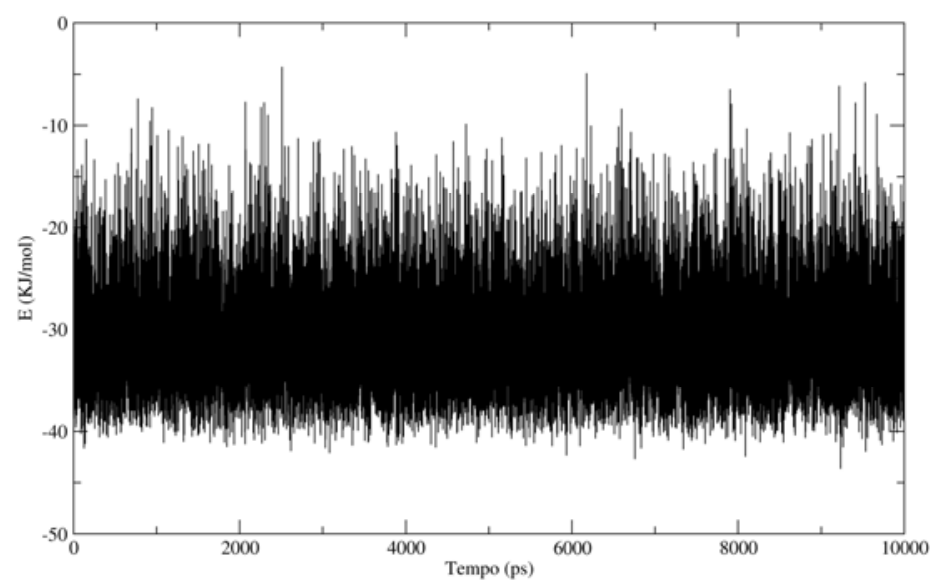

Gráfico 18 - Energia de interação não-ligada (Coulomb e Lennard-Jones) entre a molécula de acetonitrila e a cavidade hidrofóbica.

Monitoramos também as distâncias entre os átomos opostos. Nos Gráficos 19 e 20 observamos que a cavidade hidrofóbica se mantém na conformação quadrada, como esperado, devido a presença da molécula de acetonitrila.

No Gráfico 21 vemos que as distâncias entre os oxigênios carbonílicos opostos variam até $5 \AA$ durante toda a simulação, o que significa que apesar da cavidade hidrofóbica se manter na conformação quadrada, a cavidade hidrofílica não é influenciada por essa mudança, se comportando de maneira semelhante ao observado na simulação do calixareno isolado. Esse resultado é de extrema importância pois é 
uma evidência de que a presença da acetonitrila na cavidade hidrofóbica não préorganiza a cavidade hidrofílica, descaracterizando um possível efeito alostérico disparado pela entrada da acetonitrila na cavidade hidrofóbica como cogitado, a partir de resultados experimentais, na referência [12].

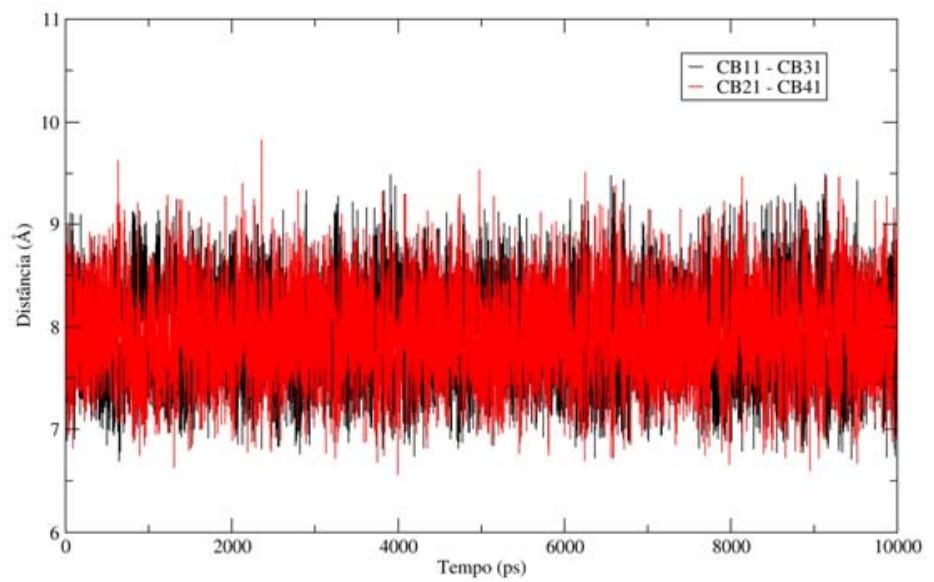

Gráfico 19 - Distância entre carbonos apicais.

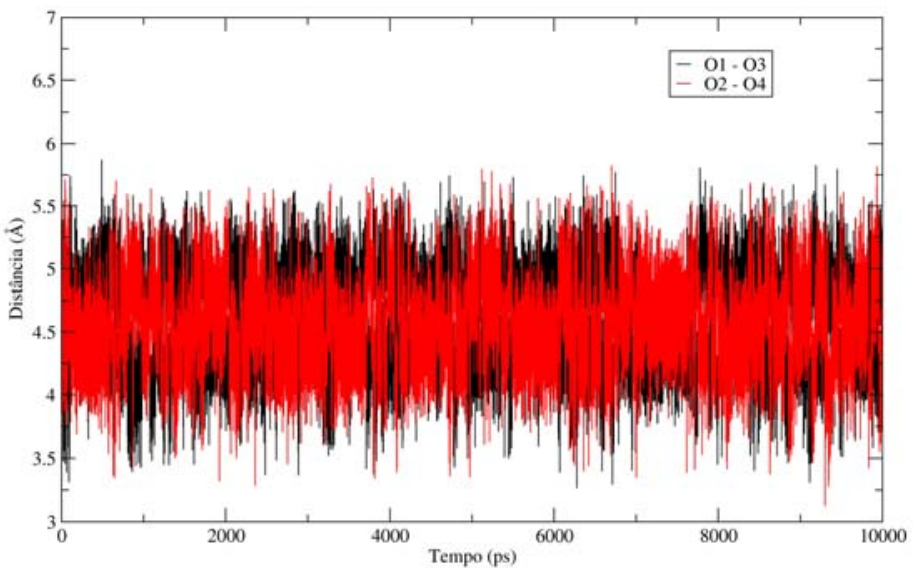

Gráfico 20 - Distância entre oxigênios fenólicos. 


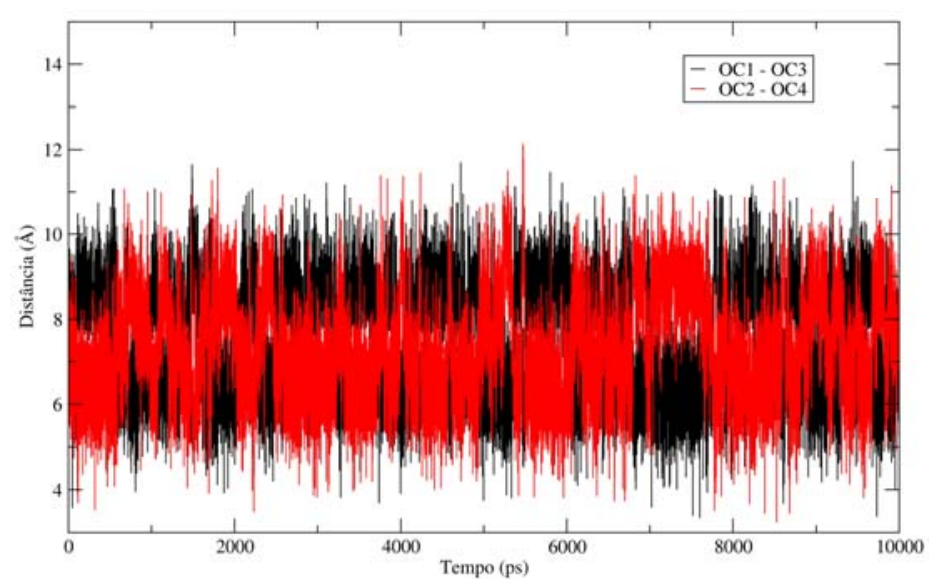

Gráfico 21 - Distância entre oxigênios carbonílicos.

\section{9 - Simulações do tetramethylketone p-tert-butyl calix[4]arene com um íon $\mathrm{Pb}^{2+}$ na cavidade hidrofílica}

Foi simulada uma molécula de calixareno com um íon $\mathrm{Pb}^{+2}$ no interior de sua cavidade hidrofílica. Executamos uma minimização de energia e a seguir uma simulação de $10 \mathrm{~ns}$ com passos de 1 fs. A conformação do sistema depois dos $10 \mathrm{~ns}$ de simulação pode ser visto na Figura 17.
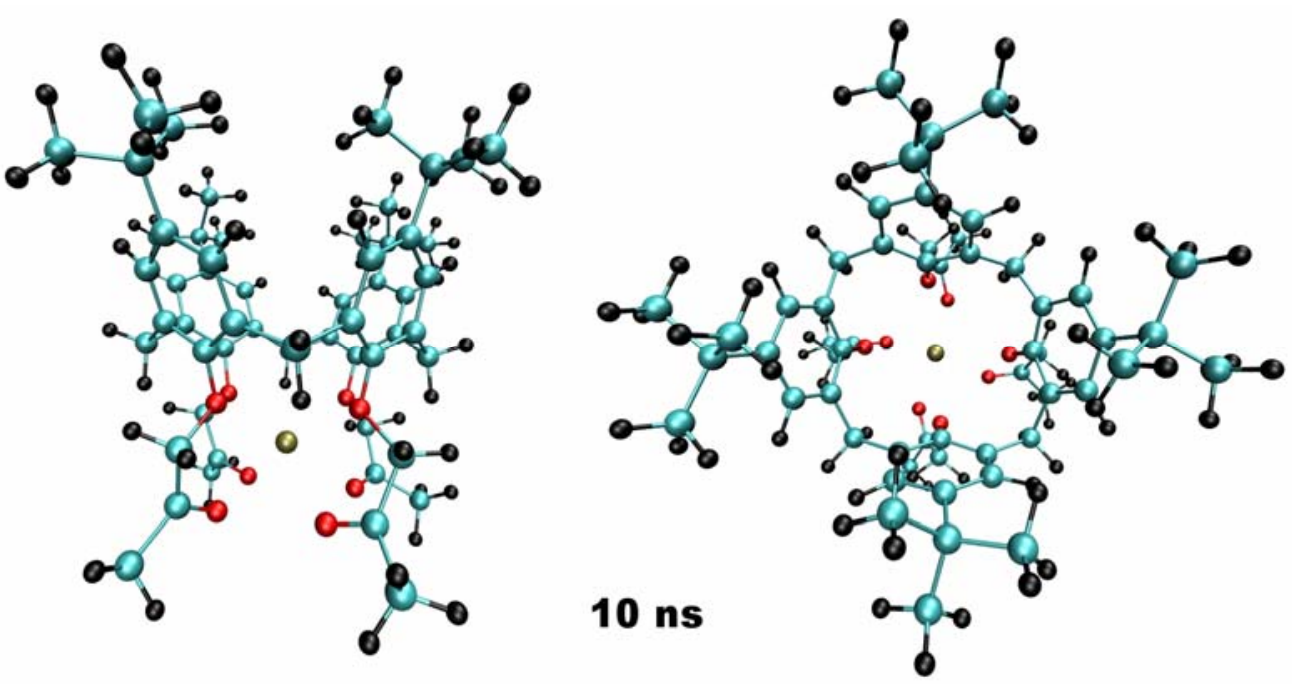

Figura 17 - Conformação do sistema depois de 10 ns de simulação. 
Durante toda a simulação o íon se manteve no interior da cavidade hidrofílica coordenando todos os oxigênios fenólicos e carbonílicos. Monitoramos a energia de interação não-ligada entre o íon e a toda a cavidade hidrofílica e obtivemos os resultados mostrados no Gráfico 22.

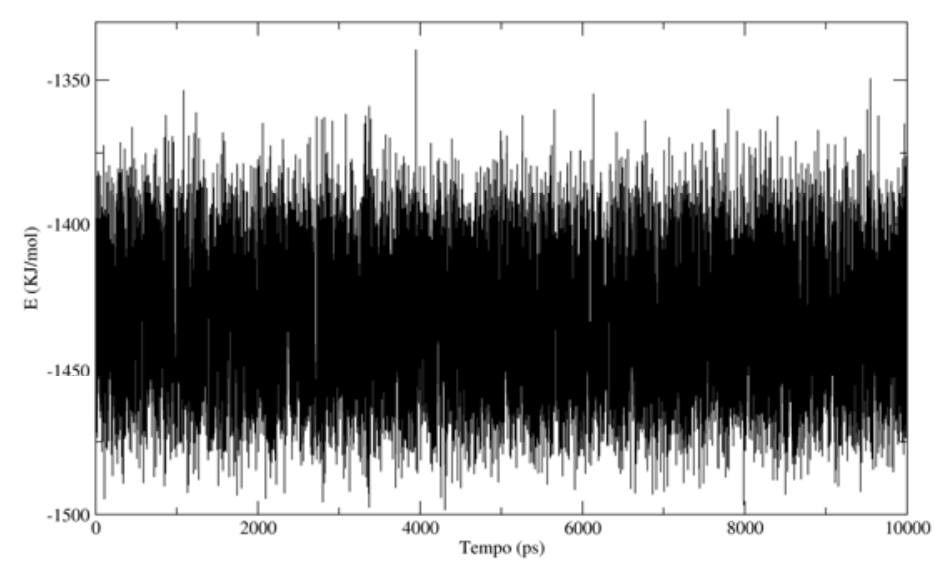

Gráfico 22 - Energia de interação não-ligada (Coulomb e Lennard-Jones) entre o $\mathrm{Pb}^{2+}$ e a cavidade hidrofilica.

A energia de interação se manteve em torno de $-1430 \mathrm{~kJ} / \mathrm{mol}$ durante toda a simulação e podemos concluir, a partir desse valor, que o íon é estável dentro da cavidade.

Calculamos também as distâncias entre os átomos opostos para podermos visualizar como a presença do íon na cavidade hidrofílica distorce todo o calixareno. Os resultados podem ser vistos nos Gráficos 23, 24 e 25. 


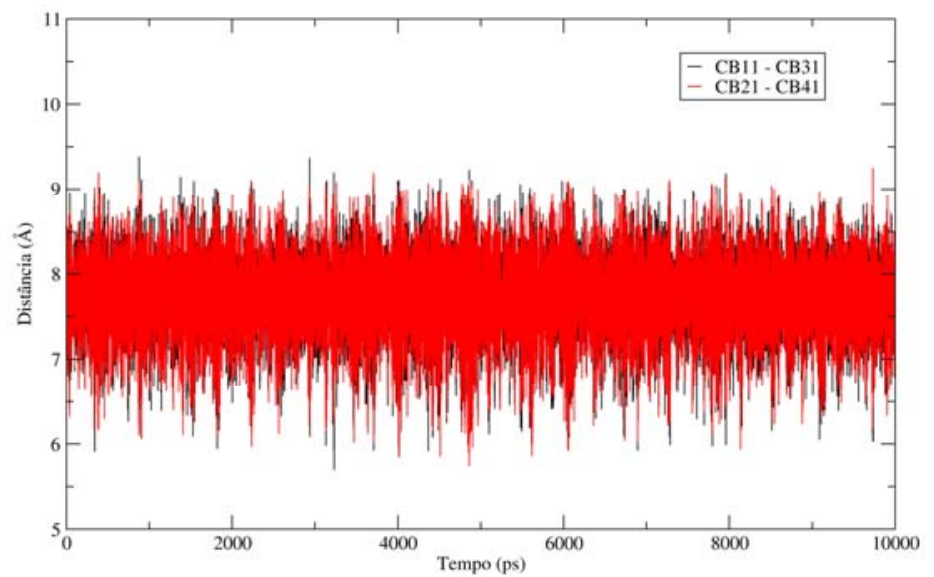

Gráfico 23 - Distância entre carbonos apicais.

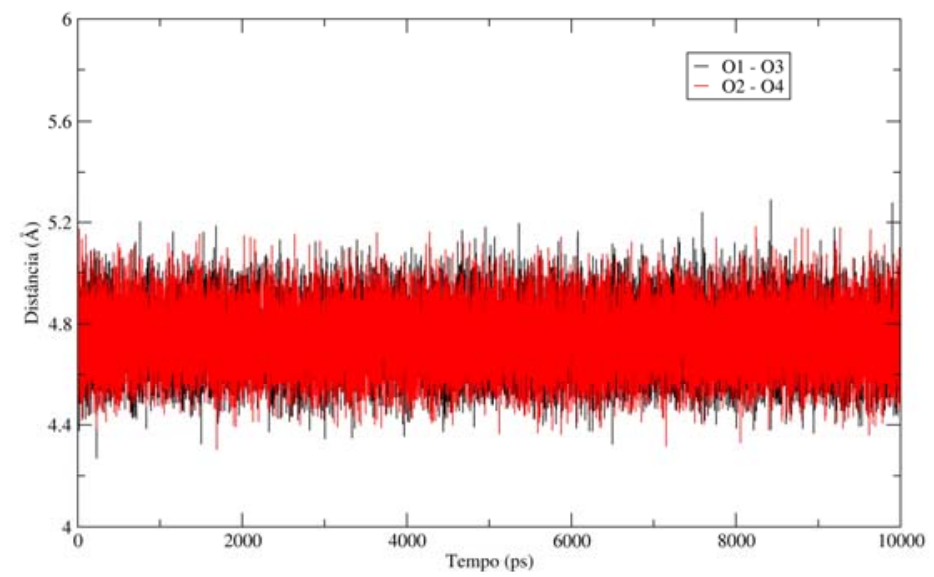

Gráfico 24 - Distância entre oxigênios fenólicos.

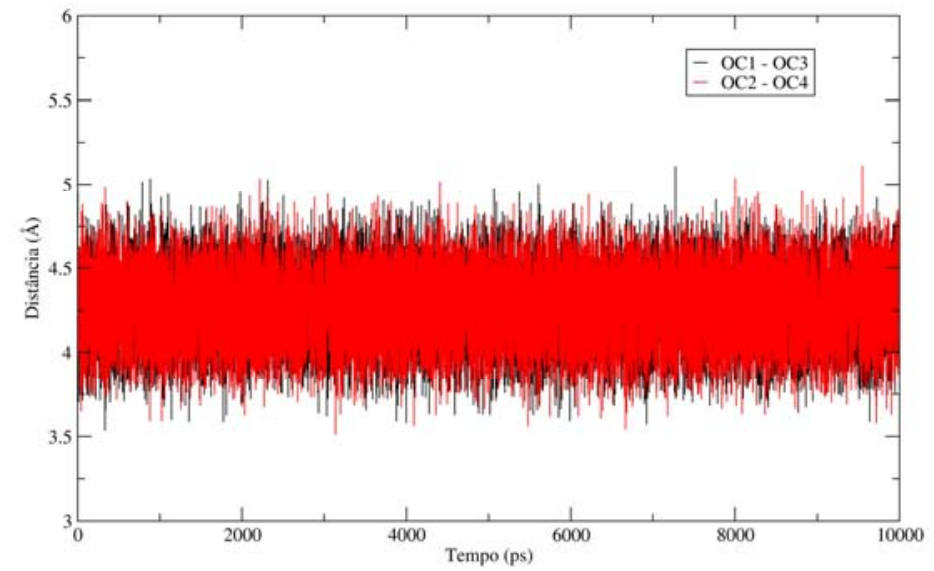

Gráfico 25 - Distância entre oxigênios carbonílicos. 
O calixareno se mantém na conformação quadrada durante toda a simulação, pois o íon coordena os oxigênios da cavidade hidrofílica mantendo-os sempre à mesma distância, o que simetriza a cavidade hidrofóbica de modo que os carbonos apicais fiquem todos equidistantes do eixo central da cavidade.

Calculamos as distâncias médias entre o íon e os oxigênios a fim de comparálas com os resultados experimentais. Obtivemos um valor médio de $(2,54 \pm 0,08) \AA$ para as distâncias $\mathrm{Pb}^{2+}-\mathrm{O}$ que pode ser considerado muito bom quando comparado com os valores experimentais [12] em torno de 2,67 $\AA$. Para as distâncias $\mathrm{Pb}^{2+}-\mathrm{OC}$ obtivemos uma média de $(2,59 \pm 0,09) \AA$, que dentro da margem de erro é idêntica aos valores experimentais que estão em torno de $2,54 \AA$.

Para uma melhor comparação entre nossas simulações e o experimento, calculamos a estrutura média do último 1 ns de simulação e, utilizando o programa Winkabsch, a superpusemos com a estrutura cristalográfica. O resultado é mostrado na Figura 18.
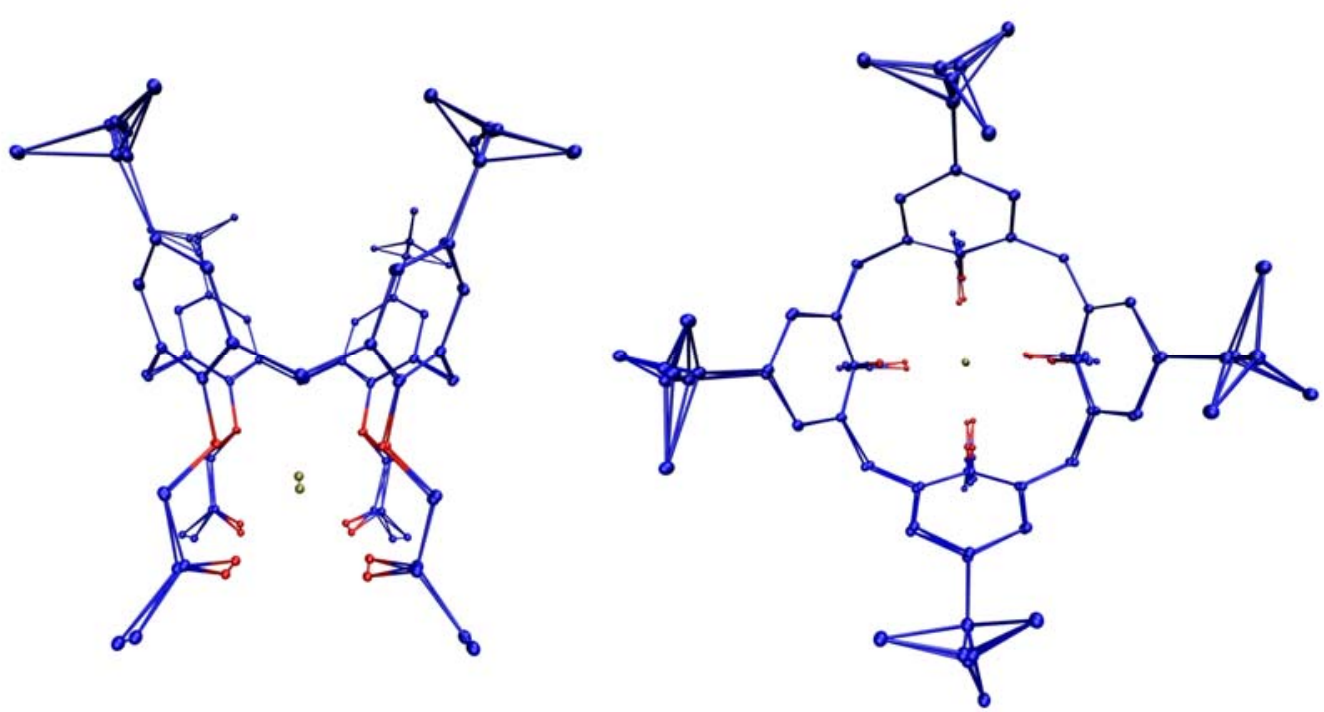

Figura 18 - Superposição da estrutura média calculada com a estrutura experimental obtida por difração de raios- $X$. 
A cavidade hidrofóbica mostra uma superposição quase perfeita a não ser pelos grupos tert-butil devido aos motivos já elucidados anteriormente. A posição do íon está deslocada $0,3 \AA$ com relação ao experimental, o que acarreta numa diferença de aproximadamente a mesma distância entre os oxigênios carbonílicos. Comparado com a distância média $\mathrm{Pb}^{2+}-\mathrm{O}$, esse deslocamento é pequeno e podemos considerar que as estruturas se superpõem muito bem. A vista superior da superposição nos mostra que o íon coordena os oxigênios de maneira idêntica ao experimento na forma de dois quadrados sobrepostos, pré-organizando a cavidade hidrofóbica na conformação quadrada.

\subsection{0 - Simulações tetramethylketone p-tert-butyl calix[4]arene com um íon $\mathrm{Cd}^{2+}$ na cavidade hidrofílica}

Foi simulada uma molécula de calixareno e um íon $\mathrm{Cd}^{2+}$ no interior da cavidade hidrofílica. Após executarmos uma minimização de energia, realizamos 10 ns de dinâmica molecular com passos de 1 fs. A configuração final da simulação é mostrada na Figura 19. 

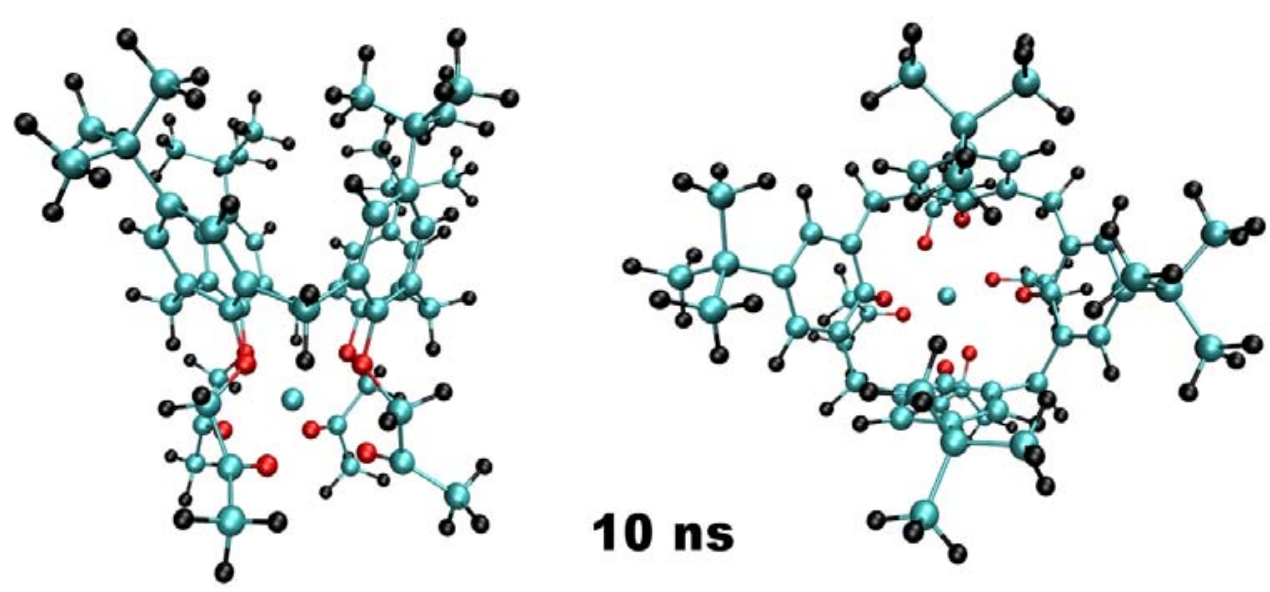

Figura 19 - Configuração final da simulação do calixareno CLC com o íon $\mathrm{Cd}^{2+}$ em sua cavidade hidrofilica.

Monitoramos a energia de interação não-ligada entre o íon e a cavidade hidrofílica. O resultado é mostrado no Gráfico 26.

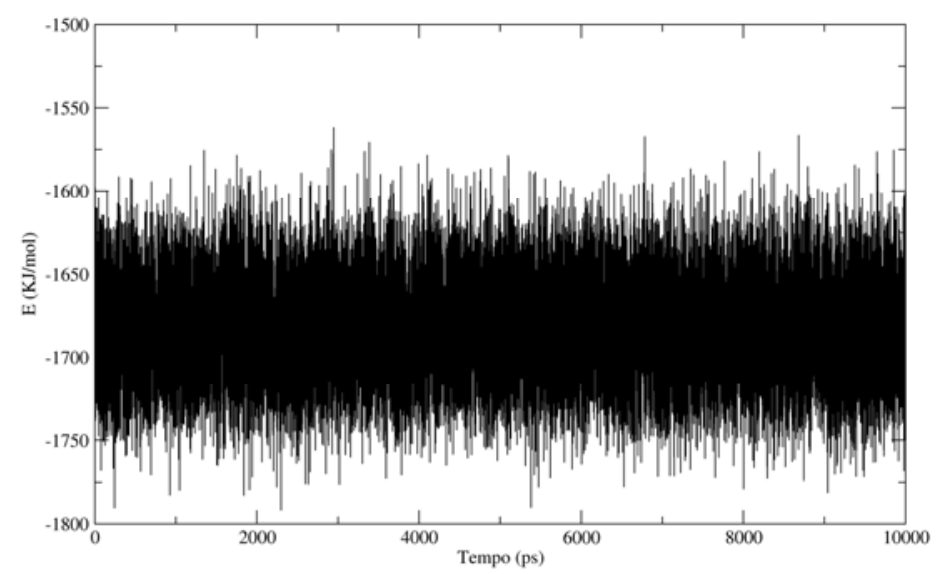

Gráfico 26 - Energia de interação não-ligada (Coulomb e Lennard-Jones) entre o $\mathrm{Cd}^{2+}$ e a cavidade hidrofilica.

Vemos que o valor da energia manteve-se em torno de $-1670 \mathrm{~kJ} / \mathrm{mol}$ durante toda a simulação, valor que comprova que o íon é estável dentro da cavidade.

Monitoramos também as distâncias entre os átomos opostos. Os resultados obtidos (Gráficos 27, 28 e 29) nos mostram que o calixareno se mantém na conformação quadrada durante toda a simulação, ao contrário das simulações 
apresentadas na seção 4.6, onde o íon $\mathrm{Cd}^{2+}$ interage com os oxigênios da cavidade hidrofílica impondo ao calixareno uma conformação levemente retangular alternando entre dois estados equivalentes energeticamente.

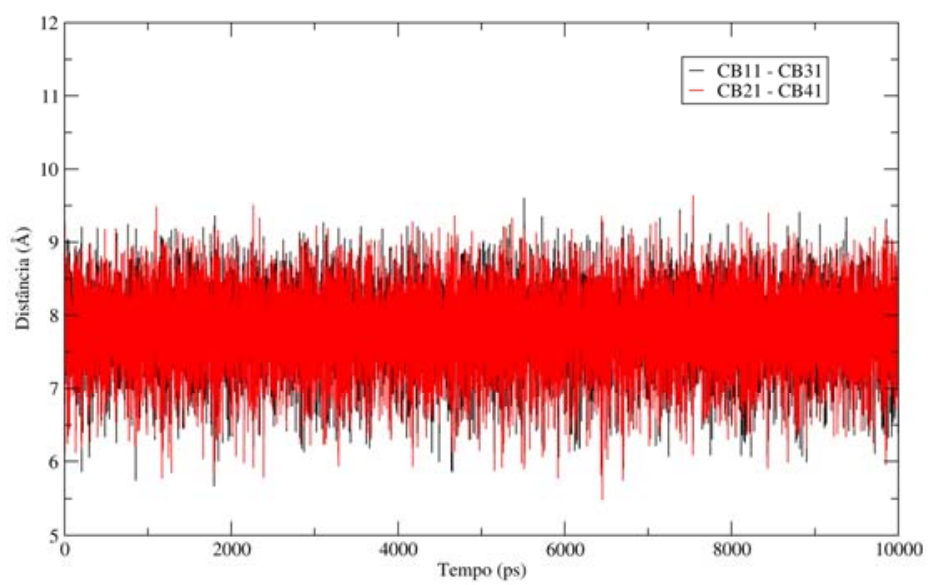

Gráfico 27 - Distância entre carbonos apicais.

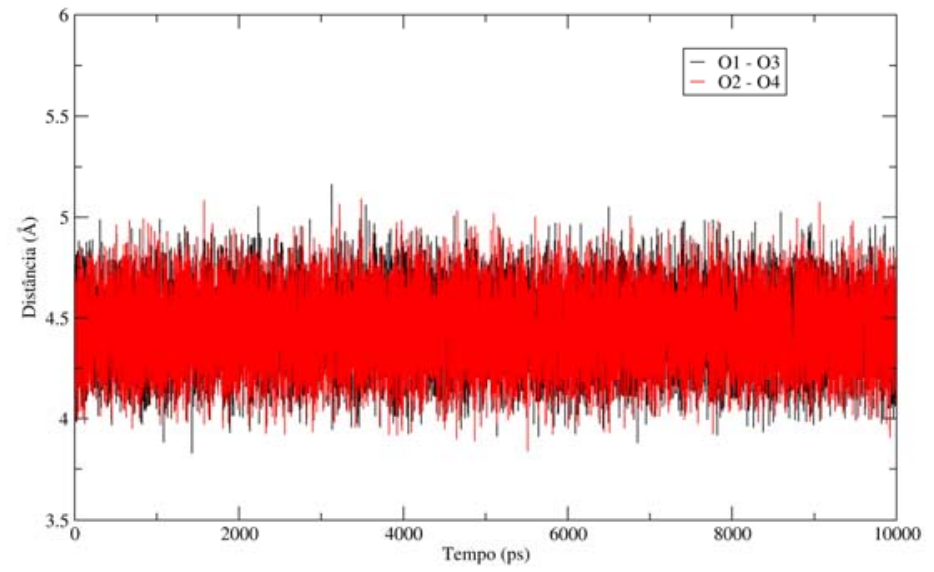

Gráfico 28 - Distância entre oxigênios fenólicos. 


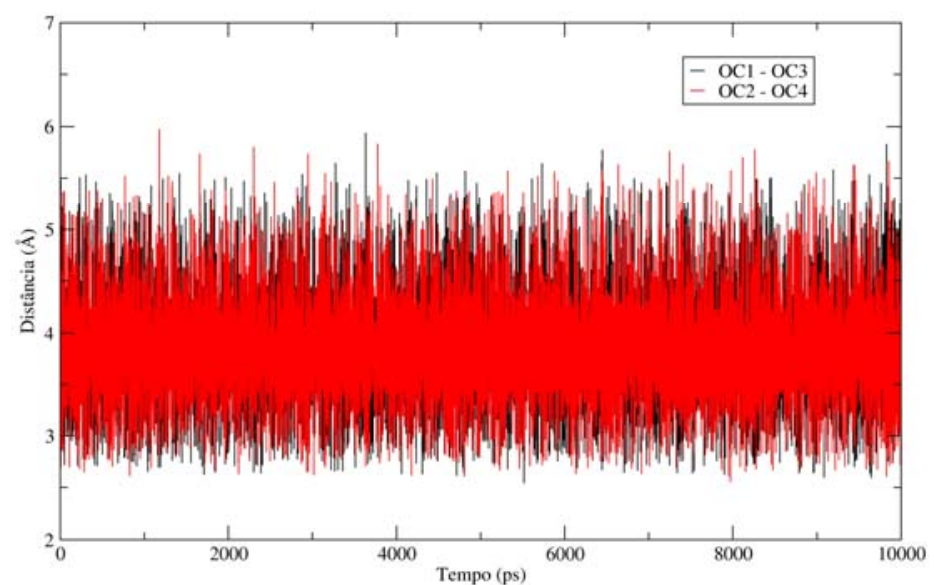

Gráfico 29 - Distância entre oxigênios carbonílicos.

Calculamos a média das distâncias entre os oxigênios e o íon para compararmos com os resultados cristalográficos. Para a distância $\mathrm{Cd}^{2+}-\mathrm{O}$ obtivemos $(2,5 \pm 0,2) \AA$, que dentro da margem de erro é idêntica à experimental $\left(\mathrm{Cd}^{2+}-\mathrm{O}\right.$ de 2,3 a 2,4 $\AA$ ). No caso da distância $\mathrm{Cd}^{2+}$ - OC calculamos a média de $(2,3 \pm 0,2) \AA$ que está em ótimo acordo comparado com as distâncias experimentais em torno de $2,3 \AA$ A. Esses resultados nos mostram que os modelos utilizados para o calixareno e $\mathrm{Cd}^{2+}$ reproduzem muito bem o sistema real.

Para uma melhor comparação realizamos uma superposição da estrutura média calculada no último $1 \mathrm{~ns}$ de simulação com a estrutura cristalográfica. O resultado é mostrado na Figura 20. 


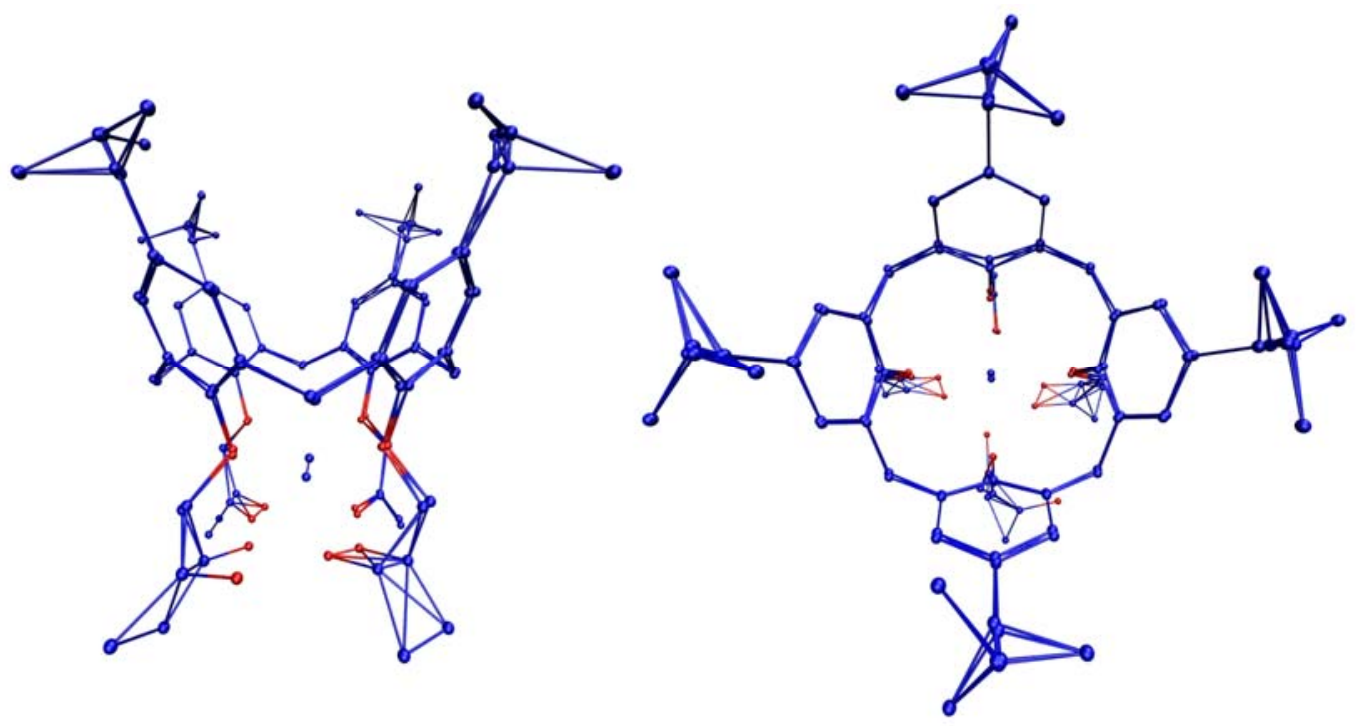

Figura 20 - Superposição da estrutura cristalográfica com a estrutura média calculada no último 1 ns de simulação.

Observamos que a superposição da cavidade hidrofóbica é praticamente perfeita, seguindo o mesmo padrão das outras simulações. A diferença principal nesse caso acontece na cavidade hidrofílica, onde experimentalmente observamos que um dos oito oxigênios não coordena o íon, enquanto que na simulação todos os 8 estão coordenando o $\mathrm{Cd}^{2+}$. Isso se deve ao fato de que na cela unitária cristalográfica existem, além das moléculas do calixareno, moléculas de solvente e contra-íons, e provavelmente as interações entre esses elementos e o calixareno mantiveram um dos oxigênios fora da coordenação do $\mathrm{Cd}^{2+}$. Como nossas simulações são realizadas no vácuo, não existem outras moléculas além do calixareno e o íon, assim todos os oxigênios da cavidade hidrofílica somente interagem com o íon. Nas simulações dos complexos calixareno-íon solvatados por acetonitrila, que serão apresentados no capítulo seguinte, poderemos observar a influência do solvente sobre os complexos.

O íon está deslocado $0,5 \AA$ com relação ao experimento, o que acarreta em deslocamento dos oxigênios que o coordenam, como podemos ver na Figura 20. De todas as superposições realizadas, essa foi a que apresentou mais diferenças na 
cavidade hidrofílica com relação à estrutura experimental, certamente devido ao diferente número de oxigênios que coordenam o íon.

\subsection{1 - Conclusões}

As simulações dos calixarenos e complexos no vácuo mostraram excelente acordo com resultados experimentais obtidos por difração de raios-X, evidenciando que os modelos utilizados para a acetonitrila, íons e calixarenos são muito bons. Outras conclusões obtidas das simulações no vácuo é que a estrutura do calixareno CLE é mais rígida que a do CLC, não realizando transições conformacionais durante toda a simulação da molécula isolada. $\mathrm{Na}$ simulação do complexo calixarenoacetonitrila o ligante inserido na cavidade hidrofóbica é expulso, o que reflete a tendência do CLE em se manter na conformação retangular. Já o CLC apresenta maior flexibilidade realizando transições durante toda a simulação do calixareno isolado e mantendo a acetonitrila complexada na cavidade hidrofóbica durante a simulação do complexo calixareno-acetronitrila. Isso explica o resultado experimental observado no estado sólido onde o calixareno CLC é cristalizado com uma molécula de acetonitrila complexada na cavidade hidrofóbica e o CLE não. Os complexos dos calixarenos com os íons no vácuo mostram grande similaridade com os complexos observados no estado sólido, o que pode ser comprovado pela superposição, realizada com o programa Winkabsch, entre as estruturas experimentais e estruturas médias obtidas a partir das simulações. 


\section{Capítulo 5- Simulações dos Calixa[4]arenos em}

\section{Acetonitrila}

\section{1 - Introdução}

Apesar dos calixarenos estudados serem assunto de diversos trabalhos experimentais que fornecem resultados esclarecedores [12, 59-62], muitas dúvidas ainda restam com relação à dinâmica de seu processo de complexação. A forma como o calixareno aprisiona o íon, a maneira como ocorre o possível efeito alostérico no processo de complexação, a estabilidade dos ligantes nas cavidades e a influência da composição dos grupos pendantes ${ }^{3}$ no comportamento do calixarenos, são algumas dúvidas que ainda não foram respondidas a partir de resultados experimentais. Na tentativa de responder algumas dessas questões realizamos as simulações apresentadas nessa seção.

A partir dos modelos validados nas simulações no vácuo e utilizando as conformações finais obtidas, realizamos simulações dos calixarenos livres e complexados em acetonitrila. Esse solvente foi escolhido por ter sido o mesmo

\footnotetext{
${ }^{3}$ Cada um dos quatro grupos que formam a cavidade hidrofílica.
} 
utilizado na obtenção das amostras para os estudos experimentais apresentados na referência [37]. Na tentativa de observar diretamente a complexação dos íons, realizamos simulações de sistemas constituídos por um calixareno livre (nãocomplexado) na presença de um dos íons. Após extensas simulações não conseguimos observar a entrada do íon na cavidade hidrofílica como observado experimentalmente. Isso provavelmente ocorre devido ao fato de que a escala de tempo alcançada por nossas simulações não é suficiente para observarmos o processo, que pode apresentar tempos característicos ordens de grandeza maiores. Resolvemos então partir dos resultados observados experimentalmente e realizar análises do comportamento conformacional e energético dos calixarenos livres e complexados em solvente. Essas análises são parecidas com as realizadas nas simulações dos calixarenos no vácuo. Entretanto, em simulações de líquidos a influência do solvente aumenta a complexidade dos sistemas, exigindo considerações mais aprofundadas para descrever seu comportamento. Realizamos simulações dos calixarenos tetraethylester p-tert-butyl calix[4]arene e tetramethylketone p-tert-butyl calix[4]arene em acetonitrila nas formas livre, complexada com um íon $\mathrm{Cd}^{2+} \mathrm{e}$ complexada com um íon $\mathrm{Pb}^{2+}$. Foram feitas análises energéticas e estruturais dos sistemas simulados que evidenciaram diferentes comportamentos em solução dos sistemas estudados. As conclusões obtidas complementaram os resultados experimentais, contribuindo para o melhor entendimento do processo de complexação dos calixarenos em questão. 


\section{2 - Metodologia e Detalhes Computacionais}

As simulações apresentadas nesse capítulo foram realizadas com modelos previamente validados e utilizaram como configurações iniciais as obtidas ao final das simulações no vácuo apresentadas no capítulo 4 . O objetivo dessas simulações é elucidar o comportamento dinâmico em solução de moléculas que experimentalmente observamos estáticas no estado sólido. A influência do solvente no estado líquido sobre as moléculas em estudo é de extrema importância principalmente nos sistemas abordados por esse trabalho, pois a competição entre o solvente e o calixareno pelos íons é o principal fator que define se o complexo calixareno-íon irá ou não se formar. No cristal as moléculas de solvente atuam somente como agentes estabilizantes do empacotamento do cristal.

As concentrações das soluções utilizadas experimentalmente são da ordem de alguns mM [12], o que seria inviável de reproduzir em nossas simulações devido ao tamanho das caixas necessárias para reproduzir tal concentração. Aproximamos-nos o máximo possível do experimental montando nossas caixas com aproximadamente $40 \AA$ Å de lado, o que resulta numa concentração da ordem de dezenas de mM. Em todas as simulações utilizamos uma caixa de acetronitrila equilibrada a $300 \mathrm{~K}$ na densidade experimental para solvatar os calixarenos. Utilizamos condições periódicas de contorno a fim de simular o líquido infinito em torno da caixa de simulação. No tratamento das interações não-ligadas foi aplicado raio de corte de 18 A para as interações de van der Waals e Coulomb de baixo alcance e as interações de Coulomb de longo alcance foram tratadas com somas de Ewald via PME (Particle 
Mesh Ewald) [63, 64]. A temperatura e pressão foram mantidas à 300K e 1 bar, respectivamente, utilizando algoritmos de Berendsen com constantes de tempo de 0,1 ps e 1,0 ps. O fato de utilizarmos passos de 1 fs no tempo exige que apliquemos constraints nas ligações envolvendo hidrogênios.

Para todos os sistemas estudados realizamos uma minimização de energia sobre a configuração inicial, obtida a partir da solvatação das configurações finais das simulações no vácuo em caixas de acetonitrila líquida termalizada. A seguir realizamos uma simulação de 500 ps com passos de 1 fs aplicando freezing à molécula de calixareno ou complexo, de modo que as moléculas de solvente se adaptassem a presença do soluto. A aquisição de dados foi feita a partir de uma simulação de 2 ns com passos de 1 fs sem aplicação de freezing à molécula alguma. A análise dos resultados das simulações se baseou em considerações estruturais e energéticas de maneira parecida com as análises feitas sobre as simulações no vácuo.

\section{3 - Simulações do tetraethylester p-tert-butyl calix[4]arene não-complexado em acetonitrila}

Foi construída uma caixa cúbica de aproximadamente $43 \AA$ de lado, contendo 864 moléculas de acetonitrila e uma molécula de calixareno na conformação obtida ao final da simulação do CLE isolado no vácuo. Nessa caixa realizamos simulações seguindo o protocolo definido na seção 5.2 e a conformação final do sistema obtida é mostrada na Figura 21. 


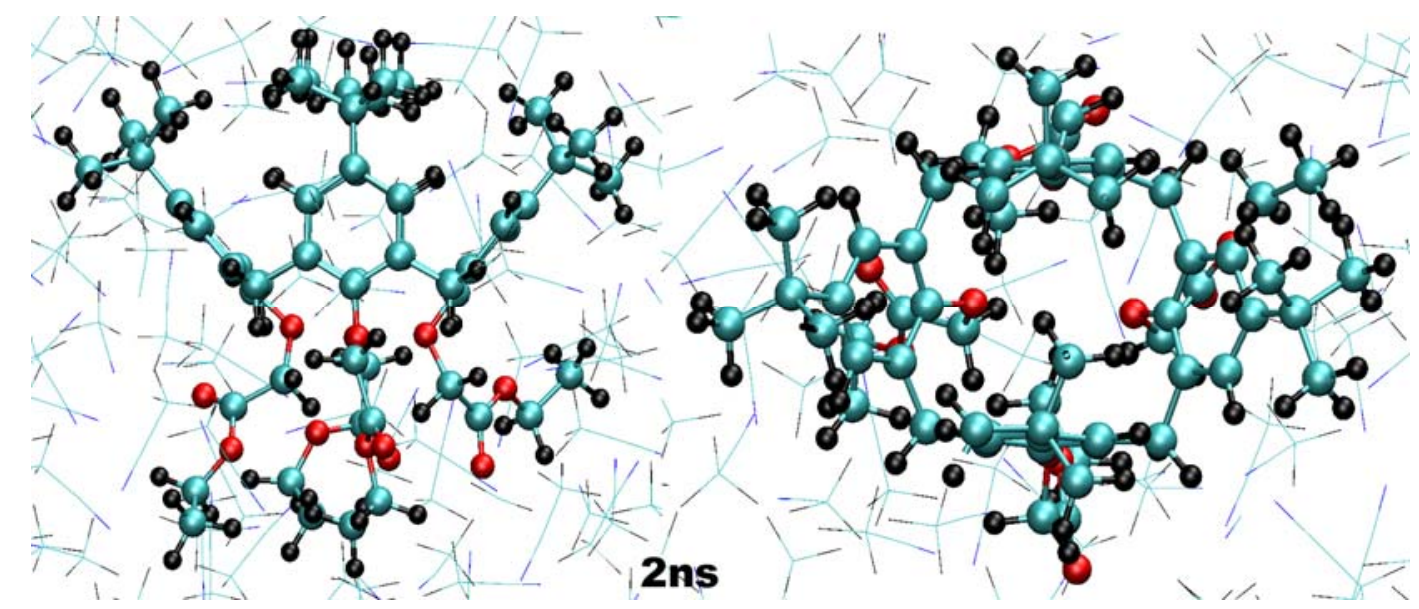

Figura 21 - Configuração final do sistema depois de 2 ns de simulação. Vista lateral e superior do calixareno onde observamos a ausência de moléculas de solvente nas cavidades hidrofóbica e hidrofilica.

Observamos que o calixareno apresenta a conformação retangular com a cavidade hidrofóbica com dois anéis paralelos e os outros dois formando um ângulo de $90^{\circ}$. Não é observada a entrada de moléculas de acetonitrila na cavidade hidrofóbica durante toda a simulação e, como no caso da simulação no vácuo, não são observadas modificações na conformação inicial. Nos Gráficos 30, 31 e 32 são mostradas as distâncias entre átomos opostos, onde podemos observar o comportamento praticamente estático da cavidade hidrofóbica.

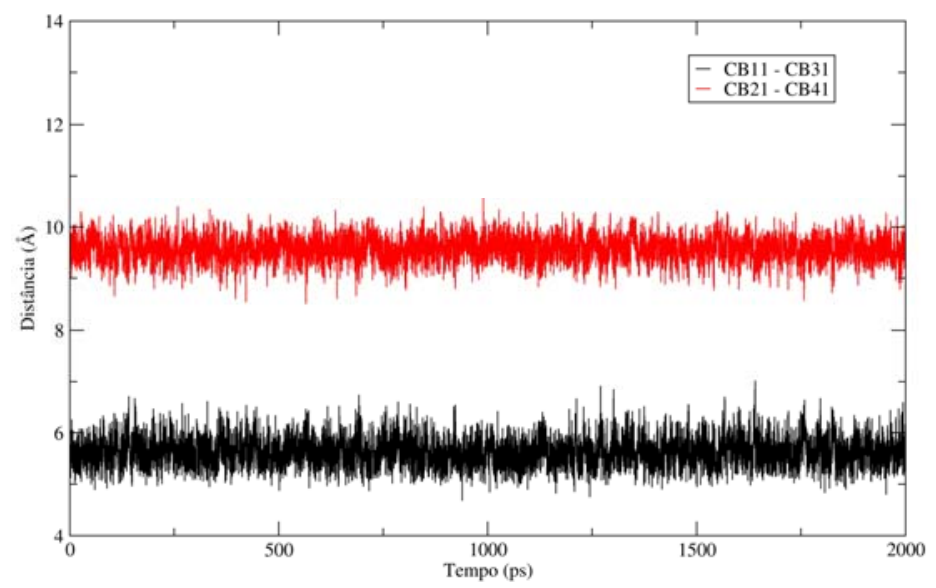

Gráfico 30 - Distância entre carbonos apicais. 


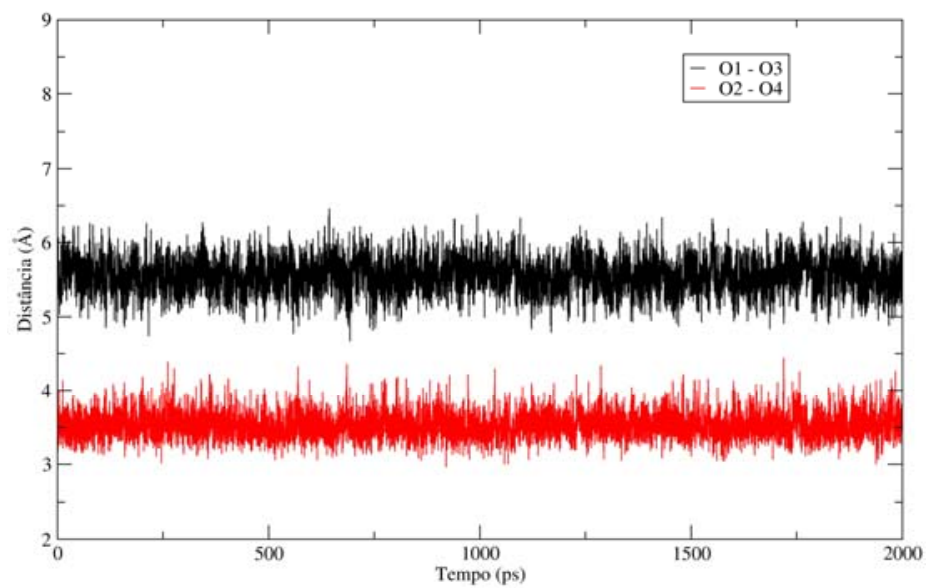

Gráfico 31 - Distância entre oxigênios fenólicos.

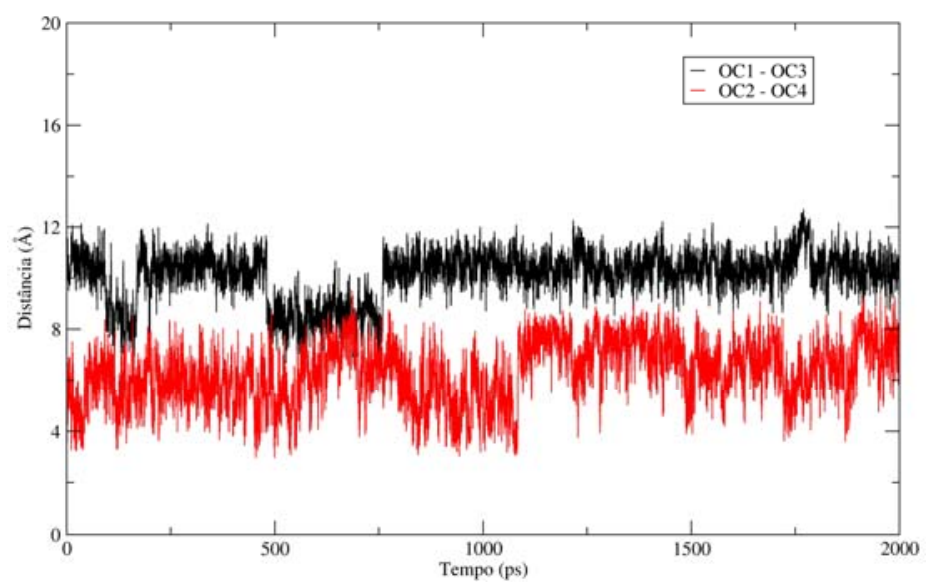

Gráfico 32 - Distância entre oxigênios carbonílicos.

Nos gráficos vemos que a cavidade hidrofóbica se mantém na conformação retangular e não executa transições durante toda a simulação. A cavidade hidrofílica apresenta uma maior mobilidade, com alterações nas distâncias entre os oxigênios carbonílicos, semelhantemente ao que é observado nas simulações do mesmo calixarenos isolado e no vácuo. Esse comportamento da cavidade hidrofílica se deve à sua constituição com átomos polares (oxigênios) e ligações sigma, aliado à presença de moléculas de acetonitrila que interagem fortemente com os grupos éster, movimentando toda a cavidade e facilitando as interações com os íons na presença destes. A ausência da molécula de acetonitrila na cavidade hidrofóbica condiz com 
dados experimentais de difração de raios-X obtidos pelo grupo e ainda não publicados.

Esses resultados mostram que o comportamento da cavidade hidrofílica é independente do comportamento da cavidade hidrofóbica e que, na ausência de íons, não é observada a entrada de uma molécula de acetonitrila na cavidade hidrofóbica, o que se supunha, a partir dos resultados experimentais, disparar o efeito alostérico que favoreceria a entrada do íon na cavidade hidrofílica.

\section{4 - Simulações do complexo tetraethylester p-tert-butyl calix[4]arene $-\mathbf{P b}^{2+}$ em acetonitrila}

Foi construída uma caixa cúbica de aproximadamente $45 \AA$ de lado, contendo 863 moléculas de acetonitrila, uma molécula do complexo $\mathrm{CLE}-\mathrm{Pb}^{2+}$ na conformação obtida ao final da simulação do complexo no vácuo e dois íons $\mathrm{Cl}^{-}$para neutralizar a caixa. Os contra-íons de cloro foram posicionados nos vértices da caixa e fixados nessa posição para evitar que interagissem com o complexo posicionado no centro. Nessa caixa realizamos simulações seguindo o protocolo definido na seção 5.2 e a conformação final do sistema obtida é mostrada na Figura 22. 


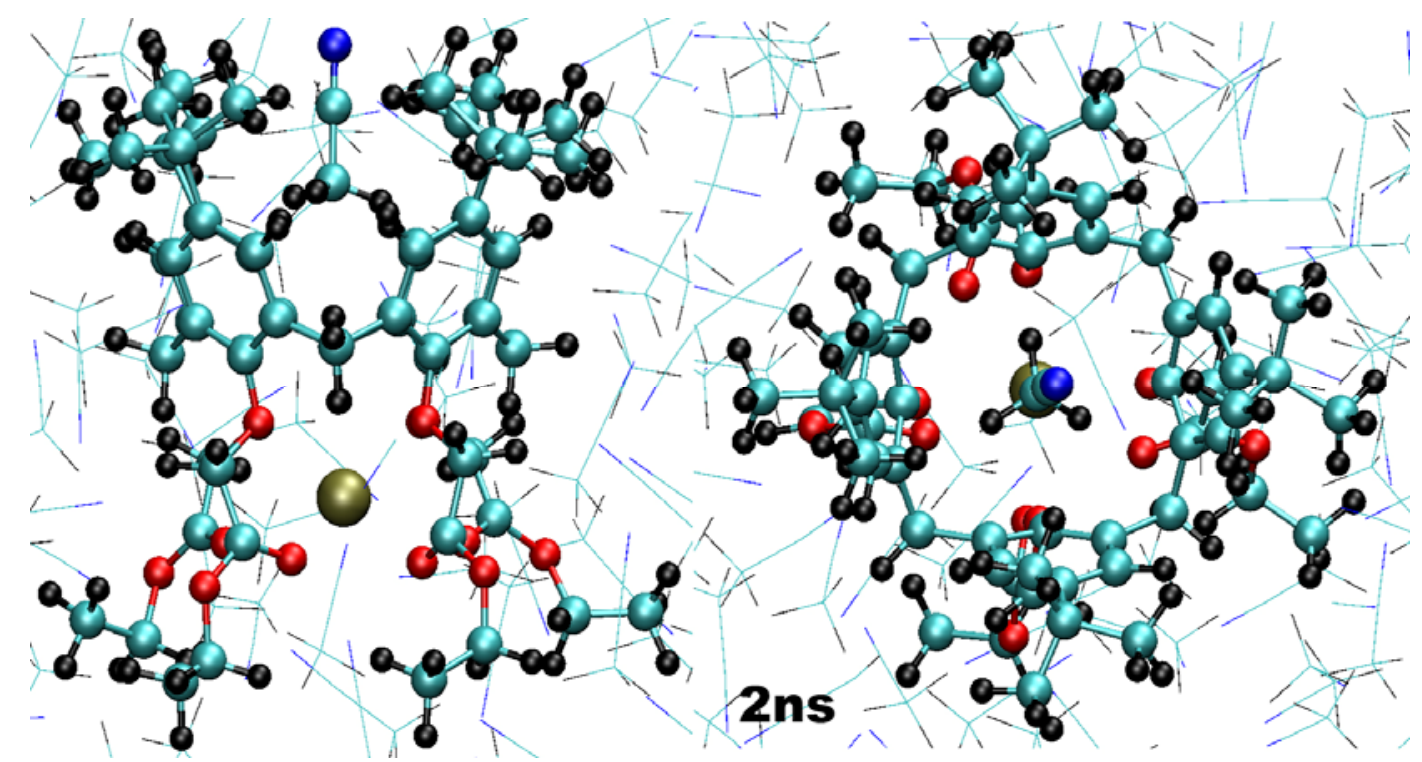

Figura 22 - Configuração final do sistema depois de 2 ns de simulação. Vista lateral e superior do calixareno onde observamos a presença de uma molécula de acetonitrila na cavidade hidrofóbica e o ion $\mathrm{Pb}^{2+}$ na cavidade hidrofilica.

Na conformação inicial do complexo o calixareno apresenta a conformação quadrada devido à presença do íon $\mathrm{Pb}^{2+}$ na cavidade hidrofílica. O íon se mantém na cavidade e o calixareno se mantém na conformação quadrada durante toda a simulação como será mostrado nas análises apresentadas a seguir. No Gráfico 33 é mostrada a energia de interação não-ligada entre o íon e a cavidade hidrofílica.

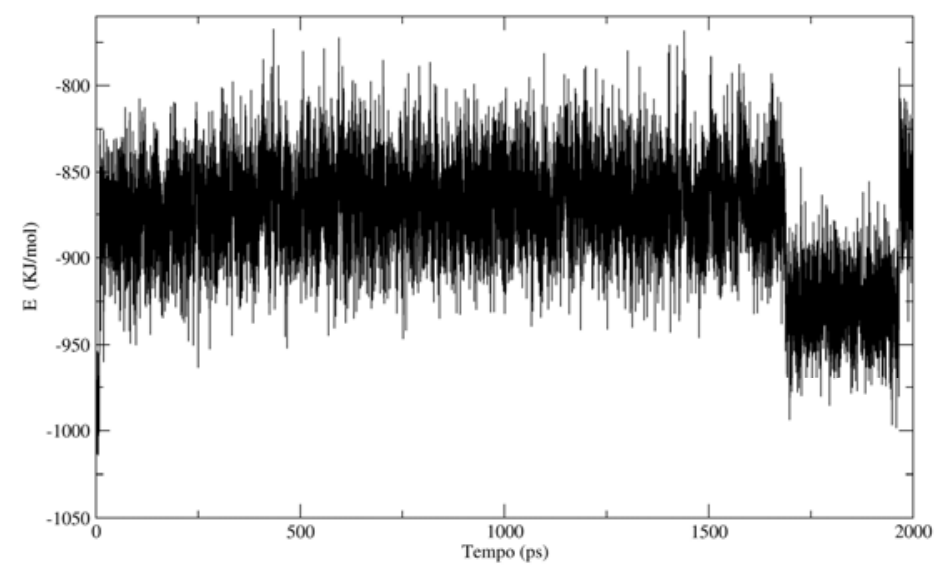

Gráfico 33 - Energia de interação não-ligada (Coulomb e Lennard-Jones) entre o $\mathrm{Pb}^{2+}$ e a cavidade hidrofilica. 
A energia de interação, que inicialmente é de aproximadamente $-1000 \mathrm{~kJ} / \mathrm{mol}$, cai para aproximadamente $-870 \mathrm{~kJ} / \mathrm{mol}$ devido à presença de moléculas de acetonitrila na parte inferior e lateral da cavidade hidrofílica deslocando o íon de sua posição inicial e afastando lateralmente os grupos pendantes. Entre 1600 e 1950 ps vemos que a energia de interação volta a aumentar devido à saída de uma molécula lateral de acetonitrila o que faz a cavidade se fechar. Entretanto, outra molécula de acetonitrila volta a interagir lateralmente com o íon, diminuindo a energia de interação após 1950 ps até o final da simulação. Isso nos mostra que na presença de solvente o íon se mantém estável dentro da cavidade hidrofílica. No entanto, existe uma competição entre as moléculas de solvente e os átomos da cavidade para coordenar o íon, fazendo a energia mostrada no Gráfico 33 flutuar em torno de 30 $\mathrm{kJ} / \mathrm{mol}$ sem ocasionar a saída do íon do interior da cavidade.

Na Figura 22 é observada uma molécula de acetonitrila no interior da cavidade hidrofóbica que entra no decorrer da simulação. O Gráfico 34 nos mostra a distância entre a molécula de acetonitrila e o fundo da cavidade e o Gráfico 35 a energia de interação entre a acetonitrila e toda a cavidade hidrofóbica.

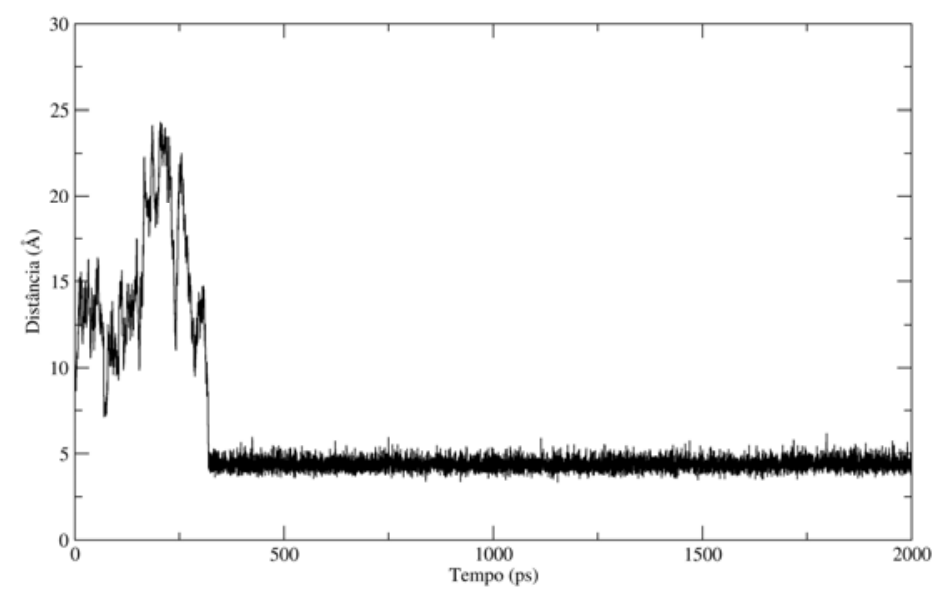

Gráfico 34 - Distância entre o centro de massa da molécula de acetonitrila complexada e o fundo da cavidade hidrofóbica. 


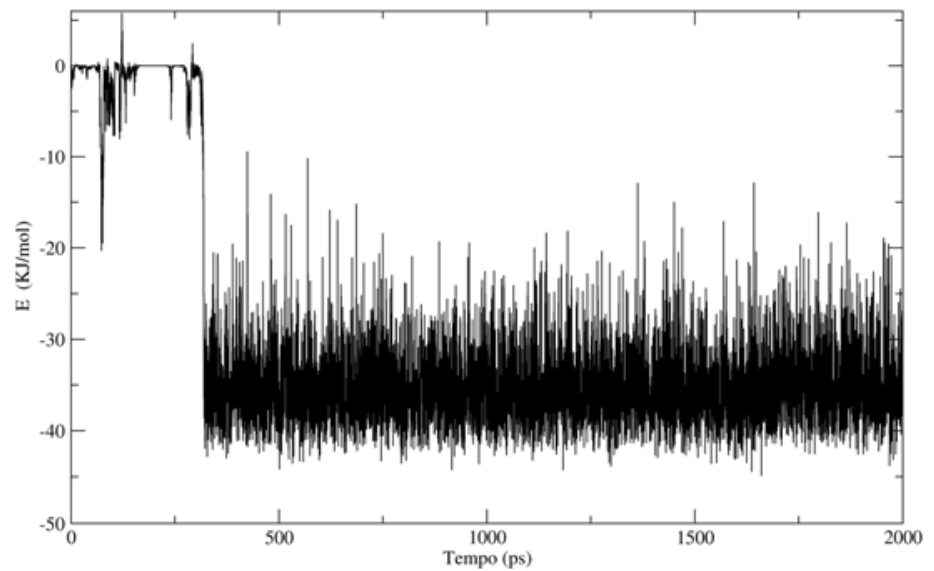

Gráfico 35 - Energia de interação não-ligada (Coulomb e Lennard-Jones) entre a molécula de acetonitrila complexada e toda a cavidade hidrofóbica

Os gráficos nos mostram que a molécula de acetonitrila entra na cavidade hidrofóbica depois de aproximadamente 300 ps de simulação e se mantém complexada até o fim. A energia fica em torno de $-35 \mathrm{~kJ} / \mathrm{mol}$ mostrando que a complexação é favorável energeticamente, apesar de ser uma interação fraca comparada com a observada entre o íon e a cavidade hidrofílica. A maneira como a molécula de solvente entra na cavidade hidrofóbica, com o grupo $\mathrm{CH}_{3}$ apontando para o íon, é a mesma observada experimentalmente por difração de raios-X [12]. O fato do grupo $\mathrm{CH}_{3}$ apresentar, no modelo da acetonitrila, carga parcial positiva, nos levou a questionar porque a molécula de acetonitrila se aloja na cavidade como observado, já que o íon, com carga altamente positiva, a princípio deveria repelir o grupo metila. O Gráfico 36 nos mostra a energia de interação $\mathrm{Pb}^{2+}$-acetonitrila onde observamos uma energia de interação repulsiva de aproximadamente $10 \mathrm{~kJ} / \mathrm{mol}$. A diferença entre a energia de interação atrativa acetonitrila-cavidade e repulsiva acetonitrila-íon é negativa, mostrando que a entrada da acetonitrila na cavidade hidrofóbica, como observado, é energeticamente favorável. 


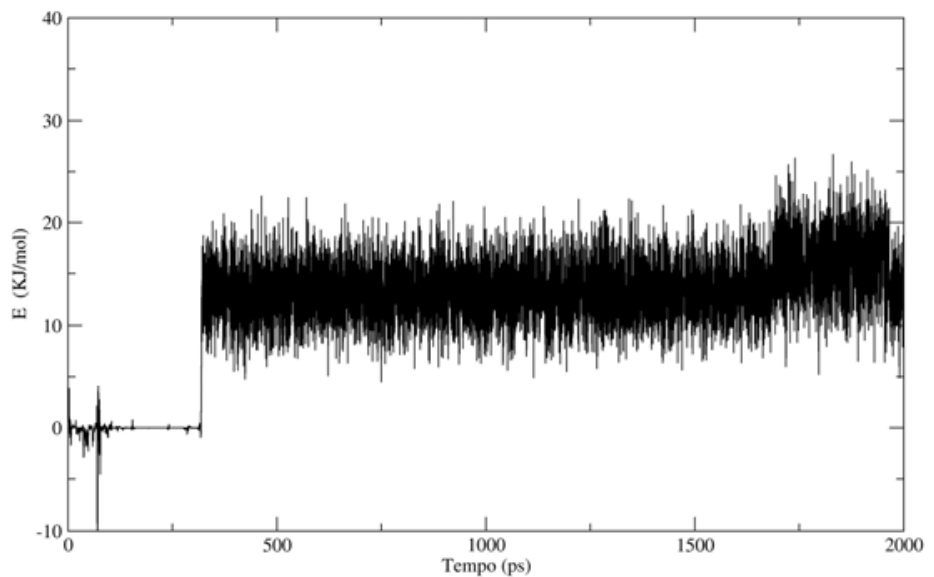

Gráfico 36 - Energia de interação não-ligada (Coulomb e Lennard-Jones) entre a molécula de acetonitrila complexada e o ín $\mathrm{Pb}^{2+}$.

Analisamos também as modificações estruturais do calixareno ocasionadas pela complexação da acetonitrila na cavidade hidrofóbica e pela ação das moléculas de solvente não-complexadas sobre todo o calixareno. Os Gráficos 37, 38 e 39 mostram as distâncias entre átomos opostos das cavidades hidrofóbica e hidrofílica.

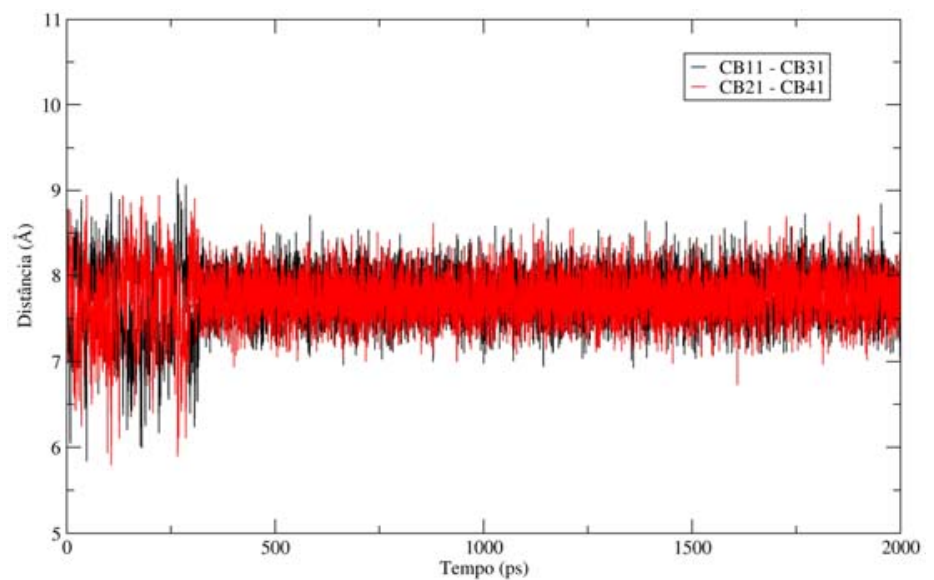

Gráfico 37 - Distância entre carbonos apicais. 


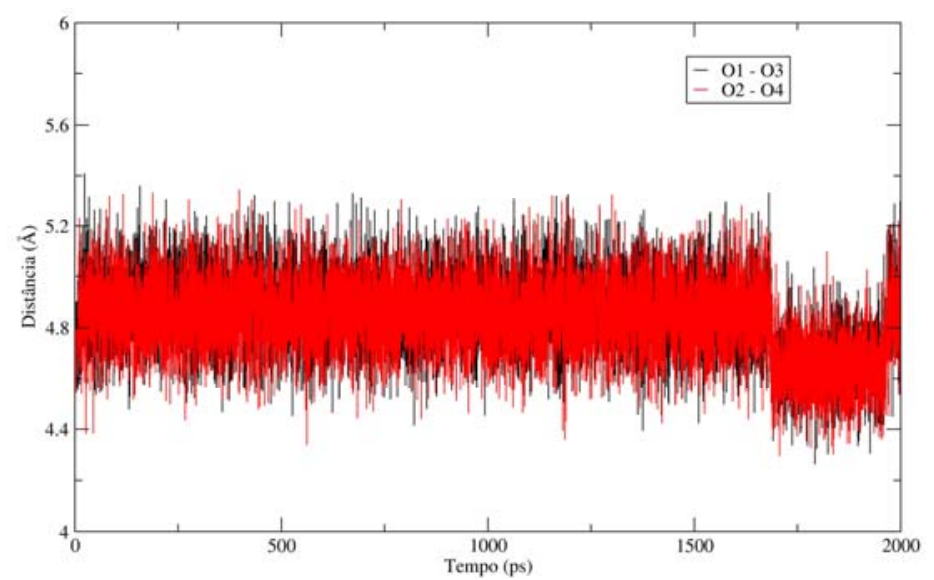

Gráfico 38 - Distância entre oxigênios fenólicos.

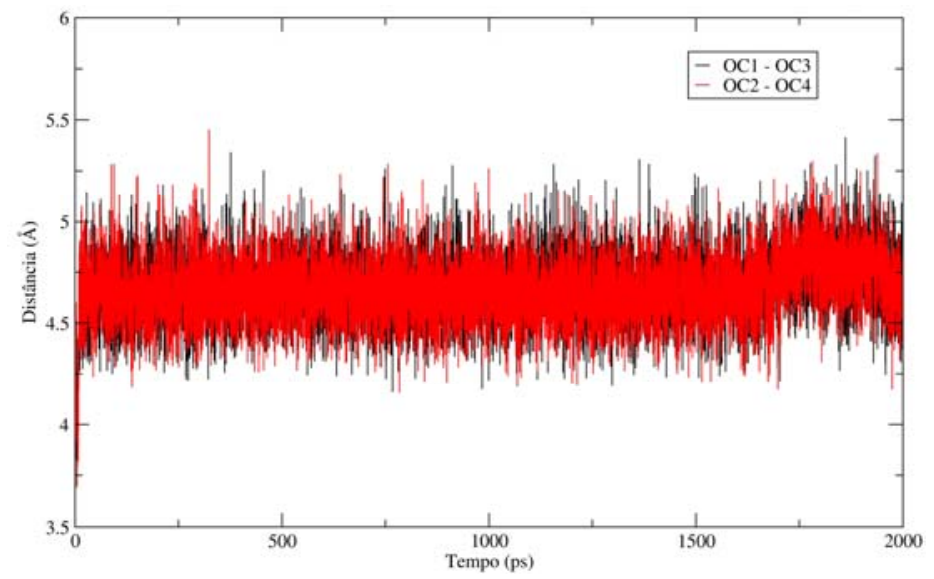

Gráfico 39 - Distância entre oxigênios carbonilicos.

Os gráficos nos mostram que o calixareno se mantém na conformação quadrada durante toda a simulação. Observamos que a entrada da molécula de acetonitrila na cavidade hidrofóbica somente influencia o comportamento dos carbonos apicais, diminuindo a flutuação da distância entre carbonos opostos e estabilizando a cavidade. Os oxigênios fenólicos e carbonílicos somente são influenciados pelo comportamento do íon e pela ação das moléculas de acetonitrila próximas à cavidade hidrofilica. Logo no início da simulação observamos que a distância entre os oxigênios carbonílicos aumenta devido ao deslocamento do íon que ocorre pela influência das moléculas do solvente. A saída da molécula de acetonitrila 
que coordena o íon lateralmente, acarreta numa reorganização da cavidade, diminuindo a distância entre os oxigênios fenólicos, que voltam a se distanciar depois que outra molécula de acetonitrila passa a interagir, novamente, com o íon pela lateral da cavidade.

Esses resultados, juntamente com os obtidos na seção 5.3, nos permitem concluir que a complexação de uma molécula de acetonitrila pelo calixareno CLE somente é possível devido às alterações conformacionais na cavidade hidrofóbica (mudança da conformação retangular para a quadrada) ocasionadas pela entrada de um íon na cavidade hidrofílica, caracterizando o efeito alostérico disparado pelo íon. Entretanto, a entrada da molécula de acetonitrila na cavidade hidrofóbica é importante pois é energeticamente favorável, estabiliza a cavidade hidrofóbica e, consequentemente, o complexo todo. Além disso, vemos que a ação das moléculas de solvente fora do complexo influencia o comportamento da cavidade hidrofílica, interagindo com o íon sem, no entanto, tirá-lo do complexo, o que mostra que em solução o complexo CLE-Pb ${ }^{2+}$ é estável.

\section{5 - Simulações do complexo tetraethylester p-tert-butyl calix[4]arene $-\mathrm{Cd}^{2+} \mathrm{em}$ acetonitrila}

Construímos uma caixa cúbica de aproximadamente $45 \AA$ de lado, contendo 865 moléculas de acetonitrila, uma molécula do complexo CLE-Cd ${ }^{2+}$ na conformação obtida ao final da simulação do complexo no vácuo e dois íons $\mathrm{Cl}^{-}$para neutralizar a caixa. Os contra-íons de cloro foram posicionados nos vértices da caixa e fixados nessa posição para evitar que interagissem com o complexo posicionado no 
centro. Nessa caixa realizamos simulações seguindo o protocolo definido na seção 5.2 e a conformação final do sistema obtida é mostrada na Figura 23.

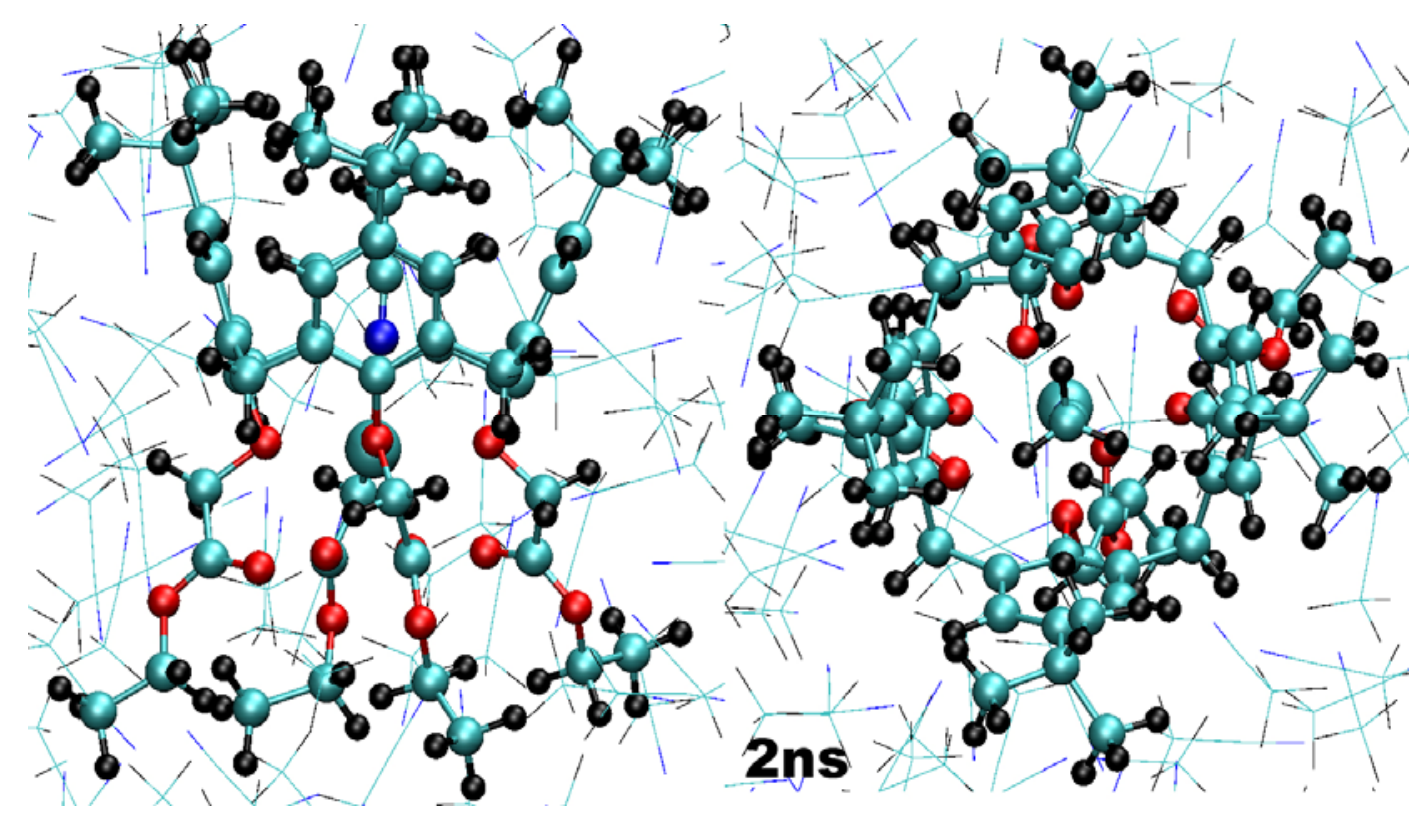

Figura 23 - Configuração final do sistema depois de 2 ns de simulação. Vista lateral e superior do calixareno onde observamos a presença de uma molécula de acetonitrila na cavidade hidrofóbica e o ion $\mathrm{Cd}^{2+}$ na cavidade hidrofilica.

Como a configuração inicial foi construída com a saída da simulação do CLE$\mathrm{Cd}^{2+}$ no vácuo, o complexo estava na conformação quadrada e, portanto, com a cavidade hidrofóbica aberta. Durante a simulação de 500 ps onde o complexo é "congelado" para que o solvente se adapte à presença do soluto, foi observada a entrada de uma molécula de acetonitrila na cavidade hidrofóbica com o átomo de nitrogênio apontando para o íon. Essa molécula se manteve estável até o fim da simulação. Na simulação de 2 ns, onde não foi aplicado freezing à molécula alguma da caixa, a acetonitrila se manteve na cavidade hidrofóbica até o fim da simulação, como podemos observar no Gráfico 40. O íon de cádmio também se manteve estável na cavidade hidrofílica até o fim da simulação, coordenando os oito oxigênios fenólicos e carbonílicos da cavidade hidrofílica e o átomo de nitrogênio da molécula 
de solvente complexada. $\mathrm{O}$ fato da molécula de acetonitrila ter sido complexada da maneira observada também é constatado experimentalmente a partir de resultados de difração de raios-X [12]. Essa concordância entre resultados teóricos e experimentais mostra que o sistema está bem modelado, pois tal comportamento não era observado com outros modelos para o cádmio utilizados anteriormente ao desenvolvimento de nossos próprios modelos. Mostra também que o comportamento observado no estado sólido para o complexo CLE-Cd ${ }^{2+}$ também é observado em solução.

Para melhor entender a formação do complexo, monitoramos as interações não-ligadas entre a molécula de acetonitrila complexada com o íon de cádmio e com a cavidade hidrofóbica. Os resultados obtidos não mostrados nos Gráficos 41 e 42 .

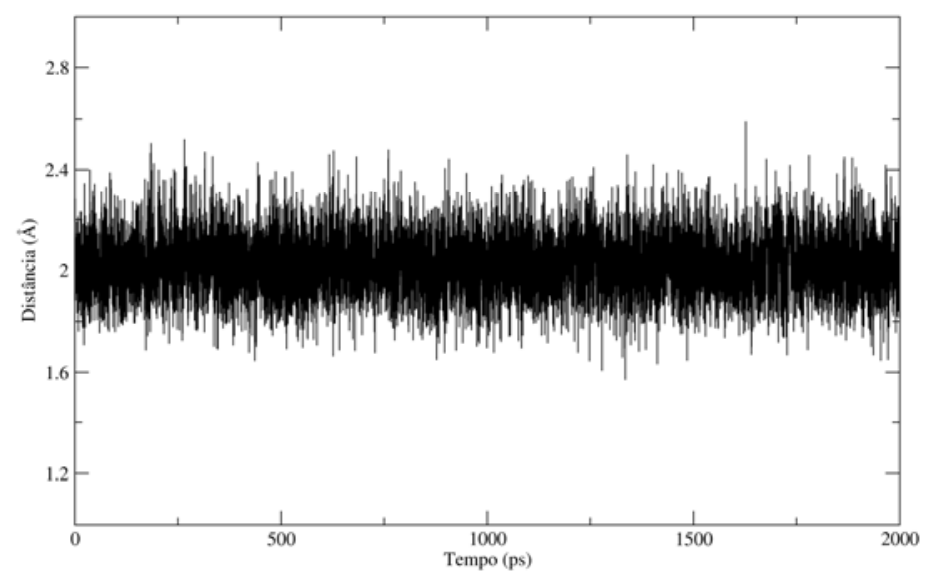

Gráfico 40 - Distância entre a acetonitrila complexada e o fundo da cavidade hidrofóbica. 


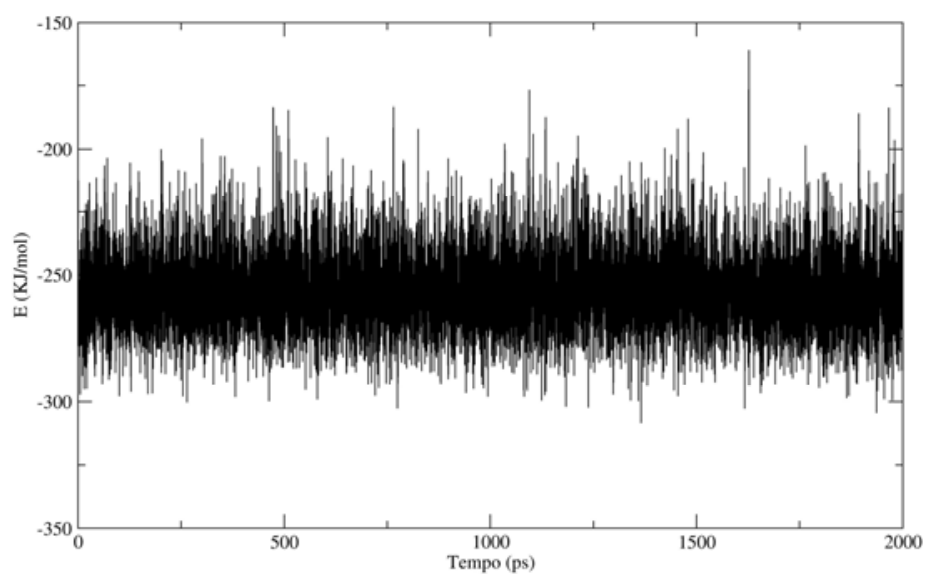

Gráfico 41 - Energia de interação não-ligada (Coulomb e Lennard-Jones) entre a molécula de acetonitrila e o ion $\mathrm{Cd}^{2+}$.

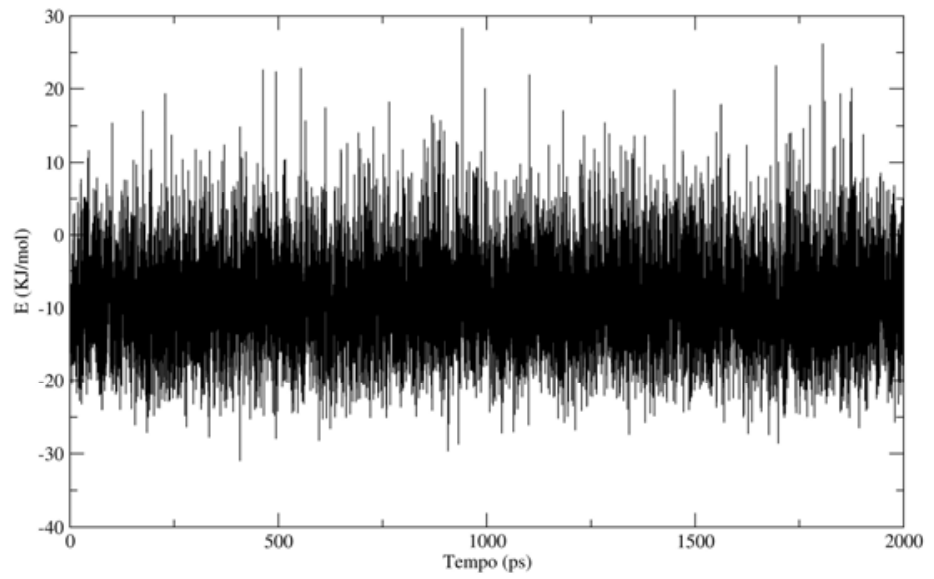

Gráfico 42 - Energia de interação não-ligada (Coulomb e Lennard-Jones) entre a molécula de acetonitrila e o a cavidade hidrofóbica.

A interação entre a acetonitrila e o íon se mantém em torno de $-250 \mathrm{~kJ} / \mathrm{mol}$, mostrando que essa interação é altamente atrativa. A interação entre a acetonitrila e a cavidade hidrofóbica fica em torno de $-10 \mathrm{~kJ} / \mathrm{mol}$ que, apesar de atrativa, apresenta um valor baixo, sendo menos intensa de que no caso observado do complexo CLE$\mathrm{Pb}^{2+}$ onde a acetonitrila é complexada com o grupo metila apontando para o íon de chumbo. Esses resultados mostram que a entrada da acetonitrila conforme observado estabiliza o complexo, pois desloca o íon de cádmio para longe das moléculas de 
acetonitrila posicionadas na região inferior da cavidade hidrofílica, que no caso do íon de chumbo ocasionam uma pequena desestabilização.

Monitoramos também a interação entre o íon $\mathrm{Cd}^{2+}$ e a cavidade hidrofílica. $\mathrm{O}$ resultado obtido é mostrado no Gráfico 43.

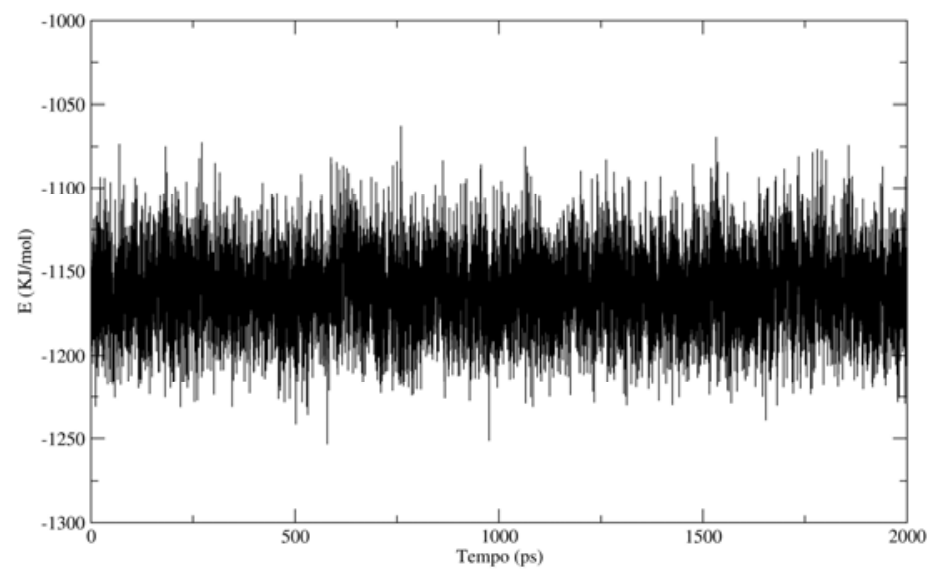

Gráfico 43 - Energia de interação não-ligada (Coulomb e Lennard-Jones) entre o ion $\mathrm{Cd}^{2+}$ e a cavidade hidrofilica.

A energia de interação se mantém em torno de $-1150 \mathrm{~kJ} / \mathrm{mol}$ durante toda a simulação, o que significa que o íon de cádmio é estável dentro da cavidade hidrofílica. Comparando com os resultados apresentados pelas simulações do complexo CLE- $\mathrm{Pb}^{2+}$, vemos que a energia de interação íon-cavidade hidrofílica no caso do cádmio é aproximadamente $150 \mathrm{~kJ} / \mathrm{mol}$ mais negativa que no caso do chumbo, o que pode ser considerado uma diferença substancial, mostrando que o íon $\mathrm{Cd}^{2+}$ é mais estável na cavidade hidrofílica que o chumbo. Isso se deve à presença da molécula de solvente na cavidade hidrofóbica com o átomo de nitrogênio coordenando o íon, mantendo-o completamente inserido na cavidade e evitando interações com moléculas de acetonitrila não-complexadas. Comprovamos isso pelo Gráfico 43, onde não observamos diminuição na energia de interação íon-cavidade 
pela ação das moléculas de solvente, como acontece no caso do complexo CLE-Pb ${ }^{2+}$, e pela Figura 23 que mostra a conformação final do sistema com o íon $\mathrm{Cd}^{2+}$ no fundo da cavidade hidrofílica sem a presença de moléculas de acetonitrila não-complexadas interagindo diretamente com o íon.

Para analisarmos as alterações conformacionais do calixareno causadas pela complexação do íon e da molécula de solvente, medimos as distâncias entre átomos opostos das duas cavidades do calixareno. Os resultados obtidos são mostrados nos Gráficos 44, 45 e 46.

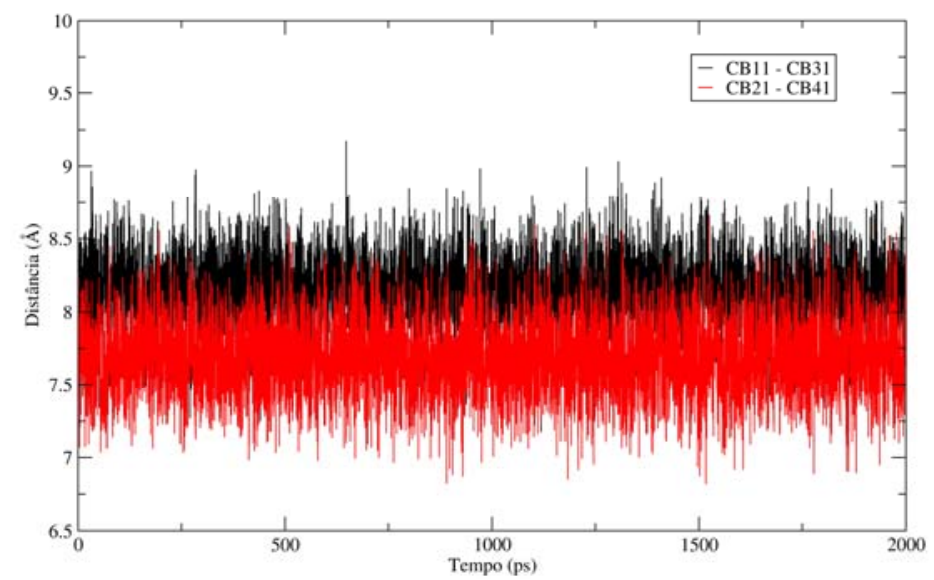

Gráfico 44 - Distância entre carbonos apicais.

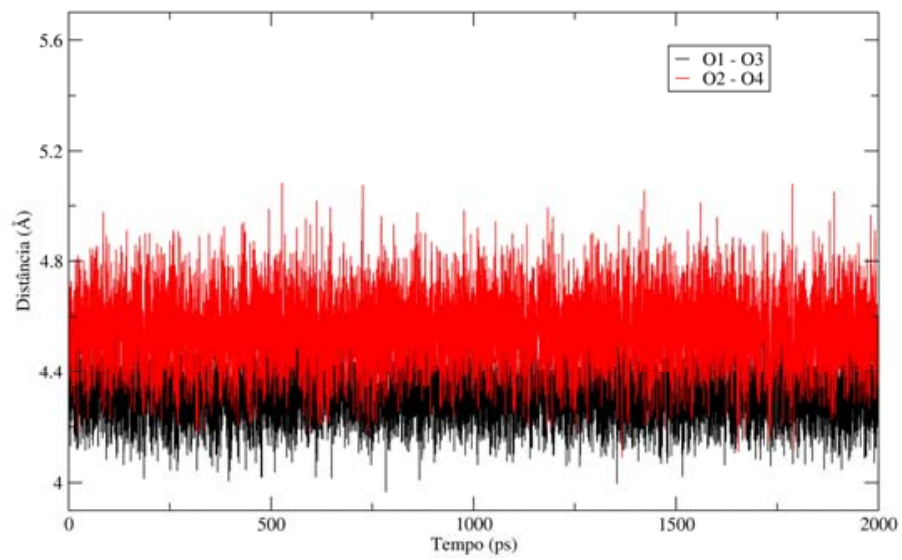

Gráfico 45 - Distância entre oxigênios fenólicos. 


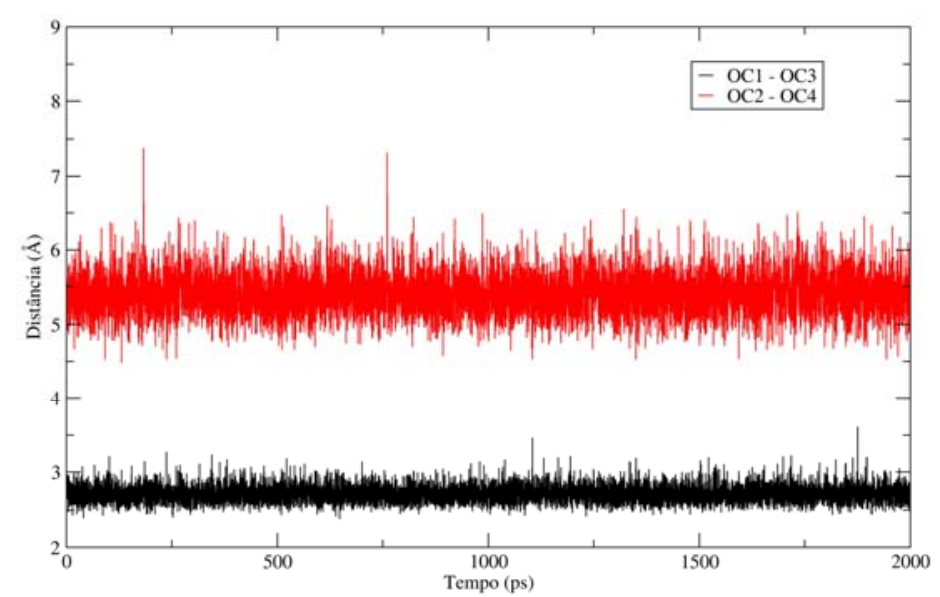

Gráfico 46 - Distância entre oxigênios carbonílicos.

Os gráficos nos mostram que o calixareno assume uma conformação levemente retangular, assim como observado nas simulações do complexo CLE-Cd ${ }^{2+}$ no vácuo, mas sem realizar transições devido à presença da molécula de acetonitrila complexada na cavidade hidrofóbica. Isso acontece porque a distância de equilíbrio Cd-O não permite, por impedimentos estéricos, que os quatro oxigênios carbonílicos coordenem o íon à mesma distância, de modo que eles se posicionam em pares opostos ficando um par mais próximo do íon, à distância mínima, e outro par mais afastado como observamos no Gráfico 46. Isso poderia resultar numa perda de estabilidade do complexo, pois com dois oxigênios carbonílicos afastados seria mais fácil a entrada de moléculas de acetonitrila não-complexadas na cavidade hidrofílica para coordenar o íon, podendo desfazer o complexo. Entretanto, a presença da molécula de acetonitrila complexada na cavidade hidrofóbica com o nitrogênio coordenando o íon mantém o $\mathrm{Cd}^{2+}$ afastado da entrada da cavidade, evitando interações diretas com outras moléculas de acetonitrila, estabilizando o complexo.

A partir dos resultados apresentados podemos concluir que o complexo CLE$\mathrm{Cd}^{2+}$ é estável, entretanto, não podemos relevar a presença da acetonitrila como solvente pois a complexação de uma dessas moléculas pela cavidade hidrofóbica 
estabiliza o complexo. Ao contrário do caso do complexo CLE-Pb ${ }^{2+}$, onde a complexação da molécula de acetonitrila é secundária e meramente decorrente da abertura da cavidade hidrofóbica promovida pela presença do íon na cavidade hidrofílica, o complexo CLE-Cd ${ }^{2+}$, segundo nossos resultados, somente é estável devido à acetonitrila complexada. No que concerne ao efeito alostérico, fica claro que a acetonitrila somente entra na cavidade devido à presença do íon na cavidade hidrofílica, o que causa mudanças conformacionais na molécula abrindo a entrada da cavidade hidrofóbica.

\section{6 - Simulações do tetramethylketone p-tert-butyl calix[4]arene não-complexado em acetonitrila}

Foi construída uma caixa cúbica de aproximadamente $43 \AA$ de lado, contendo 868 moléculas de acetonitrila e uma molécula de calixareno na conformação retangular obtida ao final da simulação do CLC isolado no vácuo. Nessa caixa realizamos simulações seguindo o protocolo definido na seção 5.2 e a conformação final do sistema obtida é mostrada na Figura 24. 


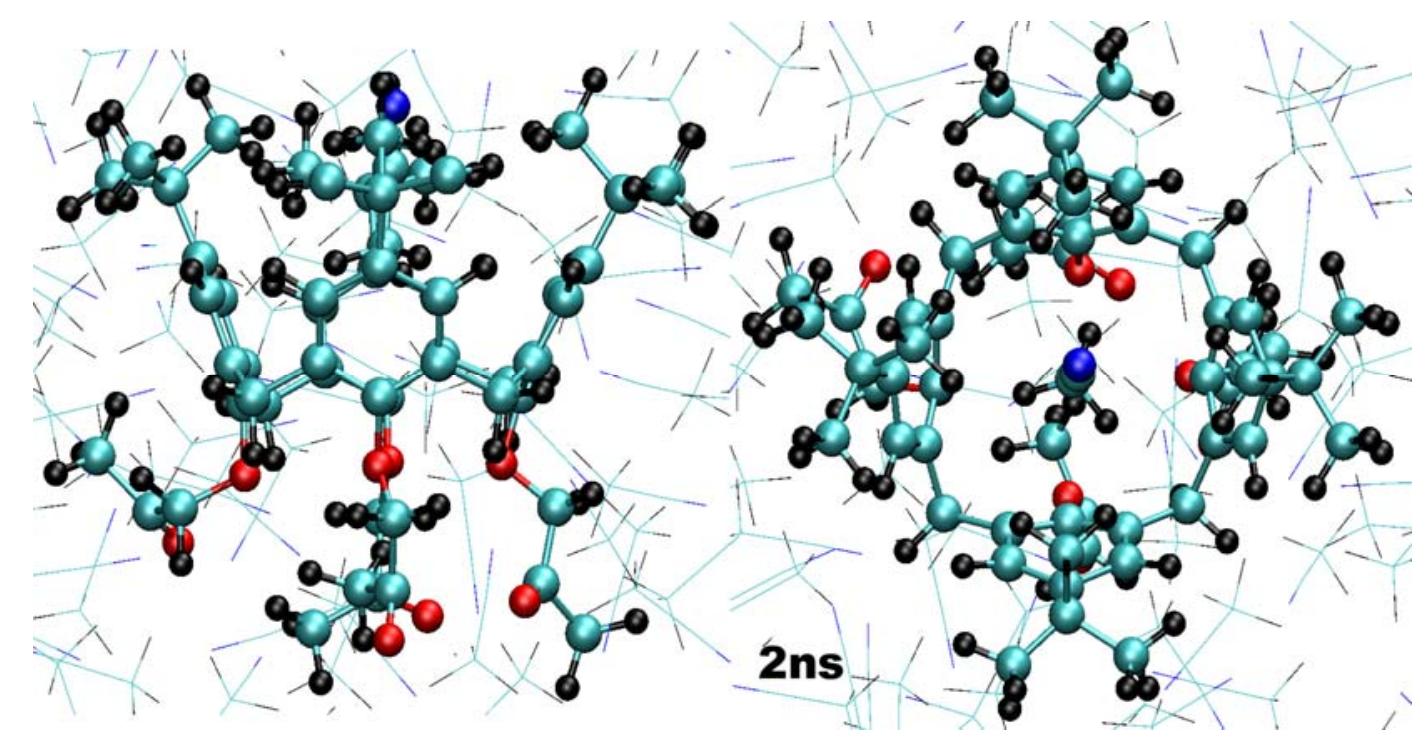

Figura 24 - Configuração final do sistema depois de 2 ns de simulação. Vista lateral e superior do calixareno onde observamos a presença de uma molécula de acetonitrila complexada na cavidade hidrofóbica.

Ao final da simulação observamos uma molécula de acetonitrila complexada na cavidade hidrofóbica com o grupo metila apontando para o fundo da cavidade. A entrada da acetonitrila sem a presença de íons na cavidade hidrofílica é observada experimentalmente em resultados de difração de raios-X obtidos em nosso laboratório e ainda não publicados, mostrando que, assim como no estado sólido, o CLC complexa uma molécula de acetonitrila em solução mesmo sem as alterações conformacionais causadas pela complexação do íon. Monitoramos a distância entre a acetonitrila complexada e o fundo da cavidade hidrofóbica para determinarmos o momento em que acontece a complexação. Medimos também a energia de interação entre a acetonitrila e toda a cavidade hidrofóbica. Esses resultados são mostrados nos Gráficos 47 e 48. 


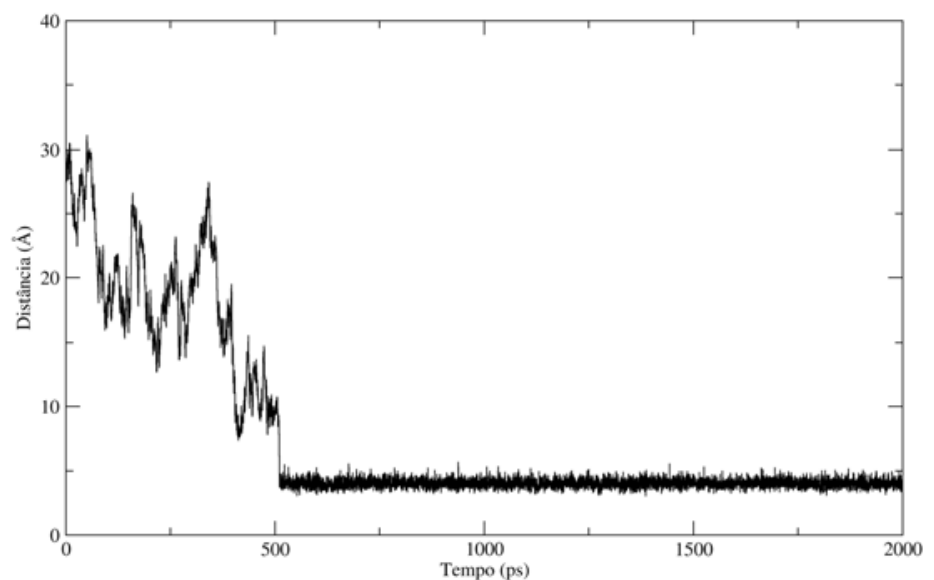

Gráfico 47 - Distância entre o centro de massa da molécula de acetonitrila complexada e o fundo da cavidade hidrofóbica.

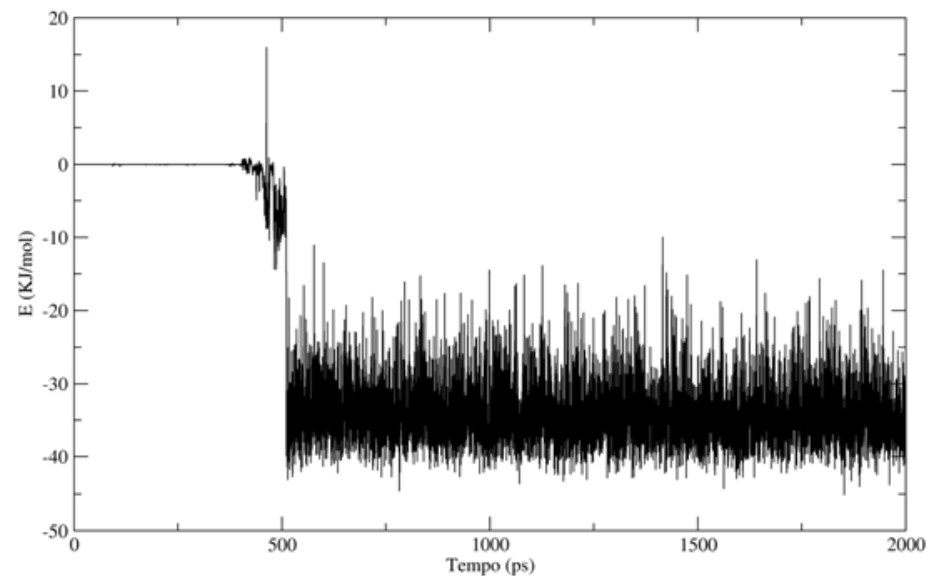

Gráfico 48 - Energia de interação não-ligada (Coulomb e Lennard-Jones) entre a molécula de acetonitrila e a cavidade hidrofóbica.

A molécula de acetonitrila é complexada aproximadamente aos 500 ps de simulação. Observamos também que a energia de interação com a cavidade hidrofóbica fica em torno de $-35 \mathrm{~kJ} / \mathrm{mol}$, um pouco maior que o valor obtido na simulação do complexo CLC-acetonitrila em vácuo, mostrando que a presença de solvente influencia na estabilidade do complexo. Entretanto, esse valor de energia não é grande o suficiente para afirmarmos que o complexo é definitivamente estável. 
Analisamos as mudanças estruturais causadas no calixareno pela complexação da acetonitrila calculando as distâncias entre átomos opostos mostrados nos Gráficos 49,50 e 51.

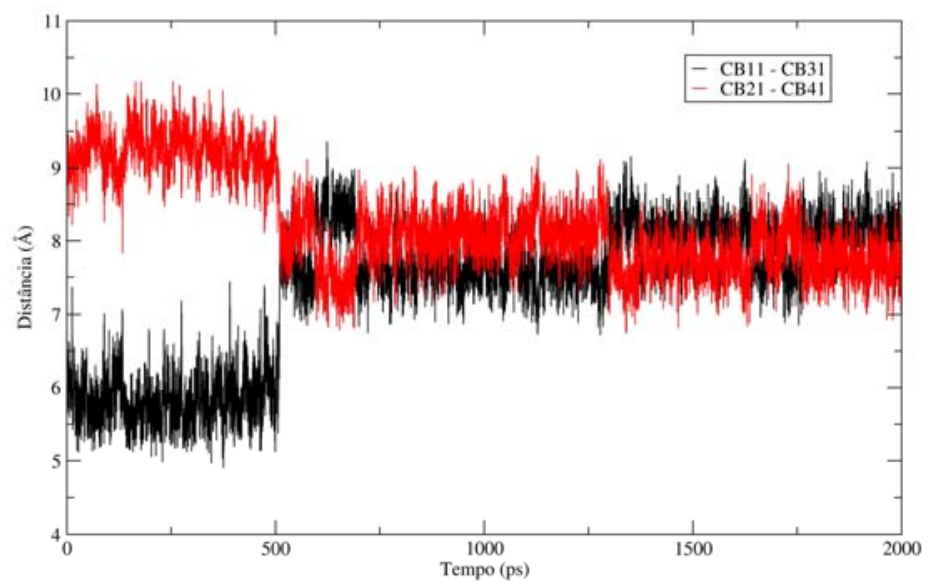

Gráfico 49 - Distância entre carbonos apicais.

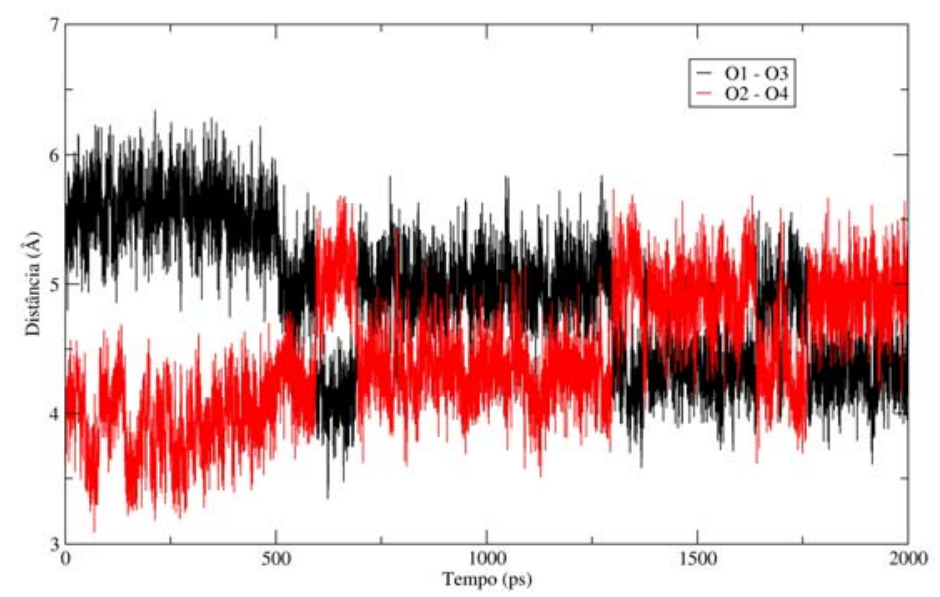

Gráfico 50 - Distância entre oxigênios fenólicos. 


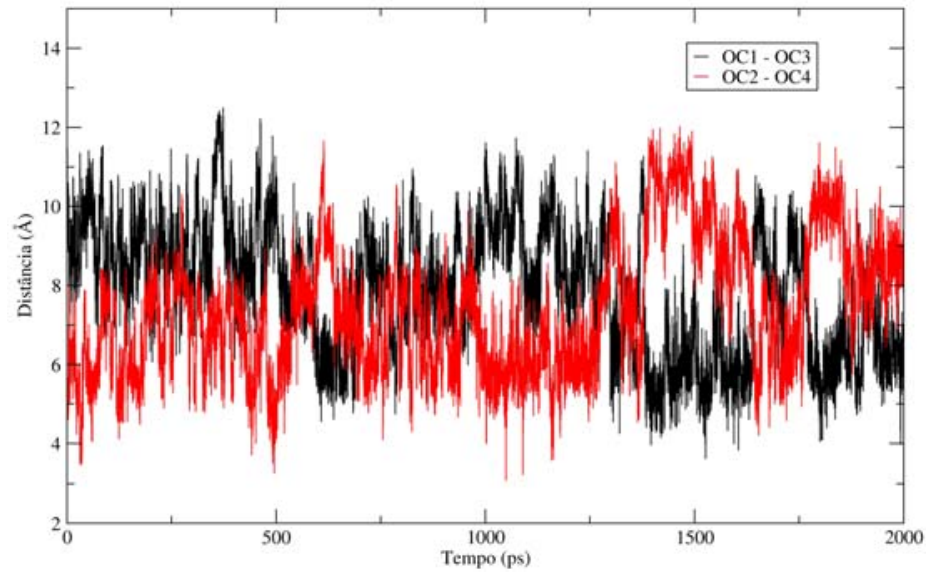

Gráfico 51 - Distância entre oxigênios carbonílicos.

A complexação da acetonitrila altera a conformação da cavidade hidrofóbica diminuindo sua excentricidade, mas não a leva para uma conformação perfeitamente quadrada. As distâncias entre os carbonos apicais e entre os oxigênios fenólicos vão para valores próximos e ficam transicionando durante toda a simulação. As distâncias entre os oxigênios carbonílicos não seguem um padrão definido e não alteram seu comportamento com a entrada da acetonitrila na cavidade hidrofóbica.

Isso mostra que a complexação da acetonitrila organiza a cavidade hidrofóbica mas não a cavidade hidrofílica, descaracterizando o possível efeito alostérico disparado pela entrada da acetonitrila. Os resultados indicam que, como já esperado pelas simulações no vácuo, o CLC possui uma estrutura mais flexível que o CLE, possibilitando a complexação de uma molécula de acetonitrila pela cavidade hidrofóbica mesmo na ausência de íons, sem no entanto influenciar o comportamento da cavidade hidrofílica. 


\section{7 - Simulações do complexo tetramethylketone p-tert-butyl calix[4]arene $-\mathrm{Pb}^{2+}$ em acetonitrila}

Foi construída uma caixa cúbica de aproximadamente $45 \AA$ de lado, contendo

864 moléculas de acetonitrila, uma molécula do complexo CLC-Pb ${ }^{2+}$ na conformação obtida ao final da simulação do complexo no vácuo e dois íons $\mathrm{Cl}^{-}$para neutralizar a caixa. Os contra-íons de cloro foram posicionados nos vértices da caixa e fixados nessa posição para evitar que interagissem com o complexo posicionado no centro. Nessa caixa realizamos simulações seguindo o protocolo definido na seção 5.2 e a conformação final do sistema obtida é mostrada na Figura 25.

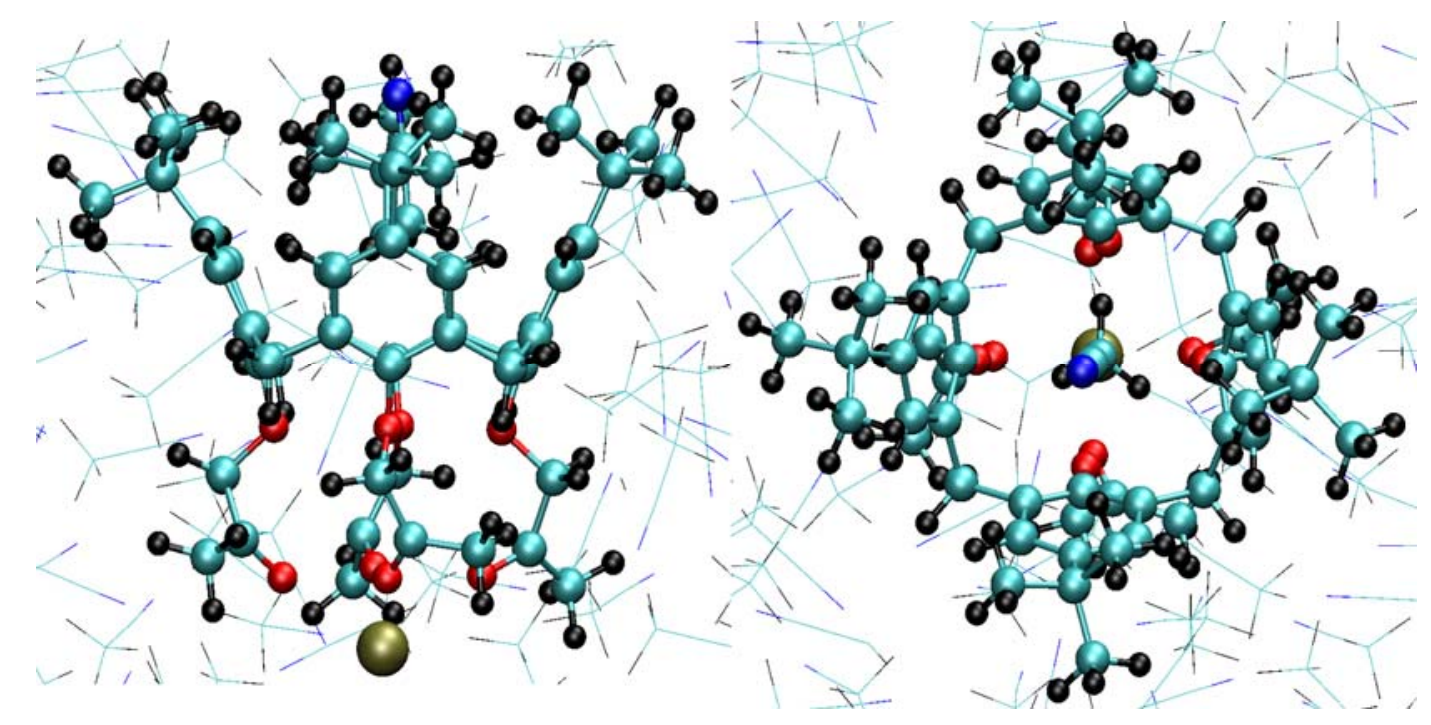

Figura 25 - Configuração final do sistema depois de 2 ns de simulação. Vista lateral e superior do calixareno onde observamos a presença de uma molécula de acetonitrila complexada na cavidade hidrofóbica e o íon $\mathrm{Pb}^{2+}$ na borda da cavidade hidrofilica.

Na conformação inicial tomada da simulação no vácuo o calixareno está na conformação quadrada, o íon $\mathrm{Pb}^{2+}$ completamente inserido na cavidade hidrofílica coordenando os oito oxigênios fenólicos e carbonílicos e a cavidade hidrofóbica 
vazia. Vemos que ao fim dos 2 ns de simulações o íon sai do interior para a borda da cavidade hidrofílica, deixando de coordenar os quatro oxigênios fenólicos para se coordenar com moléculas de solvente. Uma molécula de acetonitrila entra na cavidade hidrofóbica com o grupo metila apontando para o fundo da cavidade. Esses resultados diferem do observado por difração de raios-X, onde o íon $\mathrm{Pb}^{2+}$ está completamente inserido na cavidade hidrofílica. Entretanto, a maneira como a molécula de acetonitrila é complexada coincide com o observado experimentalmente. Com a finalidade de entendermos essa divergência com os resultados experimentais realizamos análises energéticas e conformacionais do sistema que são mostradas nos Gráficos 52, 53 e 54.

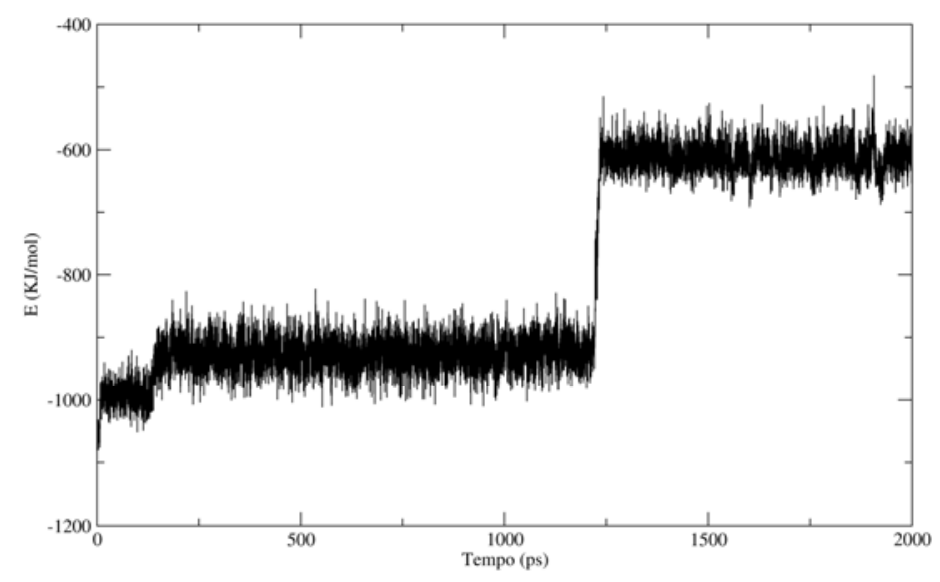

Gráfico 52 - Energia de interação não-ligada (Coulomb e Lennard-Jones) entre o $\mathrm{Pb}^{2+}$ e a cavidade hidrofilica. 


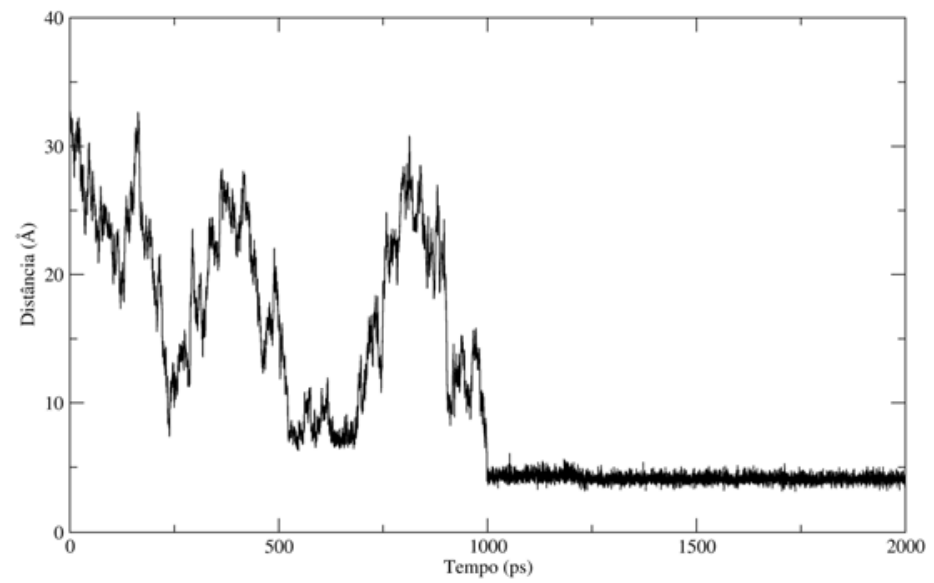

Gráfico 53 - Distância entre o centro de massa da acetonitrila complexada e o fundo da cavidade hidrofóbica.

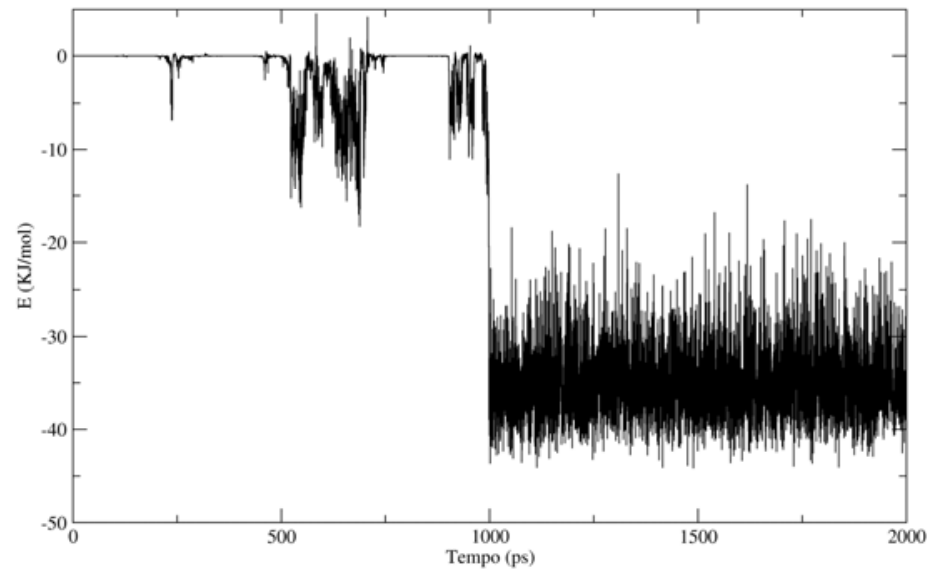

Gráfico 54 - Energia de interação não-ligada (Coulomb e Lennard-Jones) entre a acetonitrila complexada e a cavidade hidrofóbica.

No Gráfico 52 observamos que a energia de interação íon-cavidade hidrofílica, que inicialmente é de aproximadamente $-1000 \mathrm{~kJ} / \mathrm{mol}$, cai para aproximadamente $900 \mathrm{~kJ} / \mathrm{mol}$ em torno de 200 ps e para aproximadamente $-600 \mathrm{~kJ} / \mathrm{mol}$ após 1250 ps de simulação. A configuração do sistema ao final da simulação de 500 ps, onde o complexo calixareno-íon é mantido "congelado", mostra uma molécula de acetonitrila na parte inferior da cavidade hidrofílica com o átomo de nitrogênio apontando para o íon. No decorrer da simulação de 2 ns observamos que essa molécula de acetonitrila desloca as metilas dos grupos pendantes, abrindo a cavidade 
hidrofílica e coordenando o íon. Isso permite que outras moléculas de solvente se aproximem do íon, de modo que a diminuição de energia observada com 200 ps de simulação é devido à entrada de outra molécula de solvente pela lateral da cavidade, como observado na simulação do complexo $\mathrm{CLE} \mathrm{Pb}^{2+}$. Entretanto, nesse caso, devido à constituição dos grupos pendantes que formam a cavidade hidrofílica, as moléculas de acetonitrila conseguem puxar o íon para fora da cavidade, fazendo com que ele deixe de coordenar os oxigênios fenólicos e se posicione na borda da cavidade coordenando somente os oxigênios carbonílicos. Esse resultado mostra que em solução o íon não se mantém completamente inserido no interior da cavidade como observado experimentalmente no estado sólido, o que nos leva a concluir que o complexo CLC-Pb ${ }^{2+}$ é menos estável que o complexo CLE-Pb ${ }^{2+}$. Apesar de o íon interagir somente com os oxigênios carbonílicos do calixareno, essa interação é forte o suficiente para manter o íon complexado, evitando que o complexo seja desfeito.

O Gráfico 53 nos mostra a distância entre a acetonitrila complexada e o fundo da cavidade hidrofóbica. A acetonitrila complexa-se com o calixareno em torno de 1000 ps de simulação. Um detalhe importante é que a entrada da acetonitrila na cavidade hidrofóbica não está ligada à saída do íon da cavidade hidrofílica, que acontece exclusivamente devido à ação das moléculas de acetonitrila nãocomplexadas. No Gráfico 54 observamos que a energia de interação entre a acetonitrila complexada e a cavidade hidrofóbica fica em torno de $-35 \mathrm{~kJ} / \mathrm{mol}$ depois da complexação. Como nas simulações anteriores onde observamos a complexação de moléculas de solvente, a energia de interação, apesar de ser atrativa, é muito menor que a energia de interação entre o íon e a cavidade hidrofílica.

Para analisarmos as mudanças conformacionais que ocorrem no calixareno durante a simulação, monitoramos as distâncias entre os átomos opostos das 
cavidades hidrofóbica e hidrofílica. Os resultados são mostrados nos Gráficos 55, 56 e 57.

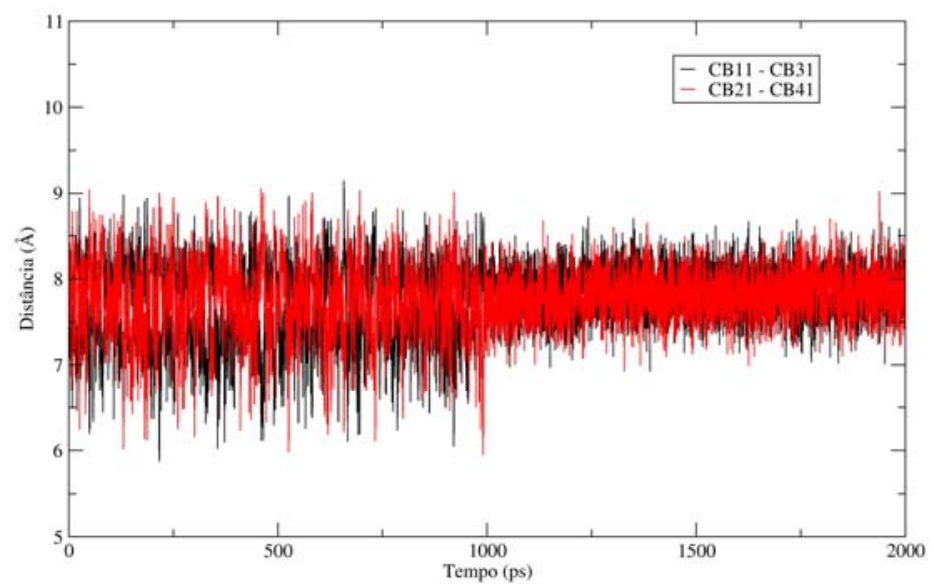

Gráfico 55 - Distância entre carbonos apicais.

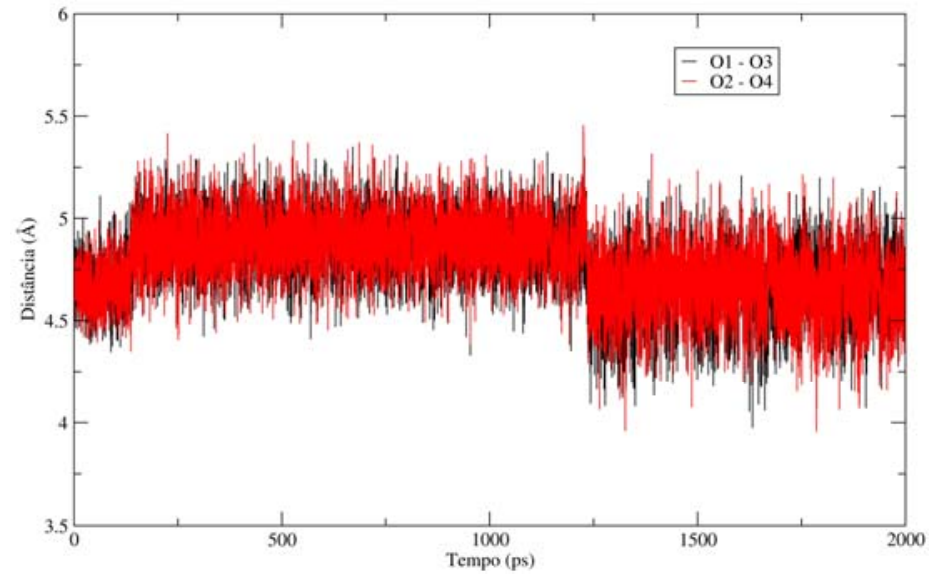

Gráfico 56 - Distância entre oxigênios fenólicos. 


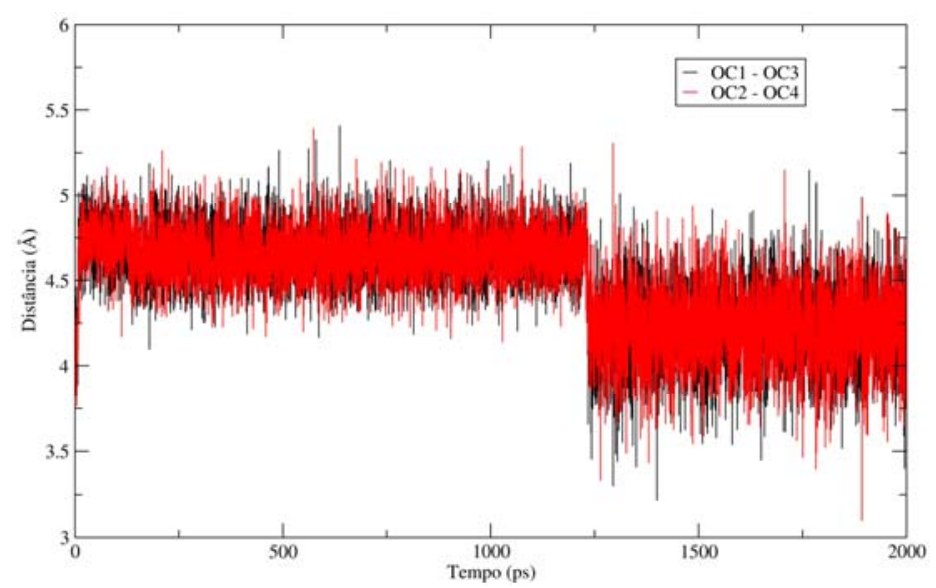

Gráfico 57 - Distância entre oxigênios carbonílicos.

Observamos pelo Gráfico 55 que a cavidade hidrofóbica somente é influenciada pela entrada da molécula de acetonitrila, não alterando seu comportamento devido ao deslocamento do íon para fora da cavidade hidrofílica. A complexação da molécula de solvente estabiliza a cavidade, fato evidenciado pela diminuição da flutuação das distâncias entre os carbonos apicais. O comportamento dos oxigênios fenólicos e carbonílicos é observado nos Gráficos 56 e 57. Vemos que à medida que o íon é deslocado para fora da cavidade pelas moléculas de solvente, as distâncias entre os oxigênios são alteradas em torno de $0.5 \AA$, sempre mantendo distâncias iguais entre átomos opostos e portanto a conformação quadrada. Isso acontece porque a molécula de acetonitrila complexada na cavidade hidrofóbica mantém os carbonos apicais opostos a distâncias iguais, influenciando indiretamente nas distâncias entre os oxigênios fenólicos, mantendo-os na conformação quadrada mesmo depois da saída do íon da cavidade hidrofílica.

Os resultados apresentados nos mostram que o complexo CLC- $\mathrm{Pb}^{2+} \mathrm{em}$ solução de acetonitrila não mantém sua conformação observada em vácuo e no estado sólido. A ação das moléculas de solvente e a constituição dos grupos pendantes do calixareno, que permitem uma interação mais próxima solvente-íon, 
resulta na saída do íon do interior para a borda cavidade hidrofílica, deixando de coordenar os oxigênios fenólicos. Entretanto, o complexo não é desfeito pois observamos que, apesar de estar na borda da cavidade, o íon se manteve ligado ao calixareno com uma energia de interação relativamente alta $(-600 \mathrm{~kJ} / \mathrm{mol})$ até o final da simulação.

\section{8 - Simulações do complexo tetramethylketone p-tert-butyl calix[4]arene $-\mathrm{Cd}^{2+}$ em acetonitrila}

Construímos uma caixa cúbica de aproximadamente $45 \AA$ de lado, contendo 867 moléculas de acetonitrila, uma molécula do complexo CLC-Cd ${ }^{2+}$ na conformação obtida ao final da simulação do complexo no vácuo e dois íons $\mathrm{Cl}^{-}$para neutralizar a caixa. Os contra-íons de cloro foram posicionados nos vértices da caixa e fixados nessa posição para evitar que interagissem com o complexo posicionado no centro. Nessa caixa realizamos simulações seguindo o protocolo definido na seção 5.2 e a conformação final do sistema obtida é mostrada na Figura 26. 


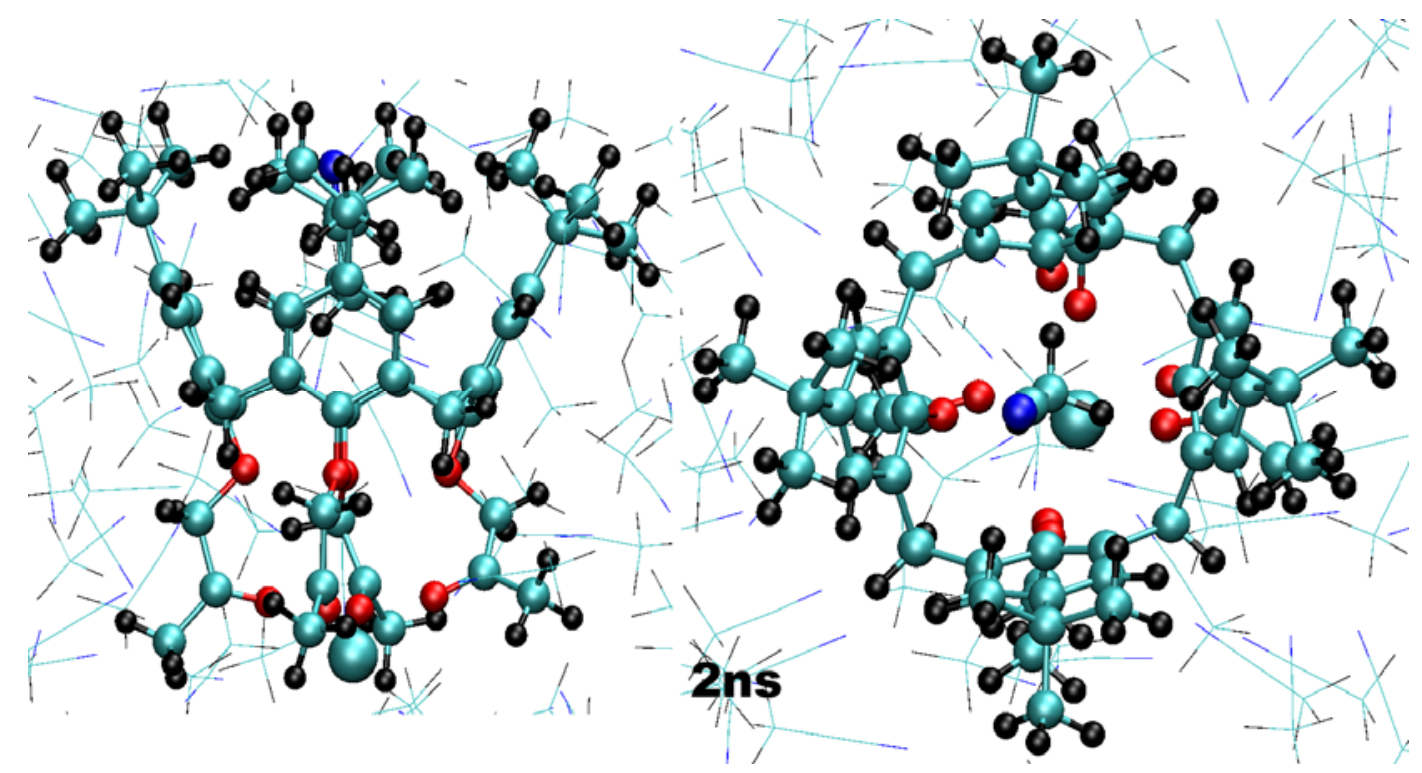

Figura 26 - Configuração final do sistema depois de 2 ns de simulação. Vista lateral e superior do calixareno onde observamos a presença de uma molécula de acetonitrila complexada na cavidade hidrofóbica e o ion $\mathrm{Cd}^{2+}$ na borda da cavidade hidrofilica.

A configuração final do sistema nos mostra o calixareno complexado com uma molécula de acetonitrila na cavidade hidrofóbica e o íon $\mathrm{Cd}^{2+}$ posicionado na borda da cavidade hidrofílica, coordenando os oxigênios carbonílicos e moléculas de acetonitrila do solvente. Na configuração inicial, obtida da simulação de 500 ps onde aplicamos freezing ao complexo CLC-Cd ${ }^{2+}$, observamos que uma molécula de acetonitrila se posiciona na abertura inferior da cavidade hidrofóbica com o átomo de nitrogênio apontando para o íon. Quando iniciamos a simulação de 2 ns, a molécula de acetonitrila desloca as metilas dos grupos pendantes e coordena o íon, puxando-o para a borda da cavidade com poucos passos de simulação. Com a saída do íon da cavidade hidrofílica e sem nenhuma molécula de acetonitrila complexada na cavidade hidrofóbica, o calixareno toma a conformação retangular de modo que um dos oxigênios carbonílicos (OC3) se afasta do íon, que passa a coordenar somente três oxigênios da cavidade hidrofílica. Após 950 ps de simulação, observamos a entrada de uma molécula de acetonitrila na cavidade hidrofóbica com o grupo $\mathrm{CH}_{3}$ 
apontando para o fundo da cavidade. A complexação dessa molécula de solvente leva o calixareno para uma conformação quase quadrada, reestruturando todo o calixareno e reaproximando do íon o oxigênio OC3 que havia saído de sua esfera de coordenação. Isso estabiliza o complexo, que se mantém inalterado até o fim da simulação.

Para visualizarmos melhor o que acontece nessa simulação, realizamos monitorações conformacionais e energéticas do sistema. Nos Gráficos 58, 59 e 60 observamos análises realizadas sobre a acetonitrila complexada e o íon $\mathrm{Cd}^{2+}$.

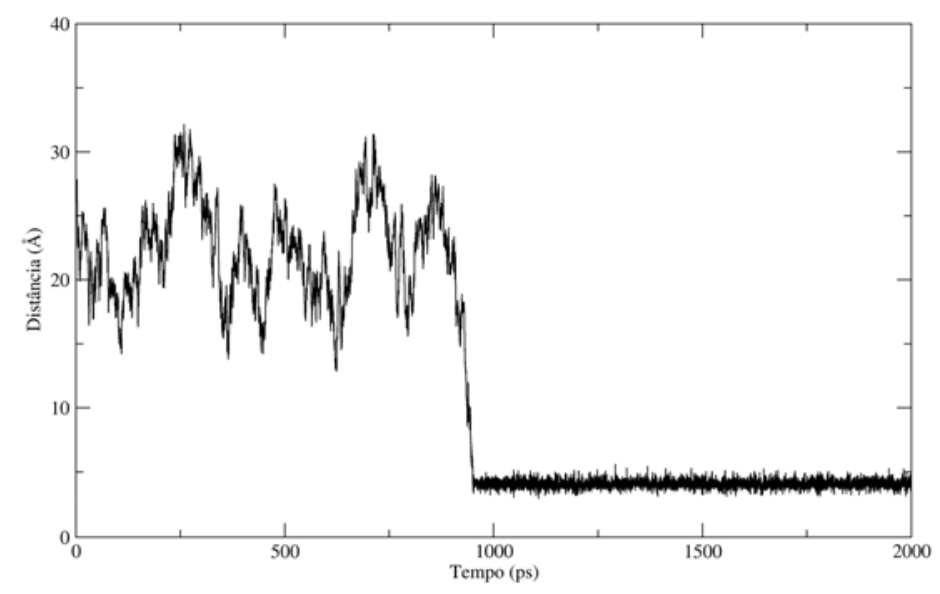

Gráfico 58 - Distância entre o centro de massa da acetonitrila complexada e o fundo da cavidade hidrofóbica.

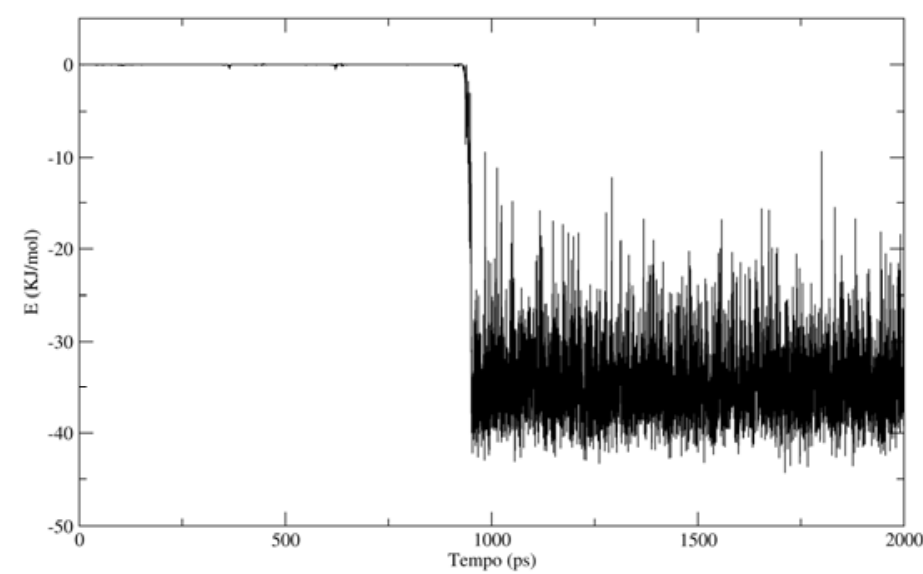

Gráfico 59 - Energia de interação não-ligada (Coulomb e Lennard-Jones) entre a acetonitrila complexada e a cavidade hidrofóbica. 


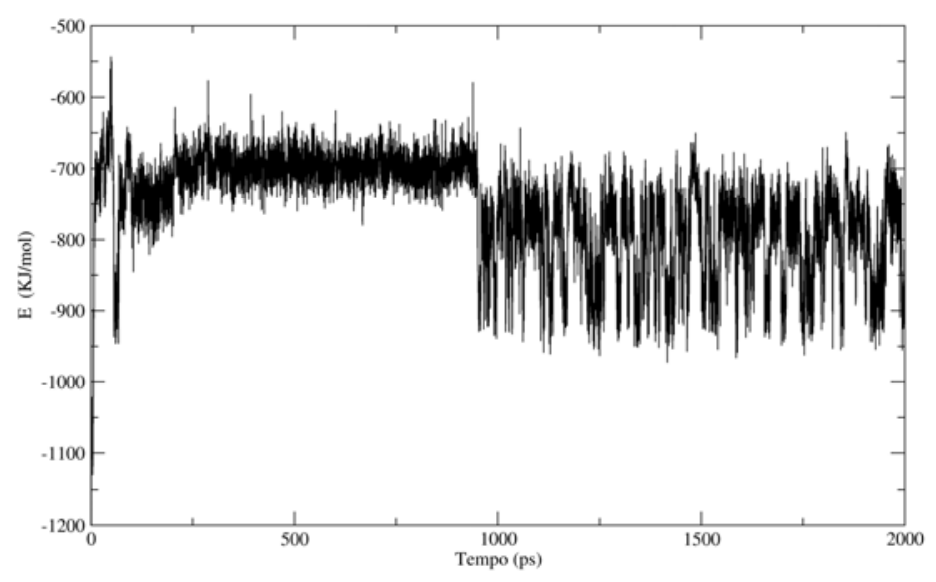

Gráfico 60 - Energia de interação não-ligada (Coulomb e Lennard-Jones) entre o $\mathrm{Cd}^{2+}$ e a cavidade hidrofilica.

Observamos que uma molécula de acetonitrila se complexa à cavidade hidrofóbica em torno de 950 ps de simulação. O Gráfico 59 mostra que a energia de interação acetonitrila-cavidade fica em torno de $-35 \mathrm{~kJ} / \mathrm{mol}$, o mesmo valor observado na simulação do complexo CLC-Pb ${ }^{2+}$. Apesar de essa interação ser fraca, comparada com a observada entre o íon e a cavidade hidrofílica, ela estabiliza o complexo todo como podemos ver pelo Gráfico 60. A energia de interação íoncavidade hidrofílica que inicialmente fica em torno de $-1100 \mathrm{~kJ} / \mathrm{mol}$, sobe para aproximadamente $-700 \mathrm{~kJ} / \mathrm{mol}$ logo no início da simulação devido ao deslocamento do íon do interior para a borda da cavidade, coordenando somente três dos quatro oxigênios carbonílicos. Após a complexação da molécula da acetonitrila observamos que uma diminuição na energia de interação íon-cavidade para um valor próximo de $-850 \mathrm{~kJ} / \mathrm{mol}$, evidenciando o retorno do oxigênio OC3 à esfera de coordenação do íon. Dos 950 ps até o fim da simulação, a energia de interação íon-cavidade flutua entre os valores de -950 e $-700 \mathrm{~kJ} / \mathrm{mol}$, evidenciando transições conformacionais que 
acontecem nos oxigênios carbonílicos que podemos observar nos perfis de distância entre os átomos opostos mostrados nos Gráficos 61, 62 e 63.

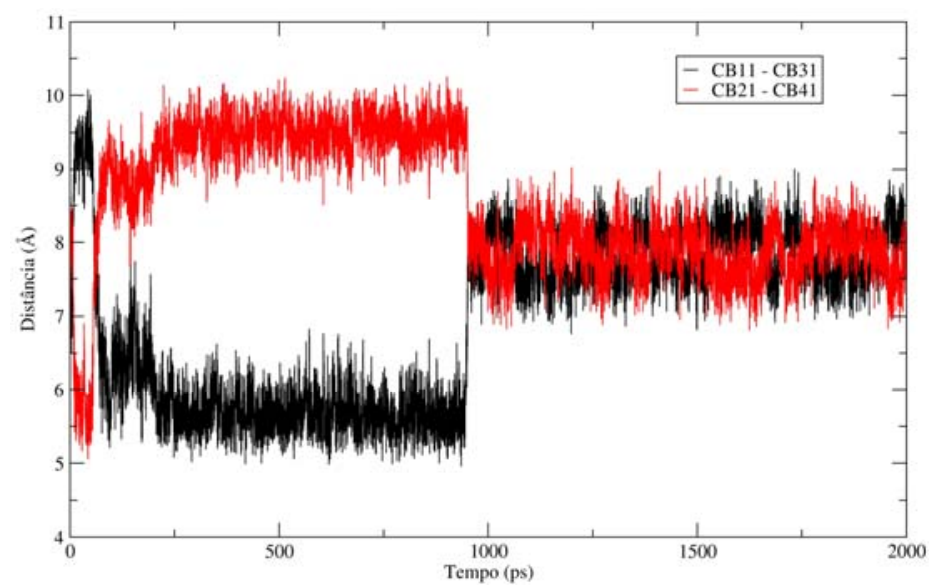

Gráfico 61 - Distância entre os carbonos apicais.

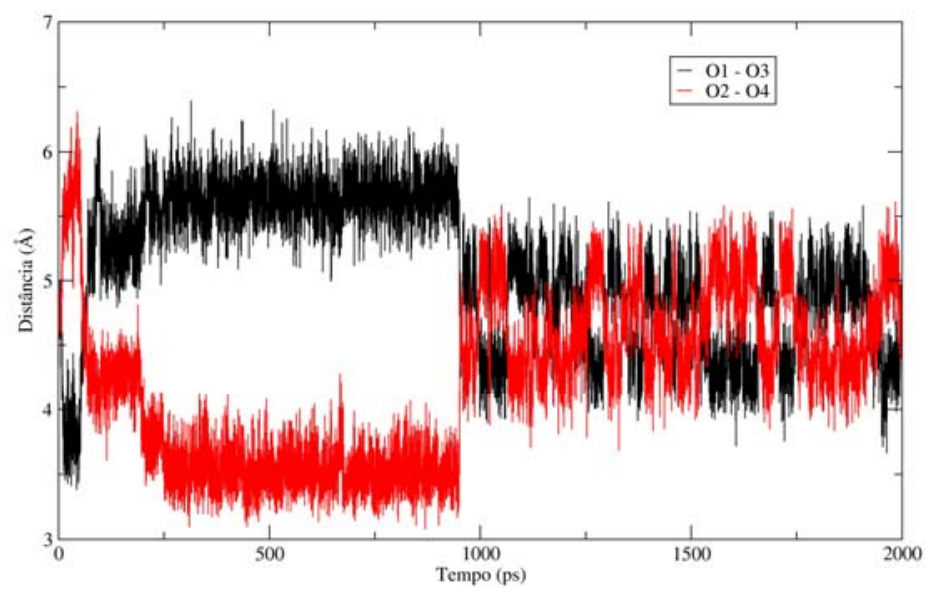

Gráfico 62 - Distância entre oxigênios fenólicos. 


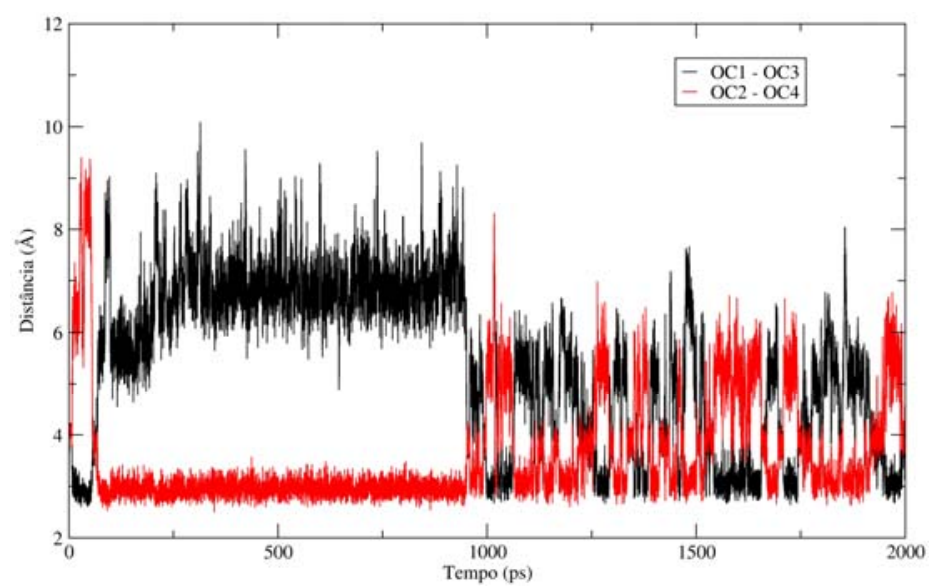

Gráfico 63 - Distância entre oxigênios carbonílicos.

Os carbonos apicais, que inicialmente apresentam as mesmas distâncias devido à conformação quadrada do calixareno, assumem um posicionamento característico da conformação retangular para a qual vai o calixareno com a saída do íon da cavidade hidrofílica. Com a complexação da molécula de acetonitrila, observamos que a cavidade hidrofóbica assume uma conformação quase quadrada, com os carbonos apicais realizando transições conformacionais. Os oxigênios fenólicos apresentam um comportamento parecido com o dos carbonos apicais. No Gráfico 63 observamos o comportamento dos oxigênios carbonílicos, onde é evidenciada a saída do OC3 da esfera de coordenação do íon pelo aumento da distância entre os oxigênios $\mathrm{OC} 1$ e OC3. As alterações conformacionais ocasionadas pela complexação da acetonitrila na cavidade hidrofóbica fazem com que o OC3 se reaproxime do íon, coordenando-o e ocasionando o aumento na energia de interação entre o íon e a cavidade hidrofílica observado no Gráfico 60. Os oxigênios carbonílicos executam transições entre 3 e $5 \AA$, fazendo a energia de interação íon-cavidade também flutuar como mostrado no Gráfico 60.

Os resultados apresentados mostram que o complexo CLC-Cd ${ }^{2+}$ depende da entrada da molécula de acetonitrila na cavidade hidrofóbica para obter uma 
estabilidade razoável. É possível que na ausência da molécula de solvente complexada o íon seria retirado da cavidade hidrofílica, desfazendo o complexo. O CLC-Cd ${ }^{2+}$ mostra a maior dependência com o solvente acetonitrila entre todos os complexos estudados, entretanto, não podemos afirmar que a complexação da molécula de acetonitrila é responsável por um efeito alostérico que favoreça a complexação do íon de cádmio, pois a simulação do CLC em acetonitrila sem a presença de íons evidenciou a total independência conformacional da cavidade hidrofílica com relação às alterações na cavidade hidrofóbica provocadas pela complexação da acetonitrila. Outro detalhe importante é que nas simulações do complexo CLC-Cd ${ }^{2+}$ a acetonitrila entra na cavidade hidrofóbica de maneira diferente da observada no estado sólido, onde o átomo de nitrogênio aponta para o íon de cádmio o que torna o complexo mais estável, pois faz com que o íon se posicione completamente inserido na cavidade hidrofílica. É possível que isso também aconteça em solução, como observado em nossas simulações do complexo $\mathrm{CLE} \mathrm{Cd}^{2+}$ em acetonitrila. Entretanto, o tempo de simulação pode não ter sido suficiente para observarmos esse acontecimento.

\section{9 - Conclusões}

Nas simulações dos calixarenos e complexos em solução de acetonitrila observamos comportamentos diferentes entre os dois calixarenos estudados. O CLE não-complexado em solução apresenta um comportamento já esperado, onde não se observa a entrada de moléculas de acetonitrila na cavidade hidrofóbica devido à rígida estrutura conferida ao calixareno pelos grupos éster que compõem a cavidade hidrofílica. O complexo $\mathrm{CLE}-\mathrm{Pb}^{2+}$ se mantém estável em solução de acetonitrila, 
assumindo a conformação quadrada devido à presença do íon na cavidade hidrofílica o que mantém aberta a entrada da cavidade hidrofóbica, permitindo a complexação de uma molécula de solvente como observado experimentalmente no estado sólido, com o grupo $\mathrm{CH}_{3}$ apontando para o fundo da cavidade. $\mathrm{O}$ efeito alostérico é claramente disparado pela complexação do íon de chumbo pela cavidade hidrofílica. O complexo CLE-Cd ${ }^{2+}$ também se mantém estável em solução. A abertura da cavidade hidrofóbica causada pela presença do íon na cavidade hidrofílica permite a complexação de uma molécula de acetonitrila numa posição em que o átomo de nitrogênio da molécula de solvente coordena o íon de cádmio, mantendo-o completamente inserido na cavidade hidrofílica e estabilizando o complexo. Isso também é observado no estado sólido em resultados de difração de raios-X, evidenciando o efeito alostérico devido à entrada do íon na cavidade hidrofílica.

As simulações envolvendo o calixareno CLC mostraram um comportamento dos complexos calixareno-íon em solução diferente do observado em cristais. $\mathrm{Na}$ simulação do CLC não-complexado em acetonitrila, observamos a entrada de uma molécula de acetonitrila na cavidade hidrofóbica sem a presença de íons na cavidade hidrofílica, o que acontece devido à menor rigidez da estrutura do calixareno ocasionada pela composição e tamanho de seus grupos pendantes formados por quatro oxigênios polares (grupos cetona) e em seguida somente um grupo metila terminal. Experimentalmente também é observado a complexação de uma molécula de acetonitrila na ausência de íons em estado sólido. O comportamento da cavidade hidrofílica no complexo calixareno-acetonitrila é completamente independente da presença da molécula de solvente na cavidade hidrofóbica, mostrando que a préorganização dessa cavidade pela entrada da acetonitrila não ocasiona mudanças conformacionais na cavidade hidrofílica, não influenciando na complexação do íon. 
As simulações do complexo CLC- $\mathrm{Pb}^{2+}$ mostraram que as moléculas de acetonitrila do solvente atuam sobre o íon complexado, puxando-o do interior para a borda da cavidade sem no entanto desfazer o complexo. É observada a complexação de uma molécula de acetonitrila pela cavidade hidrofóbica, o que aumenta a estabilidade do complexo, entretanto, a molécula de solvente complexada não influencia no comportamento da cavidade hidrofílica e nem na complexação do íon. A saída do íon da cavidade hidrofílica é atribuída à composição e tamanho dos grupos pendantes que não conseguem isolar o íon de chumbo da ação das moléculas de solvente, permitindo que ele seja retirado do interior da cavidade, diminuindo a estabilidade do complexo. Na simulação do complexo CLC-Cd ${ }^{2+}$ observamos a saída do íon da cavidade hidrofílica decorrente da ação das moléculas de solvente, causada pelos mesmos motivos que no caso do complexo CLC- $\mathrm{Pb}^{2+}$. Observamos que o íon sai da cavidade e, além de deixar de coordenar os oxigênios fenólicos, também deixa de coordenar um dos oxigênios carbonílicos (OC3), diminuindo muito a estabilidade do complexo. Entretanto, a complexação de uma molécula de acetonitrila pela cavidade hidrofóbica induz alterações conformacionais no calixareno, levando-o para uma conformação quase quadrada, o que resulta numa reaproximação do oxigênio carbonílico OC3 do íon aumentando a estabilidade do complexo. A princípio poderíamos concluir que no caso do complexo $\mathrm{CLC}-\mathrm{Cd}^{2+}$ o efeito alostérico é disparado pela complexação da molécula de solvente, entretanto, as simulações do CLC em acetonitrila sem a presença de íons mostrou que as alterações ocasionada na cavidade hidrofóbica não se refletem no comportamento da cavidade hidrofílica, descaracterizando o possível efeito alostérico. O que podemos afirmar com certeza é que, em solução, a complexação da molécula de acetonitrila estabiliza o complexo CLC-Cd ${ }^{2+}$, provavelmente evitando a completa saída do íon pela ação das moléculas 
de solvente. Não foi observada a complexação da molécula de acetonitrila com o nitrogênio coordenando o íon de cádmio como observado experimentalmente no estado sólido. Provavelmente a complexação da molécula de solvente dessa maneira ocorre também em estado líquido, trazendo o íon de cádmio para o interior da cavidade hidrofílica e estabilizando o complexo, entretanto, isso pode ocorrer em uma escala de tempo não alcançada pelas nossas simulações, não nos permitindo afirmar qualquer coisa sobre esse possível comportamento. 


\section{Capítulo 6 - Conclusões Gerais}

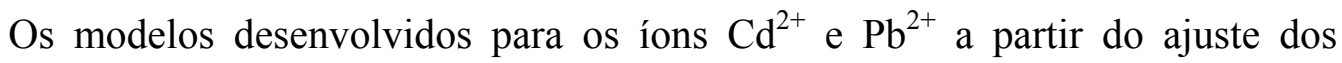
parâmetros de Lennard-Jones de modo a reproduzirem resultados experimentais e QM/MM de propriedades estruturais e termodinâmicas em água TIP3P, também reproduziram muito bem propriedades termodinâmicas, estruturais e dinâmicas para outros modelos de água, evidenciando que os parâmetros são bons e transferíveis. Esses modelos representam uma valiosa contribuição para a área de simulações computacionais, onde parâmetros para metais de transição raramente são desenvolvidos por não serem comuns em sistemas biológicos. Além disso, a metodologia desenvolvida é geral e pode ser empregada no desenvolvimento de parâmetros para outros íons.

As simulações dos calixarenos e complexos no vácuo mostraram que os modelos utilizados reproduzem com fidelidade o comportamento das moléculas reais observado experimentalmente por difração de raios-X por monocristais, o que valida nossos modelos. Essas simulações também serviram como validação adicional aos parâmetros desenvolvidos para os íons, pois as distâncias íon-O nos complexos calixareno-íon mostraram bom acordo com os valores experimentais.

Nas simulações dos calixarenos e complexos solvatados por acetonitrila observamos comportamentos diferentes entre os dois calixarenos estudados. O CLE 
apresenta uma estrutura mais rígida, conferida pela presença dos doze oxigênios na cavidade hidrofílica. As interações entre esses oxigênios e impedimentos estéricos causados pelos quatro grupos funcionais $\left(\mathrm{CH}_{2}-\mathrm{CO}-\mathrm{O}-\mathrm{CH}_{2}-\mathrm{CH}_{3}\right)$ que constituem os grupos pendantes os tornam mais estruturados, eliminando possíveis graus de liberdade conferidos pelas ligações sigma entre os átomos. Essa menor flexibilidade do CLE faz com que a molécula tenha uma maior tendência em se manter na conformação retangular, não permitindo a entrada de moléculas de solvente na cavidade hidrofóbica na ausência de íons. Quando complexado a íons de chumbo e cádmio o CLE assume a conformação quadrada, o que permite a complexação de moléculas de acetonitrila na cavidade hidrofóbica. A estabilidade dos íons na cavidade hidrofílica observada nas simulações também é associada à constituição dos grupos pendantes que proporcionam maior isolamento ao íon, evitando interações diretas que poderiam arrancar o íon da cavidade e desfazer o complexo. O calixareno CLC apresenta uma estrutura mais flexível que o CLE devido a constituição e tamanho de seus grupos pendantes. A presença de apenas oito oxigênios na cavidade hidrofílica acarreta numa diminuição de interações repulsivas, além disso, o menor tamanho dos grupos pendantes $\left(\mathrm{CH}_{2}-\mathrm{CHO}-\mathrm{CH}_{3}\right)$ permite maior movimento dos mesmos quando comparamos com os grupos pendantes do CLE. Isso é evidenciado na simulação do CLC em acetonitrila sem a presença de íons, onde observamos a complexação de uma molécula de solvente na cavidade hidrofóbica forçando o calixareno a passar da conformação retangular à quadrada. A complexação da molécula de solvente, entretanto, organiza somente a cavidade hidrofóbica não influenciando no comportamento da cavidade hidrofílica, o que descarta a possibilidade de um possível efeito alostérico disparado pela complexação da acetonitrila como proposto na referência [12] baseado em resultados experimentais. 
Os complexos CLC-íon se mostraram mais instáveis em solução que os complexos CLE-íon. Novamente, o fator determinante é a constituição dos grupos pendantes do CLC que não consegue isolar o íon no interior da cavidade hidrofílica, permitindo que moléculas de solvente interajam diretamente como o íon movendo-o para a borda da cavidade, o que diminui em muito a energia de interação entre o íon e o CLC.

Sobre o potencial uso dos calixarenos estudados para a despoluição de ambientes contaminados por cádmio e chumbo, podemos concluir que o calixareno CLE seria mais indicado, pois apresenta menor dependência com moléculas de solvente para a estabilização dos complexos com os íons. O calixareno CLC, devido a sua clara dependência com o solvente acetonitrila e a constituição de seus grupos pendantes, provavelmente não formaria complexos estáveis com os íons estudados em outro solvente como, por exemplo, a água. Trabalhos posteriores devem objetivar o estudo desses calixarenos, em especial o CLE, em água com a finalidade de observar se a propriedade de extração de íons também ocorre nesse solvente, muito mais polar que a acetonitrila, e onde realmente se espera que os calixarenos atuem.

Independentemente dos sistemas estudados e dos resultados obtidos, nesse trabalho desenvolvemos uma metodologia que pode ser aplicada como parte do processo de síntese racional de calixarenos. A simulação de Dinâmica Molecular de calixarenos virtuais, construídos segundo determinados critérios, pode evidenciar pontos positivos e negativos da nova molécula desenhada de modo a selecionar somente calixarenos que apresentem o comportamento esperado, evitando o método de tentativa e erro empregado com muita freqüência na síntese dessas moléculas. 


\section{Referências Bibliográficas}

1. Barrie, L.A., Gregor, D., Hargrave, B., Lake, R., Muir, D., Shearer, R., Tracey, B., and Bidleman, T.; Arctic Contaminants - Sources, Occurrence and Pathways. Science of the Total Environment 122(1-2), 1-74 (1992).

2. MacDonald, R.W., Barrie, L.A., Bidleman, T.F., Diamond, M.L., Gregor, D.J., Semkin, R.G., Strachan, W.M.J., Li, Y.F., Wania, F., Alaee, M., Alexeeva, L.B., Backus, S.M., Bailey, R., Bewers, J.M., Gobeil, C., Halsall, C.J., Harner, T., Hoff, J.T., Jantunen, L.M.M., Lockhart, W.L., Mackay, D., Muir, D.C.G., Pudykiewicz, J., Reimer, K.J., Smith, J.N., Stern, G.A., Schroeder, W.H., Wagemann, R., and Yunker, M.B.; Contaminants in the Canadian Arctic: 5 years of progress in understanding sources, occurrence and pathways. Science of the Total Environment 254(2-3), 93-234 (2000).

3. Muir, D.C.G., Wagemann, R., Hargrave, B.T., Thomas, D.J., Peakall, D.B., and Norstrom, R.J.; Arctic Marine Ecosystem Contamination. Science of the Total Environment 122(1-2), 75-134 (1992).

4. Rhue, R.D., Mansell, R.S., Ou, L.T., Cox, R., Tang, S.R., and Ouyang, Y.; The Fate and Behavior of Lead Alkyls in the Environment - a Review. Critical Reviews in Environmental Control 22(3-4), 169-193 (1992).

5. Hare, L.; Aquatic Insects and Trace-Metals - Bioavailability, Bioaccumulation, and Toxicity. Critical Reviews in Toxicology 22(5-6), 327-369 (1992).

6. Singh, R.P., Tripathi, R.D., Sinha, S.K., Maheshwari, R., and Srivastava, H.S.; Response of higher plants to lead contaminated environment. Chemosphere 34(11), 2467-2493 (1997).

7. Chiba, M. and Masironi, R.; Toxic and Trace-Elements in Tobacco and TobaccoSmoke. Bulletin of the World Health Organization 70(2), 269-275 (1992).

8. Dudka, S. and Miller, W.P.; Accumulation of potentially toxic elements in plants and their transfer to human food chain. Journal of Environmental Science and Health Part B-Pesticides Food Contaminants and Agricultural Wastes 34(4), 681708 (1999).

9. McLaughlin, M.J., Tiller, K.G., Naidu, R., and Stevens, D.P.; Review: The behaviour and environmental impact of contaminants in fertilizers. Australian Journal of Soil Research 34(1), 1-54 (1996).

10. Spry, D.J. and Wiener, J.G.; Metal Bioavailability and Toxicity to Fish in LowAlkalinity Lakes - a Critical-Review. Environmental Pollution 71(2-4), 243-304 (1991).

11. Porter, S.K., Scheckel, K.G., Impellitteri, C.A., and Ryan, J.A.; Toxic metals in the environment: Thermodynamic considerations for possible immobilization strategies for $\mathrm{Pb}, \mathrm{Cd}, \mathrm{As}$, and $\mathrm{Hg}$. Critical Reviews in Environmental Science and Technology 34(6), 495-604 (2004).

12. De Namor, A.F., Chahine, S., Kowalska, D., Castellano, E.E., and Piro, O.E.; Selective interaction of lower rim calix[4]arene derivatives and bivalent cations in solution. Crystallographic evidence of the versatile behavior of acetonitrile in lead(II) and cadmium(II) complexes. J Am Chem Soc 124(43), 12824-36 (2002).

13. de Namor, A.F.D., Kowalska, D., Castellano, E.E., Piro, O.E., Velarde, F.J.S., and Salas, J.V.; Lower rim calix(4)arene ketone derivatives and their interaction 
with alkali metal cations. Structural and thermodynamic (solution and complexation) characterisation of the tetraphenyl ketone derivative and its sodium complex. Physical Chemistry Chemical Physics 3(18), 4010-4021 (2001).

14. Baaden, M., Burgard, M., Boehme, C., and Wipff, G.; Lanthanide cation binding to a phosphoryl-calix[4]arene: the importance of solvent and counterions investigated by molecular dynamics and quantum mechanical simulations. Physical Chemistry Chemical Physics 3(7), 1317-1325 (2001).

15. Baaden, M., Wipff, G., Yaftian, M.R., Burgard, M., and Matt, D.; Cation coordination by calix [4]arenes bearing amide and/or phosphine oxide pendant groups: how many arms are needed to bind Li+vs. Na+? A combined NMR and molecular dynamics study. Journal of the Chemical Society-Perkin Transactions 2(7), 1315-1321 (2000).

16. Grote Gansey, M.H.B., Verboom, W., van Veggel, F.C.J.M., Vetrogon, V., Arnaud-Neu, F., Schwing-Weill, M.J., and Reinhoudt, D.N.; Model studies toward trivalent cation binding by appropriately functionalized calix[4]arenes. Journal of the Chemical Society-Perkin Transactions 2(11), 2351-2360 (1998).

17. Guilbaud, P., Varnek, A., and Wipff, G.; Molecular-Dynamics Study of P-TertButylcalix[4]Arenetetraamide and Its Complexes with Neutral and Cationic Guests - Influence of Solvation on Structures and Stabilities. Journal of the American Chemical Society 115(18), 8298-8312 (1993).

18. Van der Spoel, D., Lindahl, E., Hess, B., Groenhof, G., Mark, A.E., and Berendsen, H.J.C.; GROMACS: Fast, flexible, and free. Journal of Computational Chemistry 26(16), 1701-1718 (2005).

19. Jorgensen, W.L., Maxwell, D.S., and TiradoRives, J.; Development and testing of the OPLS all-atom force field on conformational energetics and properties of organic liquids. Journal of the American Chemical Society 118(45), 1122511236 (1996).

20. Allen, M.P. and Tildesley, D.J., Computer simulation of liquids. 1987, Oxford [England]; New York: Clarendon Press; Oxford University Press. xix, 385 p.

21. Frenkel, D. and Smit, B., Understanding molecular simulation : from algorithms to applications. 2nd ed. 2002, San Diego: Academic Press. xxii, 638 p.

22. Leach, A.R., Molecular modelling : principles and applications. 2nd ed. 2001, Harlow, England ; New York: Prentice Hall. xxiv, 744 p., [16] p. of plates.

23. Alder, B.J. and Wainwright, T.E.; Phase Transition for a Hard Sphere System. Journal of Chemical Physics 27(5), 1208-1209 (1957).

24. Rahman, A.; Correlations in Motion of Atoms in Liquid Argon. Physical Review a-General Physics 136(2A), A405-\& (1964).

25. Stilling.Fh and Rahman, A.; Improved Simulation of Liquid Water by MolecularDynamics. Journal of Chemical Physics 60(4), 1545-1557 (1974).

26. Verlet, L.; Computer Experiments on Classical Fluids .I. Thermodynamical Properties of Lennard-Jones Molecules. Physical Review 159(1), 98-\& (1967).

27. Hockney, R.W., Goel, S.P., and Eastwood, J.W.; Quiet High-Resolution Computer Models of a Plasma. Journal of Computational Physics 14(2), 148-158 (1974).

28. Swope, W.C., Andersen, H.C., Berens, P.H., and Wilson, K.R.; A ComputerSimulation Method for the Calculation of Equilibrium-Constants for the Formation of Physical Clusters of Molecules - Application to Small Water Clusters. Journal of Chemical Physics 76(1), 637-649 (1982). 
29. Brooks, B.R., Bruccoleri, R.E., Olafson, B.D., States, D.J., Swaminathan, S., and Karplus, M.; Charmm - a Program for Macromolecular Energy, Minimization, and Dynamics Calculations. Journal of Computational Chemistry 4(2), 187-217 (1983).

30. Jorgensen, W.L. and Tiradorives, J.; The Opls Potential Functions for Proteins Energy Minimizations for Crystals of Cyclic-Peptides and Crambin. Journal of the American Chemical Society 110(6), 1657-1666 (1988).

31. van Gunsteren, W.F., Billeter, S.R., Eising, A.A., Hünenberger, P.H., Krüger, P., Mark, A.E., Scott, W.R.P., and Tironi, I.G., Biomolecular Simulation: The GROMOS96 manual and user guide. 1996, Zürich, Switzerland: Hochschuleverlag AG an der ETH Zürich

32. Pearlman, D.A., Case, D.A., Caldwell, J.W., Ross, W.S., Cheatham, T.E., Debolt, S., Ferguson, D., Seibel, G., and Kollman, P.; Amber, a Package of ComputerPrograms for Applying Molecular Mechanics, Normal-Mode Analysis, Molecular-Dynamics and Free-Energy Calculations to Simulate the Structural and Energetic Properties of Molecules. Computer Physics Communications 91(13), 1-41 (1995).

33. Aqvist, J.; Ion Water Interaction Potentials Derived from Free-Energy Perturbation Simulations. Journal of Physical Chemistry 94(21), 8021-8024 (1990).

34. Chandrasekhar, J., Spellmeyer, D.C., and Jorgensen, W.L.; Energy Component Analysis for Dilute Aqueous-Solutions of $\mathrm{Li}+, \mathrm{Na}+, \mathrm{F}$-, and $\mathrm{Cl}$ - Ions. Journal of the American Chemical Society 106(4), 903-910 (1984).

35. Reichert, D.E., Norrby, P.O., and Welch, M.J.; Molecular modeling of bifunctional chelate peptide conjugates. 1. Copper and indium parameters for the AMBER force field. Inorganic Chemistry 40(20), 5223-5230 (2001).

36. van Veggel, F.C.J.M. and Reinhoudt, D.N.; New, accurate Lennard-Jones parameters for trivalent lanthanide ions, tested on [18]crown-6. Chemistry-a European Journal 5(1), 90-95 (1999).

37. Babu, C.S. and Lim, C.; Empirical force fields for biologically active divalent metal cations in water. Journal of Physical Chemistry A 110(2), 691-699 (2006).

38. Burgess, J., Metal ions in solution. 1978, Chichester; New York: Ellis Horwood; distributed by Halsted Press. 481 p.

39. Bol, W., Gerrits, G.J.A., and Panthale.Cl; Hydration of Divalent Cations in Aqueous Solution - an X-Ray Investigation with Isomorphous Replacement. Journal of Applied Crystallography 3(Dec1), 486-\& (1970).

40. Hofer, T.S. and Rode, B.M.; The solvation structure of Pb(II) in dilute aqueous solution: An ab initio quantum mechanical/molecular mechanical molecular dynamics approach. Journal of Chemical Physics 121(13), 6406-6411 (2004).

41. Kritayakornupong, C., Plankensteiner, K., and Rode, B.M.; Structure and dynamics of the $\mathrm{Cd} 2+$ ion in aqueous solution: Ab initio QM/MM molecular dynamics simulation. Journal of Physical Chemistry A 107(48), 10330-10334 (2003).

42. Jorgensen, W.L., Chandrasekhar, J., Madura, J.D., Impey, R.W., and Klein, M.L.; Comparison of Simple Potential Functions for Simulating Liquid Water. Journal of Chemical Physics 79(2), 926-935 (1983).

43. Berendsen, H.J.C., Postma, J.P.M., et al. Interaction models for water in relation to protein hydration. in Intermolecular Forces. 1981. Jerusalem, Israel: D Reidel Pub Co. 
44. Berendsen, H.J.C., Grigera, J.R., and Straatsma, T.P.; The Missing Term in Effective Pair Potentials. Journal of Physical Chemistry 91(24), 6269-6271 (1987).

45. Aqvist, J., Medina, C., and Samuelsson, J.E.; New Method for Predicting Binding-Affinity in Computer-Aided Drug Design. Protein Engineering 7(3), 385391 (1994).

46. Torrie, G.M. and Valleau, J.P.; Monte-Carlo Free-Energy Estimates Using NonBoltzmann Sampling - Application to Subcritical Lennard-Jones Fluid. Chemical Physics Letters 28(4), 578-581 (1974).

47. Kirkwood, J.G.; Statistical Mechanics of Fluids Mixtures. Journal of Chemical Physics 3, 300-313 (1935).

48. Impey, R.W., Madden, P.A., and Mcdonald, I.R.; Hydration and Mobility of Ions in Solution. Journal of Physical Chemistry 87(25), 5071-5083 (1983).

49. Aqvist, J., Luzhkov, V.B., and Brandsdal, B.O.; Ligand binding affinities from MD simulations. Accounts of Chemical Research 35(6), 358-365 (2002).

50. Hansson, T., Marelius, J., and Aqvist, J.; Ligand binding affinity prediction by linear interaction energy methods. Journal of Computer-Aided Molecular Design 12(1), 27-35 (1998).

51. Floris, F.M., Selmi, M., Tani, A., and Tomasi, J.; Free energy and entropy for inserting cavities in water: Comparison of Monte Carlo simulation and scaled particle theory results. Journal of Chemical Physics 107(16), 6353-6365 (1997).

52. Rappe, A.K., Casewit, C.J., Colwell, K.S., Goddard, W.A., and Skiff, W.M.; Uff, a Full Periodic-Table Force-Field for Molecular Mechanics and MolecularDynamics Simulations. Journal of the American Chemical Society 114(25), 10024-10035 (1992).

53. Berendsen, H.J.C., Postma, J.P.M., Vangunsteren, W.F., Dinola, A., and Haak, J.R.; Molecular-Dynamics with Coupling to an External Bath. Journal of Chemical Physics 81(8), 3684-3690 (1984).

54. Mahoney, M.W. and Jorgensen, W.L.; Diffusion constant of the TIP5P model of liquid water. Journal of Chemical Physics 114(1), 363-366 (2001).

55. Eisenberg, D.S. and Kauzmann, W., The structure and properties of water. 1969, Oxford,: Clarendon P. xii, 296, [3] p.

56. Lide, D.R., CRC handbook of chemistry and physics. 84th ed. 2003: CRC Press.

57. Obst, S. and Bradaczek, H.; Molecular dynamics study of the structure and dynamics of the hydration shell of alkaline and alkaline-earth metal cations. Journal of Physical Chemistry 100(39), 15677-15687 (1996).

58. Araujo, A.S. and Castellano, E.E., Determinação de estruturas moleculares cristalinas por difração de Raios $X$ e desenvolvimento de um sistema computacional para a comparação de fragmentos moleculares de configuração similar, em FFI. 2002, USP: São Carlos. p. 122

59. Asfari, Z., Calixarenes 2001. 2001, Dordrecht ; Boston: Kluwer Academic Publishers. $\mathrm{x}, 683 \mathrm{p}$.

60. de Namor, A.F.D., Cleverley, R.M., and Zapata-Ormachea, M.L.; Thermodynamics of calixarene chemistry. Chemical Reviews 98(7), 2495-2525 (1998).

61. Denamor, A.F.D., Gil, E., Tanco, A.L., Tanaka, D.A.P., Salazar, L.E.P., Schulz, R.A., and Wang, J.J.; Thermodynamics of Alkyl P-TertButylcalix(4)Arenetetraethanoates .2. Solution Studies of Calix(4)Arene Esters and Lithium and Sodium Ethylcalix(4)Arene Ester Complexes - Coordination 
Data in the Solid-State. Journal of Physical Chemistry 99(45), 16781-16785 (1995).

62. Denamor, A.F.D., Gil, E., Tanco, M.A.L., Tanaka, D.A.P., Salazar, L.E.P., Schulz, R.A., and Wang, J.J.; Thermodynamics of Calix(4)Arene Esters .1. Complexation of Alkyl P-Tert-Butylcalix(4)Arenetetraethanoates and AlkaliMetal Cations in Acetonitrile and in Benzonitrile. Journal of Physical Chemistry 99(45), 16776-16780 (1995).

63. Darden, T., York, D., and Pedersen, L.; Particle Mesh Ewald - an N.Log(N) Method for Ewald Sums in Large Systems. Journal of Chemical Physics 98(12), 10089-10092 (1993).

64. Essmann, U., Perera, L., Berkowitz, M.L., Darden, T., Lee, H., and Pedersen, L.G.; A Smooth Particle Mesh Ewald Method. Journal of Chemical Physics 103(19), 8577-8593 (1995). 